University of Louisville ThinkIR: The University of Louisville's Institutional Repository

Electronic Theses and Dissertations

$5-2014$

\title{
Housing first, neighborhood second? : the role of housing and neighborhood characteristics on residential stability in two housing first projects.
}

Carey D. Addison

University of Louisville

Follow this and additional works at: https://ir.library.louisville.edu/etd

Part of the Public Affairs Commons, and the Urban Studies and Planning Commons

\section{Recommended Citation}

Addison, Carey D., "Housing first, neighborhood second? : the role of housing and neighborhood characteristics on residential stability in two housing first projects." (2014). Electronic Theses and Dissertations. Paper 13.

https://doi.org/10.18297/etd/13

This Doctoral Dissertation is brought to you for free and open access by ThinkIR: The University of Louisville's Institutional Repository. It has been accepted for inclusion in Electronic Theses and Dissertations by an authorized administrator of ThinkIR: The University of Louisville's Institutional Repository. This title appears here courtesy of the author, who has retained all other copyrights. For more information, please contact thinkir@louisville.edu. 
HOUSING FRIST, NEIGHBORHOOD SECOND? THE ROLE OF HOUSING AND NEIGHBORHOOD CHARACTERISTICS ON RESIDENTIAL STABILITY IN TWO HOUSING FIRST PROJECTS

By

Carey D. Addison, Jr.

B.S., Radford University, 2004

M.A., University of Delaware, 2007

\author{
A Dissertation \\ Submitted to the Faculty of the \\ College of Arts and Sciences of the University of Louisville \\ in Partial Fulfillment of the Requirements \\ for the Degree of \\ Doctor of Philosophy \\ Department of Urban and Public Affairs \\ University of Louisville \\ Louisville, Kentucky
}

May 2014 

HOUSING FRIST, NEIGHBORHOOD SECOND? THE ROLE OF HOUSING AND NEIGHBORHOOD CHARACTERISTICS ON RESIDENTIAL STABILITY IN TWO HOUSING FIRST PROJECTS

$$
\text { By }
$$

Carey D. Addison, Jr.

B.S., Radford University, 2004

M.A., University of Delaware, 2007

\section{A Dissertation Approved on}

April 15, 2014

By the following Dissertation Committee:

Dissertation Director
Dr. Steven Bourassa

Dr. Sumei Zhang

Dr. Steven Koven

Dr. Gerard Barber 


\section{DEDICATION}

This dissertation is dedicated in loving memory of my grandmother,

Patricia Counts Addison (1942-2007)

and grandfather,

Edgel St. Clair (1938-2002)

who both always believed that I could accomplish anything. Your spirits are very much with me in my celebration of this accomplishment and in everything that I do. 


\section{ACKNOWLEDGMENTS}

Throughout the seven years it has taken to complete this degree, I have realized that I could not have accomplished this task on my own. I owe many thanks to those that have helped me along the way. I would like to thank Dr. Steven Bourassa and Dr. Sumei Zhang for their support, guidance, and patience throughout the dissertation writing process. I would also like to thank my other committee members, Dr. Steven Koven and Dr. Gerard Barber, for providing their insight and feedback throughout the writing of this dissertation. I would also like to express my appreciation for the invaluable assistance provided by the Department of Urban and Public Affairs support staff, Juli Wagner, Patricia Sarley, and Yani Vozos. A special debt of gratitude is owed to Dr. Andy Patterson, my supervisor and mentor at Family Health Centers-Phoenix for providing me with the ability to complete this work and making sure that I never gave up. I am also grateful to Gregg Pieples and Carey Carr at Greater Cincinnati Behavioral Health for their indispensable assistance in gathering data from their agency. I would also like to thank Shireen Deobhakta, Brandi Scott, Ross Young, Charles Sword, Andrea Pompei Lacy, and Jessica Gray Butler for being my unwavering support system throughout this long process. Finally, I would like to thank my loving family members, Carey Addison, Sr., Mary Elizabeth Addison, Nicholas Addison, Joe Addison, and Jean St. Clair. Without the help of my family and friends, none of my accomplishments would have been possible. Thank you so much for your encouragement and support in this endeavor. 


\begin{abstract}
HOUSING FRIST, NEIGHBORHOOD SECOND? THE ROLE OF HOUSING AND NEIGHBORHOOD CHARACTERISTICS ON RESIDENTIAL STABILITY IN TWO HOUSING FIRST PROJECTS
\end{abstract}

Carey D. Addison, Jr.

April 15, 2014

This study examined the impacts of neighborhood and housing type on housing stability for formerly homeless individuals participating in Housing First projects in Louisville, Kentucky, and Cincinnati, Ohio. Both projects operate similarly except that the Louisville project has only scattered-site housing while the Cincinnati project has both project-based and scattered-site housing. The first chapter presents five key research questions that frame the study. Chapter 2 reviews literature on homelessness and policies to address this urban problem with a specific emphasis on Housing First. Chapter 3 proposes qualitative and quantitative methods for answering the proposed research questions.

Chapter 4 summarizes findings from interviews with staff and participants at both projects. Staff identified tradeoffs between the two housing types, often stating that the best fit depended on the individual participant. Participants placed high value on housing amenities, access to transportation and services, and neighborhood safety, but expressed mixed reviews as to how their housing ranked in terms of these criteria. While staff and participants alike felt that neighborhood was important, most agreed that other factors 
such as access to services and personal determination were more crucial to success in the program.

Chapter 5 describes how GIS was used to merge administrative records, census data, and other demographic data to map various characteristics of the census tracts in which participants live. These maps demonstrate that participants in both cities tended to live in less affluent, more urban, and more crime ridden tracts compared to other tracts in their cities. This was especially true for Cincinnati's project-based participants. Chapter 6 discusses how this data was used to construct binary logistic and survival models to determine whether neighborhood affected the likelihood of participants remaining in housing. Both analysis methods demonstrated that it was personal attributes, rather than neighborhood, that significantly increased the likelihood of being forcibly exited from a placement. However, higher quality neighborhoods were found to decrease the odds of a participant moving due to other reasons such as dissatisfaction with housing. Chapter 7 concludes this work with a discussion of how this research can guide future consideration for Housing First policy and research. 
TABLE OF CONTENTS

PAGE

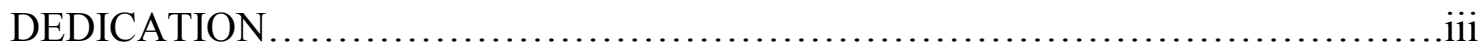

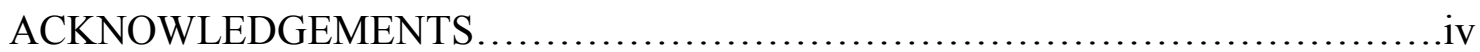

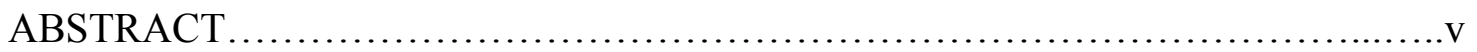

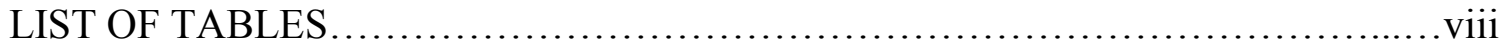

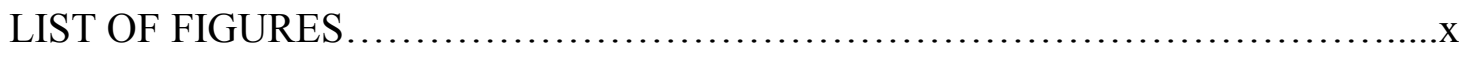

CHAPTER 1: INTRODUCTION ..............................................

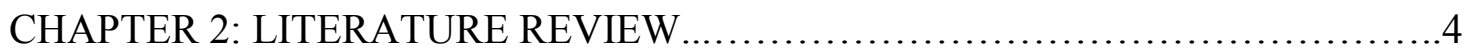

CHAPTER 3: METHODOLOGY ............................................52

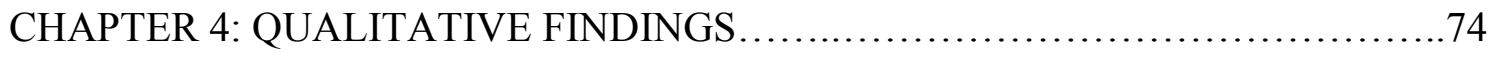

CHAPTER 5: DATA.........................................................

CHAPTER 6: QUANTITATIVE FINDINGS................................... 133

CHAPTER 7: CONCLUSION............................................149

REFERENCES ........................................................ 163

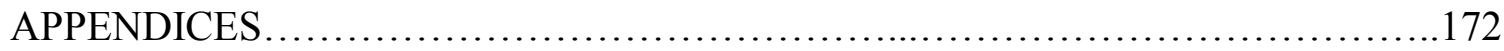

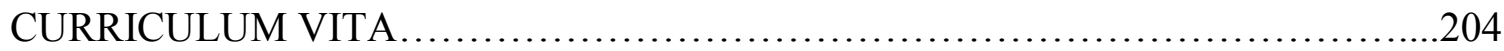




\section{LIST OF TABLES}

TABLE

PAGE

3.1. Demographic Characteristics............................................5 54

3.2. HUD Point-in-Time Homeless Population Estimates (2005-2012)...............55

3.3. Independent Variables and Data Sources...................................67

4.1. Most and Least Favorite Housing Characteristics...............................94

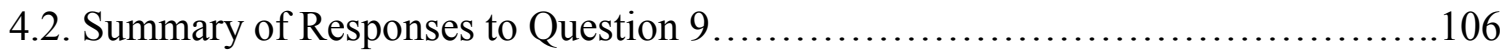

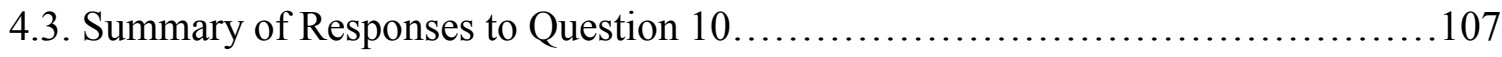

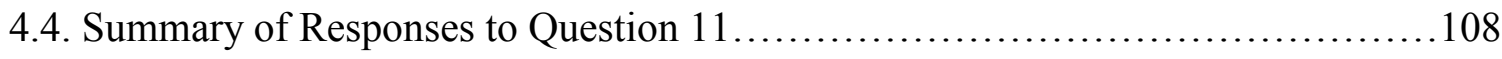

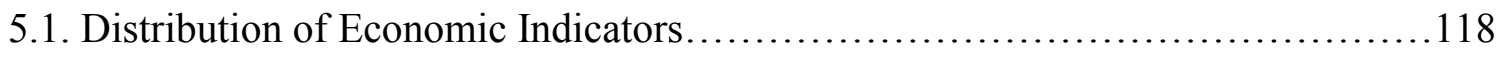

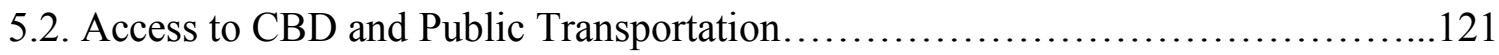

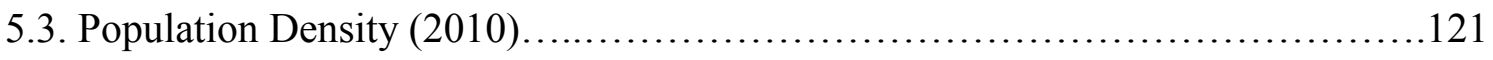

5.4. Distribution of Crimes per Census Tract (2013)...............................124

5.5. Demographic Characteristics of Housing First Participants.......................126

5.6. Days of Alcohol and Drug Use in 30 Days Prior to Intake........................127

5.7. Days of Mental Health Symptoms in 30 Days Prior to Intake....................128

5.8. Involvement with Criminal Justice System in 30 Days Prior to Intake.............129

5.9. Number of Days in Housing First Placement..................................131 


\section{LIST OF TABLES (continued)}

TABLE

PAGE

6.1. PCA Analysis Component Matrix.

135

6.2. Classification Table for Forced Moves....

138

6.3. Binary Logistic Regression: DV=Forced Moves

6.4. Classification Table for Other Moves

6.5. Binary Logistic Regression: DV=Other Moves

6.6. Cox Regression: DV=Forced Moves. 143

6.7. Cox Regression: DV=Other Moves . 144 


\section{LIST OF FIGURES}

FIGURE

PAGE

5.1. Housing First Placements

GCBH, Cincinnati/Hamilton County, Ohio.

5.2. Housing First Placements

FHC-Phoenix, Louisville/Jefferson County, Kentucky.

5.3. Percent of Households Below Poverty Level

in Cincinnati/Hamilton County, Ohio....

5.4. Percent of Households Below Poverty Level

in Louisville/Jefferson County, Kentucky.

5.5. Median Household Income

in Cincinnati/Hamilton County, Ohio.

5.6. Median Household Income

in Louisville/Jefferson County, Kentucky

5.7. Percentage of Vacant Housing Units

in Cincinnati/Hamilton County, Ohio.

5.8. Percentage of Vacant Housing Units

in Louisville/Jefferson County, Kentucky.

5.9. Persons Per Square Mile

in Cincinnati/Hamilton County, Ohio.

5.10. Persons Per Square Mile

in Louisville/Jefferson County, Kentucky.

5.11. Crimes Per Capita (2013)

in Cincinnati/Hamilton County, Ohio 


\section{LIST OF FIGURES (continued)}

FIGURE

PAGE

5.12. Crimes Per Capita (2013)

In Louisville/Jefferson County, Kentucky ........................................123 


\section{CHAPTER 1}

\section{INTRODUCTION}

Housing First is an evidence based approach for permanently housing chronically homeless persons through the provision of subsidized housing and supportive services such as case management. This study is intended to answer questions regarding what types of housing and neighborhood settings can best provide long-term stable accommodation for formerly homeless individuals participating in a Housing First project. The study focuses on two specific Housing First projects: the Louisville Housing First Project administered by Family Health Centers-Phoenix Health Care for the Homeless (FHC-Phoenix) and Paths to Recovery administered by Greater Cincinnati Behavioral Health Services $(\mathrm{GCBH})$. As housing itself is considered to be the primary intervention of Housing First, the question of what type of housing best serves this population is highly pertinent.

The Housing First model calls for scattered-site housing in which no more than 10 percent of a project's participants are located within the same apartment building (Tsemberis 1999). Most Housing First projects provide scattered-site housing through voucher programs which allow participants to rent units from private landlords. Both projects in this study follow this approach, which is believed to promote greater community integration and demarcate housing from supportive services. However, in addition to providing scattered-site housing, the Cincinnati Pathways to Housing program also provides project-based housing through its 25-unit Jimmy Heath House (JHH) 
facility. While there has been substantial research conducted on the effectiveness of the Housing First approach in addressing homelessness, mental illness, and substance abuse, there has been much less consideration of how the aspects of housing choice and neighborhood characteristics influence the outcomes of a Housing First project.

A combination of qualitative and quantitative methods is used to better understand how variations in housing characteristics affect the outcomes of two Housing First projects. The study is framed by the following questions:

1. What factors determine the location and housing type of a Housing First placement? What housing and neighborhood characteristics are most desired by project participants?

2. What are the characteristics (social, economic, etc.) of the neighborhoods in which Housing First participants live? Do these characteristics match the preferences of the program and its participants?

3. How do housing stability outcomes in a scattered-site Housing First project differ from those of a single-site project?

4. How do neighborhood characteristics affect the success of a Housing First project in meeting its housing stability goals?

5. What are the implications of this evaluation for designing and implementing future Housing First projects?

These questions set a framework that divides this research into three specific areas of interest: process, outcomes, and implications. Questions 1 and 2 pertain to the processes that determine what housing options are available to Housing First participants and the factors which influence a participant's housing placement. These questions are also intended to explore the general characteristics of the participant's living environment. Questions 3 and 4 turn to the outcomes of these projects. Their intent is to shed light on how these housing placements impact the success of participants in meeting 
the intended goals of the project. Question 5 seeks to synthesize these findings and examine which housing and neighborhood components are most vital, what components may be ineffective or detrimental to success, and how this information can be used to enhance the ability of Housing First to effectively mitigate homelessness.

The following chapter provides a review of literature on homelessness and policy responses to this urban problem including a discussion of Housing First and the implications of providing scattered-site housing. Chapter 3 provides an overview of the qualitative and quantitative methodologies employed to answer the research questions described above. Chapter 4 discusses key findings from in-depth interviews with staff and participants at GCBH and FHC-Phoenix. Chapter 5 serves as a descriptive analysis of data on the individual characteristics of participants at these two programs and the demographic characteristics of the neighborhood that they occupy. Chapter 6 empirically tests whether these characteristics impacted housing stability for these participants through binary logistic and Cox survival regression modeling. The final chapter summarizes key findings and concludes with a discussion of implications for Housing First policy and research. 


\section{CHAPTER 2}

\section{LITERATURE REVIEW}

In the U.S., the homeless are one of the most visible symbols of poverty in contemporary urban society (Susser 1996). While estimates on the exact number of persons living in homelessness are difficult to ascertain, the population was estimated to be 656,129 in 2009 (National Alliance to End Homelessness 2011), and the majority of the nation's homeless dwell in cities. The 1999 National Survey of Homeless Assistance Providers and Clients (NSHAPC) found that 71 percent of all homeless persons in their sample were located in central cities. While the presence of persons sleeping on the streets, panhandling, and standing in line for food, shelter, and other services is difficult to overlook in most cities, this "visibly homeless" group only partially captures the true extent of homelessness in our cities. Many other less visible homeless individuals can be found in institutional settings such as hospitals and transitional shelters. Many more live doubled-up with friends or relatives (Sommer 2001).

The presence of both the visible and the invisible homeless creates a number of demands and complications for cities as they strive to provide safe, livable, and economically viable environments for all citizens. Policy makers and service providers are faced with the seemingly insurmountable tasks of both serving the needs of homeless and also rectifying the causes of homelessness. To better understand this challenge and the evolution of homeless policy in the U.S., this literature review: defines and describes homelessness in the U.S.; explores the theoretical explanations of this phenomenon; 
discusses the impacts of homelessness on our cities; and provides an in-depth review of the evolution of programmatic responses to homelessness.

\section{Defining the Problem: What Is Homelessness and Who Homeless?}

An operative definition of homelessness is necessary for studying this phenomenon and its ramifications because it allows us to identify who the homeless are and what challenges they pose for urban policy. In its simplest form, homelessness means the lack of a place of habitation. For many, the word "homelessness" may produce a number of images such as vagrancy, substance abuse, and mental illness. However, homelessness is a multifaceted issue that impacts individuals on a number of different levels. In modern urban society, homelessness cuts across numerous demographic groups including, but not limited to, families, youth, the elderly, veterans, and those with mental illness and substance abuse disorders (Sommer 2001). Further, the homeless both legally and illegally occupy a number of public and private spaces (Waldron 2000). Thus, to be accurate, an operative definition should capture this complexity and diversity which comprises the homeless population. Researchers, policy makers, and organizations have used these considerations to assist in developing in-depth definitions of homelessness. However, such definitions can vary across the different agendas and purposes for which the term is used.

Scholars attempting to identify the causes of homelessness commonly define the term in an explanatory context to address its individual or systematic causes. For example, Rossi and Wright (1987) define the homeless as "the long-term very poor who have been unable to maintain supportive connections with (or have been rejected by) 
their parental families and friends and who have not been able for a variety of reasons to establish their own households" (p. 26). Sommer (2001) identifies extreme poverty, high rates of personal disability, and social estrangement as prevalent defining characteristics of the homeless. Bahr (1970) considers homelessness to be practically synonymous with disaffiliation with mainstream social ties by defining homelessness as a personality disorder (Main 1998). Definitions such as these demonstrate homelessness as a manifestation of poverty and disability as well as a detachment from family and social ties. Thus homelessness is defined in very specific terms and other segments of the population, such as the working homeless, are excluded. As stated in the previous paragraph, homelessness simply implies an individual's absence of a residence or place for sleeping and thus should not be inclusive of any other personal characteristics. While definitions that do include other characteristics will be further considered when reviewing theories of homelessness, they provide little context for identifying and categorizing the entire homeless population of American cities.

For a more categorical understanding of homelessness, it is helpful to look at how homelessness has been defined by the organizations and policies that directly address it. Because these interests must determine who they will and will not serve, they are required to carefully draft definitions that draw clear lines of who is homeless and who is not. For example, the NSHACP defines homelessness as an individual's lacking a fixed, regular, nighttime residence or maintaining nighttime residence in a shelter or institutional setting of a supervised or temporary nature (NSHACP 1999). Similarly, the U.S. Department of Health and Human Services defines homelessness to include individuals and families living on the streets, in shelters and transitional housing, and 
temporarily "doubled up" with friends, neighbors, or relatives (Health Care for the Homeless 2012). In order to develop policies and fund projects, the U.S. Department of Housing and Urban Development (HUD) puts this definition into a more technical context by expanding it to specifically address all groups that are impacted by homelessness including those that are in imminent danger of losing their homes. HUD defines an individual or household homeless if they are living in any of the following places or situations:

- In places not meant for human habitation, such as cars, parks, sidewalks, abandoned buildings (on the street).

- In an emergency shelter.

- In transitional or supportive housing for homeless persons who originally came from the streets or emergency shelters.

- In any of the above places but is spending a short time (up to 30 consecutive days) in a hospital or other institution.

- Is being evicted within a week from a private dwelling unit and no subsequent residence has been identified and lacks resources and support networks needed to obtain housing.

- Is being discharged within a week from an institution, such as a mental health or substance abuse treatment facility or a jail/prison, in which the person has been a resident for more than 30 consecutive days and no subsequent residence has been identified and the person lacks the resources and support networks needed to obtain housing.

- For example, a person being discharged from prison after more than 30 days is eligible only if no subsequent residence has been identified and the person does not have money, family or friends to provide housing.

- Is fleeing a domestic violence housing situation and no subsequent residence

- Has been identified and lacks the resources and support networks needed to obtain housing (U.S. Department of Housing and Urban Development 2013).

For the purposes of this thesis, these definitions will be synthesized to state that homelessness is inclusive of any individual lacking a fixed, permanent residence who occupies an area not normally designated for human habitation, including the following: streets or public spaces, emergency or transitional shelters, abandoned buildings, or housing in which acceptable occupancy limits have been exceeded. The following 
section considers the characteristics that are associated with each of these forms of homelessness. Subsequent sections will discuss variations in the causes of each of these forms of homelessness and how policy responses may vary accordingly.

\section{Who Are the Homeless?}

Studying homelessness, its causes, and policy responses requires an understanding of the diversity of the homeless population. While homelessness has traditionally been thought of as a problem of single adults plagued by mental illness or substance abuse disorders, rapid societal changes, economic restructuring, and erratic local housing markets have made many more groups susceptible to homelessness (Burt et al. 1999). Homelessness has been documented as a problem that impacts families, all age groups, and working individuals (Burt et al. 1999, Sommer 2001, Culhane et al. 2007). For example, individual homelessness is more prevalent among males but homeless families tend to be headed by females that are younger and have a lower prevalence of substance abuse and mental health disorders than the unaccompanied homeless (Burt and Cohen 1989, Metraux and Culhane 1999, Culhane et al. 2007). To address the differing dimensions of these groups, homelessness has most commonly been classified across three categories: transitional, episodic, and chronic (Snow and Anderson 1987, Sosin et al. 1990, Kuhn and Culhane 1998). These three categories have been especially useful for addressing homelessness because they provide a framework for capturing the full scope of homelessness, including both individuals and families. This typology has guided much academic work and policy pertaining to homelessness (Kuhn and Culhane 1998, Sommer 2001, Culhane et al. 2007). 
Kuhn and Culhane (1998) and Culhane et al. (2007) use cluster analysis to formally test this typology of homelessness for individuals and families, respectively. These analyses have provided a clear description of the demographic and socioeconomic backgrounds that characterize these groups as well as how they utilize shelters and treatment services. For approximately 80 percent of homeless adults, homelessness is a temporary state generally characterized by short-term shelter stays and independent returns to long-term housing without formal assistance (Kuhn and Culhane 1998). This group, known as the transitional homeless, has been found to be younger, less likely to have mental health, substance abuse, or medical problems, and to be less representative of racial minorities (Kuhn and Culhane 1998). This group is more likely to be homeless for reasons such as unemployment, separation, fire, death of householder, or other personal catastrophe (Sossin et al. 1990, Weitzman et al. 1990, Kuhn and Culhane 1998). In their research on New York City shelter users, Kuhn and Culhane (1998) found that this group spent an average total of 58 days in shelters during a three-year observation period. They tend to use the shelter system in instances of emergencies and do not return once they exit. Homeless families exhibited a similar trend with 72 to 80 percent falling in the transitional or single incidence category (Culhane et al. 2007).

The next group in the spectrum of homelessness is the episodically homeless, who have been found to comprise approximately 10 percent of the population of individual homeless adults and about 2 to 8 percent of homeless families (Kuhn and Culhane 1998, Culhane et al. 2007). This group was also comparatively young but was more likely to be inclusive of non-white minorities and persons with mental health, substance abuse, or medical problems (Kuhn and Culhane 1998). In contrast to the transitionally homeless, 
the episodically homeless cycle in and out of shelters multiple times. While they have been found to spend similar intervals of time in shelters as the transitionally homeless, they generated a much higher number of stays (1.4 stays for transitionally homeless adults versus 4.9 stays for episodically homeless adults) and spent an average total of 264 days in shelters (Kuhn and Culhane 1998). When this group is not living in the shelter system, they are likely to be in hospitals, jails, detoxification centers, or on the street (Culhane et al. 1996, Kuhn and Culhane 1998). Culhane et al. (2007) find that families with episodic use of shelter facilities have the highest rates of intensive behavioral health treatment, placement of children in foster care, disability, and unemployment. Although this group may not be living within shelters, this does not mean that they are not homeless during these periods. In this regard, episodically homeless households may in fact be consistently homeless but only using shelters on an as-needed basis.

The third type of homelessness, the chronically homeless, constitutes individuals who are homeless for extended periods of time. Kuhn and Culhane (1998) found that the chronically homeless constituted only 10 percent of the total homeless populations of New York and Philadelphia. Culhane et al. (2007) found that 17.9 to 21.5 percent of families fell into the chronically homeless category. One reason this number may be substantially higher for families is that they may be less flexible or willing to stay in streets and other alternative spaces used by the episodically homeless. While chronically homeless individuals and families constitute a relatively small portion of the homeless population, they have been shown to exhibit the most severe problems and require the most substantial service costs among the three groups. Chronically homeless unaccompanied adults used an average of 638 shelter days during the three-year 
observation period and consumed one half of all shelter days in the sample (Kuhn and Culhane 1998). Chronically homeless families were also found to account for approximately half of all shelter days despite the fact that they comprise less than 20 percent of the homeless population.

According to HUD (2011), a chronically homeless person is an individual who has been homeless for a duration of one year or more or has been homeless a minimum of four times in the past three years. Therefore, the chronically homeless under this federal definition are also likely to include those individuals considered episodically homeless in the typology of Kuhn and Culhane (1998) and Culhane et al. (1996). Arguably, the reason much of this group did not fall into the chronically homeless category described above is their extensive stays in other institutions, including correctional facilities, detoxification centers, and mental institutions (Culhane et al. 1996, Kuhn and Culhane 1998). This stratification of homeless populations has strong implications for homeless policy. Because demographics and other characteristics fundamentally set the episodically and chronically homeless apart from the transitionally homeless, these two groups will likely exhibit differing service needs. These factors will be considered in further detail as this paper examines the causes of homelessness as well as public responses to this problem.

\section{Why Are People Homeless? Theories of Homelessness}

A logical first step in developing homeless policy is to consider what factors cause an individual to be homeless. However, delving through the complexities of understanding how and why one becomes and remains homeless is a complex task. Such 
questions entail a high degree of economic, political, and social controversy. While some contend that homelessness is associated with personal attributes and may even be considered a lifestyle choice (Sommer 2001), others argue that homelessness is a result of forces beyond the control of the individual, such as changes in economic structures. These two strains of thought largely frame the theoretical debate about why people are homeless. These perspectives can be classified as either "individual" or "structural" theories (Main 1998, Tsemberis 2000, Sommer 2001). Individual factors point to the role of human agency or action as the primary driver of a person's homelessness. Conversely, structural factors pertain to societal forces largely beyond the control of the individuals. While not all explanations fit perfectly within the confines of these two strands of theory, they do provide a legible framework for facilitating a discussion on the causes of homelessness in the U.S. and building a model for analyzing homeless policy.

The prevailing theme of individualist theory is essentially personal efficacy and self-interest. In other words, people make individual choices with the intention of survival and enhancing their own welfare. In this perspective, personal actions play the most significant role in shaping an individual's life trajectory. In a sense, homelessness would seem paradoxical in this context because very few individuals would rationally choose a lifestyle as problematic as homelessness. Instead, within individualist theory, homelessness is often viewed as a product of personal deficits (Sommer 2001). Theories focused on individualistic causes of homelessness argue that the nature of homeless persons' disabilities would leave them incapable of maintaining long-term housing even if affordable housing was in abundant supply (Sommer 2001). These may include any number of personal disabilities, including age, gender, mental illness, substance use 
disorder, or lack of other capacities for self-support (Main 1998, Tsemberis 2000, Sommer 2001). According to Rossi and Wright: "Long-term abject poverty, rejection by family and friends, and difficulties in establishing and maintaining normal social networks are in turn no doubt related to disability levels" $(1987$, p. 26). Such theories are often supported by the presence of certain personal attributes, such as chemical dependency or severe mental illness, among the homeless. For example, mental illness has been found to be prevalent in 20 to 33 percent of the homeless population (Robertson 1992). If homeless policies are developed from this perspective, personal disability will be the driving force for developing effective remedies to homelessness (Baum and Burns 1993).

Increasing diversity within the homeless population suggests that homelessness stems from causes beyond personal disabilities. In a critique of the individualist perspective, Sommer (2001) questions whether any correlation existed between the disabilities attributed to homelessness and the increase in homelessness that occurred in the 1970s and 1980s. Because rates of mental illness and substance abuse remain remained relatively consistent throughout this period (Burt 1992), some other forces are likely responsible for the growing prevalence of homelessness (Sommer 2001). Causes of homelessness that fall within this camp include such forces as unemployment and poverty, increasing wage gaps, the housing market, the general economy, social policies, and access to support services for persons suffering from mental illness and substance abuse disorders (Appelbaum et al. 1991, Main 1998, Sommer 2001). According to Susser (1996), changes in the economy demonstrate their spatial manifestation through housing discrimination, gentrification, and urban development policies that have played a 
role in structuring the visibility of the poor. In their analysis of homeless families in Philadelphia, New York City, Columbus, and Massachusetts, Culhane et al. (2007) find prolonged shelter stays to be the result of policy and program factors rather than personal characteristics. With growing evidence of how such factors affect homelessness, Main (1998) states that the bulk of modern theory on homelessness is derived from the structural perspective and attributes individual characteristics and disabilities as at most secondary causes of homelessness. For example, survey research has shown that persons with mental illness feel it is lack of income, rather than disability that stands as their main barrier to stable housing (Tanzman 1993). Further, in this perspective, the "deviant" behaviors exhibited by the homeless may be considered an adaptation to the hostile realm of homelessness rather than the cause of the phenomenon (Main 1998).

One of the most prevalent structural explanations for homelessness is the changing dynamics of the job market and the deindustrialization of the modern economy. Within this perspective, deindustrialization implies a decrease in the need for manual labor; low-skilled workers are still needed but not at the same levels as in the era of industrialization (Susser 1996). This reduction in the availability of jobs for low-skilled workers directly affects the ability of unskilled persons to provide housing for themselves and can also limit the ability of family members to provide support (Rossi and Wright 1987). In addition to a decrease in need for skilled workers, a growing wage gap is also relevant to the deindustrialization argument. This is attributed to structural factors including a decline in living wages, union organization, and "Fordism."

Based on Henry Ford's philosophy that employees should be able to consume the products they create, Fordism implies that workers in the industrial economy be able to 
maintain a "fair day's wage." In the 20th century industrial economy, working households enjoyed the benefits of a "fair day's wage", including expanded wages, job security, occupational safety, health benefits, and seniority polices (Susser 1996). Today's economy, however, has been said to be post-Fordist in that manufacturing is more likely to be flexible and temporary (Soja 1989, Flusty and Dear 1998). Further, globalization and the decline of the welfare state have played a role in dismantling these privileges for many members of the working class. According to Susser, today's economy is characterized by "a growing informal economy, enfeebled unions, less security for most workers [including middle-income professionals], the shrinking of the welfare state, and escalating poverty" (1996, p. 415). These factors imply both less income and job security for workers, especially the least skilled and educated, reducing their ability to procure and maintain safe, decent, and affordable housing.

Changes in the housing market have also created another structural explanation for the proliferation of homelessness. Within this perspective, homelessness is also commonly considered to be a manifestation of a housing market that is inaccessible to certain segments of the urban population (Rossi and Wright 1987). Increasing housing costs throughout the 1990s and early 2000s exerted the strongest impact on the lowincome and working class households who were also contending with the changing labor market described above (Sommer 2001). In their analysis of 224 metropolitan areas, Early and Olsen (2002) find increases in the price of rental housing to have increased the number of sheltered homeless persons and the total homeless. Urban revitalization and gentrification contributed to shrinkage in the affordable housing stock because formerly low-cost housing has been improved to meet the housing preferences of higher income 
groups (Sommer 2001). One metaphor likens the housing market to a game of musical chairs where someone will always be caught without shelter when the music stops and personal attributes are at most acting as a mechanism for selecting who is left out of the game (Main 1998).

A number of individual and structural factors have been identified as factors attributing to homelessness. These theories have played a role in determining what policy agendas are used to address homelessness (Kogel 1996, Burt 1997, Wright et al. 1998, Sommer 2001). For example, individual theories are likely to support policies for remedying individual deficits such as prescribed services. Conversely, structural theories are likely to target preventive strategies that alter housing and labor market conditions (Koegel et al. 1996). However, no one factor will likely explain the entire breadth of homelessness and its many manifestations. Main (1998) contends that the root causes of homelessness are too complicated to be described by one explanation, and that this phenomenon is caused by both individual and structural factors. In this view, it is helpful to think of each of these strands of theory in the context of a multi-dimensional understanding of homelessness. Theories regarding individualist theories explain both how personal deficits lead to homelessness and how various interests in society allow it to exist. To explain departures from traditional observations of homelessness, structural theories have shown how economic and political structures have contributed to the continued growth of homelessness. When considering the striking relevance of both of these theories, it becomes evident that homelessness in the U.S. is a multi-tiered problem that is unlikely to be explained by any one theory. Thus, the most effective homeless policies will be those that address homelessness from a multifaceted angle. 


\section{Ramifications of Homelessness}

In the context of urban space, homelessness is a problem with a highly visible presence. Waldron describes this eloquently in a very simple statement: "Everything that is done has to be done somewhere" (1991, p. 296). Within our cities, class conflict plays a prevalent role in determining the boundaries, services, and maintenance of communities (Susser 1996). This conflict for urban space can be captured through Kleinberg's concept of urban ecology. According to Kleinberg (1995), the development of the urban landscape can be viewed as the result of the struggle between groups of individuals for the most advantageous ecological resources. Groups with the greatest resources will occupy more prestigious neighborhoods while groups of lesser stature will reside in less desirable places, creating a continuum of housing based on one's functional position in urban society. The homeless add an extension to Kleinberg's ecological order. At the lowest point of the continuum are those who can acquire no form of housing: the homeless. This group essentially has no space to claim as its own and is relegated to occupy various zones of public space throughout the city.

For most citizens, daily living activities, such as sleeping, bathing, urinating, and eating, occur within private homes. However, for a person experiencing homeless, this is not an option and the only place for daily activities to occur is space that can be accessed by the general public. For some homeless individuals, this may occur in an institutional setting, such as a shelter or other community facility. For others, these activities will likely occur in much more conspicuous public space. Waldron (1991) classifies such space as either being collective or common property that is essentially controlled by the community or an official acting on its behalf. Such common property includes streets, 
sidewalks, public transit, train stations, and city parks (Waldron 1991, Susser 1996).

Additionally, the homeless may reoccupy spaces used during the day by housed persons, including lobbies, hallways, and public spaces, giving a second use to some of the most coveted spots in the city. These are the spaces constitute some of the most visible aspects of the urban landscape. As Waldron states, "wandering in public space is their only option" (1991, p. 300-301). Hence, when homelessness occurs on a large scale, its visible presence can become quite substantial.

Susser (1996) remarks that, while homeless persons making camp in the tourist destinations of our largest cities are generally not doing so to make a deliberate political point, their undeniably visible level of need clearly manifests itself as one. Arguably, when city streets, parks, and other public spaces are filled with the homeless and their possessions (tents, shopping carts, and sleeping bags), these spaces become undesirable for other citizens to use (Waldron 2000). Further, most public space is not designed for activities such as bathing, urinating, or even loitering, and these activities may be a nuisance to the public at large (Waldron 1991). Waldron (2000) argues that these behaviors are often further exacerbated by other behaviors associated with homeless persons, including panhandling, drinking, and drug use. As a result, citizens of the city may feel compelled to flee to private spaces including cyberspace, shopping malls, and private walled or gated communities (Ellickson 1996).

The transient and often turbulent dynamics of homelessness have implications for how this group interacts within the realm of urban space. Susser (1996) observes that, for homeless people in cities, certain routines must be established to attain certain necessities and services. The homeless spend long parts of their day waiting in line for 
institutionalized services like food and shelter, most commonly provided during workday hours. This amplified visibility in areas where services are provided will likely detract from the desirability of such locations. While the housed population is likely to remain in the same residence for a number of years, homeless individuals are more likely to be in a perpetual state of flux, alternating between different spaces and types of living arrangements. Susser describes this as a state of constant shifting of occupation of various spaces, including streets, shelters, mental institutions, detoxification facilities, jails, and apartments. Thus, each of these settings is likely to be affected by the presence of homelessness, with many institutions experiencing substantial burdens in serving these groups. Further, many members of the homeless population transition from city to city in search of employment, services, better weather, or other conditions to enhance their opportunity for survival (Susser 1996).

Because the homeless are a dynamic and diverse group of individuals, their impact on the city is quite substantial. A simple lack of private space to perform daily living activities often causes the homeless to be seen as a public burden to the city and its public spaces. This perceived nuisance is further exacerbated by substance abuse, mental health, and other characteristics often associated with the homeless. Combined, these nuisances have a large collective consequence (Ellickson 1996). The presence of the homeless is often seen to deter tourism and other economic development activities within central cities. Shelters and other institutions are required to meet the needs of the homeless, with much of the expense often being incurred by the municipality and other levels of government. Further, the presence of the homeless also causes substantial strain on other service systems such as hospitals and correctional facilities. With such explicit 
consequences, urban policy has been compelled to address the issue of homelessness from a number of different angles. As cities have become increasingly aware of the dynamic impacts of homelessness, many have formed partnerships across private, public, and non-profit sectors to combat homelessness. The following section considers the evolution of public responses to homelessness as well as their implications for the homeless and the city at large.

\section{Responses to Homelessness}

The magnitude of homelessness and its ramifications have presented cities with the daunting challenge of eliminating or at least curbing its presence. To meet this challenge, city, state, and federal government have implemented a number of initiatives. These responses exist within a complex framework of policies and services that allow cities to address homelessness from multiple levels. Strategies vary based on pervading political interests as well as perceptions of homelessness and its causes. Policies have also changed over time as an understanding of the nature of homelessness has changed. Approaches are also likely to differ depending on the targeted subpopulation (temporary, episodic, chronic, families, individuals, etc.). Further, because homelessness, especially chronic homelessness, is associated with behavioral health problems, responses are often geared at providing treatment for these issues. However, this does not mean that housing and services are mutually exclusive. In reality, both components are often linked together in some fashion. This section reviews the evolution of homeless policies and services since the 1980s. It also considers variation in approaches and the tradeoffs associated with each of these approaches. 
The causal argument to which one subscribes is important because it exerts a strong influence on the types of policies and interventions espoused (Burt 1997, Wright et al. 1998). Sommer (2001) succinctly categorizes these perspectives by dividing homeless theory into three camps. Someone with a purely individualist interpretation of homelessness will see homelessness as a "lifestyle choice" and prescribe either no action or punitive action to alleviate the negative aspects of homelessness on a city. Conversely, a strictly structural viewpoint will see homelessness as a manifestation of societal inequalities that the government must remedy. Sommer additionally proposes a third group that falls in the middle of the continuum and acknowledges the disabilities commonly associated with homelessness and lack of ability to combat these disabilities. This perspective, according to Sommer, supports treatment and other services as the most appropriate reaction to homelessness.

\section{Outpatient Services}

One response to combating homelessness has been to provide services to address problems plaguing homeless individuals, such as mental illness and chemical dependency. As deinstitutionalization occurred in the 1970s, the need for such services in the community was readily apparent and plans were made for enhancement of outpatient services for people with mental illness (Sommer 2001). However, the number of community mental health centers intended to be created never came to fruition and priority was given to higher functioning individuals with less severe mental illness (Schutt and Garrett 1992, Sommer 2001). This lack of treatment created a gap in the service system, preventing individuals with the most severe disabilities from achieving a self-sufficient lifestyle, and thus further perpetuating the likelihood of homelessness. In 
the absence of these services, the deinstitutionalized become reliant on a substitute system of services including jails, prisons, and nursing homes (Sommer 2001). Such systems not only create undesirable conditions for users but also incur a highly expensive system for providing shelter to this vulnerable population. Further, they have largely failed to address the most fundamental problem of homelessness: a lack of housing.

\section{Punitive Policies}

One response to the presence of homeless individuals in cities is to enact punitive policies, such as anti-nuisance laws or ordinances, to penalize activities often associated with homelessness. This is done through ordinances and other initiatives that target the homeless by charging police and social service agencies with the task of removing homeless individuals from areas where they are deemed undesirable (Waldron 2000). Examples include ordinances against sleeping, panhandling, storing property, peddling, and sitting in public spaces (Sommer 2001, Saelinger 2006). They may also specifically target the homeless by selectively enforcing laws that prohibit actions such as littering, jaywalking, or loitering. While such laws have existed for centuries, they have become increasingly aggressive since the 1980s. According to Saelinger (2006), the most recent punitive policies have become increasingly threatening and include the most severe penalties. Further, Saelinger notes that they are often inconsistently enforced in ways that specifically target the homeless.

Such policies largely serve as legal mechanisms to essentially criminalize the daily living activities of the homeless and restrict the ability of the homeless to exist with urban realm (Waldron 1991). Waldron cites the example of New York City prohibiting 
sleeping on its subway cars, specifically targeting the group most likely to sleep on cars: the homeless. The stringency of these punitive policies varies substantially with fines as low as $\$ 10$ (Roanoke, Virginia) or as high $\$ 1,000$ and 30 days in jail (Hawaii) for offenses such as sleeping in a public space (Saelinger 2006). These punitive policies all contain the common element of exceeding a homeless person's ability to pay, which in turn lengthens their criminal records, increases their debt to the city, and in some cases forces them to leave the city due to fear of prosecution (Saelinger 2006). The justification for such policies is often in the name of reclaiming public spaces such as parks and boulevards (Waldron 2000). They have been noted to be particularly prevalent in areas undergoing revitalization or trying to maintain their tourism bases and are most strictly enforced during tourist seasons (Saelinger 2006). In her review of literature on this criminalization of homelessness or "mean policies," Sommer states that these policies are linked to urban revitalization's emphasis on making "quality of life improvements," compassion fatigue among the public and the perception that the shelter system has failed, the political efforts of an economically elite political minority, and NIMBY-ism (Sommer 2001).

While punitive policies can in fact make the homeless less visible, critics have raised ethical, constitutional, and fiscal arguments about this strategy for addressing homelessness (Waldron 2000, Saelinger 2006). Ellickson (1996) states that many of these activities, such as bench sitting and panhandling, are merely "street nuisances" rather than activities that truly threaten or harm other citizens. This criminalization can result in the homeless individual being constantly at odds with the urban legal system (Waldron 1991). Waldron (2000) questions whether these discomforts should be 
considered harmful at all. Further, such policies do little to mitigate the problem of homelessness because they merely prohibit their existence in one realm and force them to interact in another. In this regard, such policies seek to take homeless persons off the street but provide little alternative other than a correctional facility. Saelinger (2006) cites a 2003 survey (by the National Law Center on Homelessness and Poverty) which found that, of 50 municipal codes in the nation's largest cities, all of them imposed some policy restricting use of public space yet that policy did not include provisions for the shelter or housing units needed to get these homeless individuals off of the street. While punitive policies may alleviate central cities of the negative impacts of homelessness, they often merely shift the problem to different areas of the urban realm. Thus other services and policies are required to actually meet the needs of the homeless.

\section{The Homeless Shelter}

One of the most common responses to the problem of homelessness has been to provide immediate, short-term housing through congregate living facilities, known as shelters. Throughout time, the shelter and the role that it plays in the lives of a homeless person has changed substantially. A 1996 enumeration of homeless individuals found 63 percent of homeless individuals to be residing in some sort of emergency or transitional shelters (Sommer 2001). While shelters can vary greatly in size, structure, and philosophical mission, they are most commonly placed in one of two categories: emergency or transitional shelters. The fundamental difference between these two forms of shelter is that emergency shelters have a mission of providing for the immediate housing needs of the homeless while transitional shelters are intended to not only provide shelter but also assist individuals in transitioning from homelessness. Hence, transitional 
shelters often include substance abuse and mental health treatment components. The following sections describe how each of these types of shelters has been used to address the needs of the homeless and their successes in mitigating homelessness.

\section{Emergency Shelters}

Emergency shelter facilities provide for the most urgent needs of the homeless (Sommer 2001). By providing a place to sleep, eat, and take care of bodily hygiene, emergency shelters replicate, albeit temporarily, some of the basic functions of a home (Gounis 1992, Stark 1994). As the magnitude of the homeless epidemic gained increasing recognition in the 1970s and 1980s, providing shelter on an emergency basis was a common response to what was often regarded as a short-term problem and temporary shelters sprang up around the nation (Stark 1994, Cragg and O'Flaherty 1999, Sommer 2001). However, as the nation became increasingly aware that homelessness could not be solved quickly, shelters established a more permanent place within the realm of urban services (Stark 1994). Emergency shelters and their operations vary in terms of their size, location, and funding (Burt 1992). DeVerteuil (1996) coins the terms "megashelter" and "storefront shelter" to capture the two ends of this spectrum. Mega-shelters refer to large well-established facilities located in downtowns or close to other established service hubs. Such shelters may also offer a range of other social services including employment and housing assistance (Stark 1994, Hoch 2000). Storefront shelters, on the other hand, refer to smaller facilities located in underserved areas. Shelter conditions may also vary according to gender and family status (Susser 1996). For example, facilities for families are believed to be superior to those for single adults in 
aspects such as privacy, space, comfort, sanitation, and availability of treatment and counseling (Cragg and O'Flaherty 1999).

Prior to the 1990s, homelessness was believed to be more homogenous and providing shelter on an emergency basis was the predominant response to homelessness (Sommer 2001). However, as homelessness became known as a more complex phenomenon, the long-term value of the emergency shelter came into question. Analysis across 224 metropolitan areas found that the number of additional shelter beds in a city had minimal impact on the number of street homeless (Early and Olson 2002). Hoch (2000) states that while the homeless shelter system provided a means for "warehousing" the nation's growing homeless population, it has done little to actually remedy the problem of homelessness. Kuhn and Culhane (1998) found that 80 percent of New York City and Philadelphia emergency shelter users were temporarily homeless, 10 percent were episodically homeless, and 10 percent were chronically homeless. Despite the small number of chronically homeless shelter users, this group was found to consume half of all shelter days, demonstrating that their emergency shelter use occurs on a more permanent basis.

In the continuum of homeless theories, emergency shelters fill a gray area of sorts in that they have been critiqued for recognizing neither the individualistic nor the systemic roots of homelessness. DeVerteuil (1996) notes that shelters are often critiqued for their orientation toward immediate crisis and not addressing more systemic long-term issues such as housing affordability, marginalization, and welfare cutbacks. On the other hand, emergency shelters by nature do not address those individual factors that have been associated with homelessness, including substance abuse, mental health disorders, and 
other disabilities. For example, a survey of 68 homeless individuals in eight Hennepin County, Minnesota, homeless shelters found that only six percent of users were receiving mental health services despite the fact that more than 50 percent were deemed to need such care (Kroll et al. 1986).

Another critique of the shelter system is that shelters often enforce a strict set of rules that may hamper the personal liberties of homeless individuals. Stark (1994) contends that the shelter essentially operates as a "total institution" with a set of rules and norms that further isolate homeless persons from mainstream society. Curfews, fixed hours for entering and leaving, set meal times, storage of personal items, personal hygiene, prohibition of substance abuse, and other codes of conduct are commonly found in shelters and create a set of requirements for contingency of use. Such policies are often enforced with the justification that they facilitate personal improvement and protect shelter users from harm and chaos (Stark 1994). A 1984 HUD study found that 70 percent of shelters required attendance at some sort of religious service and forced the residents to leave after a night's stay (Hoch 2000). Baxter and Hopper (1981) observe that, considering the state of the shelter system and its required regiments, life on the streets may in fact be a preferred alternative. This may be especially true for individuals with biological chemical dependencies and untreated mental health disorders that are incapable of following the rules and regulations of the shelter. Stark (1994) argues that these rigid "mechanisms of control" actually strip the ability of homeless persons to regain economic self-sustainability. According to Stark, mandates such as curfews and prohibitions against staying in shelters during the day make it extremely difficult for 
shelter users to conform to the requirements of work schedules, forcing them into a sort of "institutional dependency."

\section{Transitional Housing}

As the dynamics of homelessness changed throughout the later decades of the 20th century and knowledge about homelessness and its causes increased, it become apparent that, for many, especially the episodic and chronically homeless, emergency services were not sufficient for assisting some individuals to regain independence and stability. From this awareness, new models to promote transitions to stable housing began to surpass the emergency shelter model (Culhane and Metraux 2008). Transitional programs pair shelter with supportive services needed to empower homeless individuals to live independent lives (Washington 2002). This model, also known as linear residential treatment or continuum of care, generally provides a step-by-step sequence of housing placement and services to allow an individual to develop the ability to maintain independent housing (Tsemberis 1999, 2000). Housing services are provided in a sequence that includes outreach, transitional housing, supervised single-room occupancy, and then independent permanent housing as the last step (Tsemberis 1999). Therefore, homeless persons housed through this approach will likely experience a number of housing arrangements and levels of supervision throughout their program tenures. Services may target areas of need for homeless individuals, including job training, case management, substance abuse treatment, and mental healthcare (Washington 2002). These programs tend to have requirements for mental health treatment, medication compliance, and abstinence from alcohol and drugs as conditions for moving toward independent housing. 
According to Lederman (1993), the first "modern" transitional program appeared in Los Angeles in 1983. By 1987, the need for assistance beyond emergency services had become well recognized by Congress and a Supportive Housing Demonstration Act was included in the McKinney Act of 1987 (Hoch 2000, Washington 2002). Between 1987 and 1990, HUD had awarded $\$ 338.5$ million in grants to 534 transitional housing programs with the purpose of preparing homeless individuals for independent housing within 24 months or less (Washington 2002). Through this Act, emergency shelters were intended to become a point of entry into a more specialized shelter system that could address a multitude of needs for homeless individuals, including disability, mental illness, domestic abuse, and addiction recovery (Hoch 2000).

Tsemberis discusses four major problems with this approach to serving homeless individuals "(a) lack of client choice; (b) the stress created by multiple moves; (c) the long time required to reach the final step; (d) the destabilization created when clients' housing status is tied to their treatment compliance" $(1999$, p. 227). It has been stated that the intent of transitional programs is to empower homeless individuals (Sowers et al. 2002, Washington 2002). However, the actual level of empowerment created through such a program is debatable, especially in terms of consumer choice. From one perspective, these programs empower people through the provision of the services believed to be most needed by homeless individuals. For example, while research has found that consumers are primarily concerned with having their basic needs met, service providers are focused on mental health services (Tsemberis 2000).

In his evaluation of a Memphis, Tennessee, transitional housing program for families, Washington (2002) captures firsthand experiences of individuals who 
successfully graduated from the program and finds a high level of satisfaction with the services offered and that participants did work with counselors to determine individual goals. However, the program presented clients with personal choices; for example, counseling sessions were not mandatory. Further, transitional programs may "cream" clients or pick those most likely for success. For example, Washington (2002) state that the Memphis program he evaluated explicitly seeks those who show "eagerness" to develop independent living skills. Families seeking placement must complete a lengthy interview process and have a negative drug screen and no felony convictions in the previous two years. While such creaming increases the likelihood of successful program outcomes, it allows the program to avoid the more difficult to serve individuals; this may be especially true of the chronically homeless for whom such requirements present the strongest barriers. These individuals also tend to be the least successful in "treatment first" programs because these programs tend to have strict requirements for abstinence and mental health treatment that pose substantial barriers to housing this population (Gulcur et al. 2003, Tabol et al. 2010). Thus, this group is often viewed as the most difficult to serve and becomes entrenched in a paradox of continued homelessness because they are not deemed as being "housing ready." Washington demonstrates how the transitional shelter was effective for successful participants. However, the question of how unsuccessful participants are affected by the program remains to be explored.

The transitional model has also been critiqued for its insufficiency in fostering the ability of participants to live independently (Tsemberis 1999, 2000). The skills learned in one setting of the continuum may not be applicable to the next phase (Anthony and Blanch 1989, Tsemberis 1999). For example, characteristics of congregate living, such 
as a division of household chores, do not transfer well to independent living where an individual is responsible for all household tasks. Under this model, individuals can also lose their housing placement for a number of reasons, such as relapsing into substance abuse, not taking psychiatric medications, or not participating in required activities (Ridgway and Zipple 1990, Hopper et al.1997, Shinn and Tsemberis 1998, Tsemberis 1999). For participants with chronic substance abuse and mental health conditions, this can present a considerable barrier. Finally, even though the purpose of such programs is to provide individuals with independent living skills, appropriate housing may not necessarily be available upon program completion. When and if the final step of independent housing is reached, there are often little or no support services at what can be viewed as one of the most critical and stressful transitions of the housing process (Tsemberis 1999).

The approaches to homelessness discussed above have been used to address the immediate needs of homeless persons and alleviate homelessness whenever possible. While they have done so effectively for many subpopulations of homeless individuals, the chronically homeless have remained difficult to permanently house compared to other groups. This group tends to face challenging barriers such as persistent mental illness and substance abuse disorders that have often left them ill served by programs with transitional settings and mandatory treatment plans (Tabol et al. 2010). Transitional programs for homeless persons often operate on the philosophy that individuals "work their way through the system" of emergency and transitional shelters before they receive permanent housing (Tabol et al. 2010). Many of these programs have policies requiring lengthy periods of sobriety before entering housing and consider the use of substances in 
housing as a violation that warrants the termination of housing services. Such policies are especially problematic for individuals with chronic substance use disorders, as eviction from housing simply perpetuates the cycle of homelessness. The inflexibility of treatment programs that terminate participants who relapse means that such programs will not likely be successful in serving chronically homeless populations with severe substance abuse problems (Caton et al. 2007). Because homelessness is a chaotic lifestyle that does not promote recovery from substance abuse and mental health problems, programs that return these individuals to the streets and shelters exhibit little success in housing this population. The transitional model is further critiqued because it induces residential instability by continually moving participants to new environments where they must establish new social supports (Blanch et al. 1988, Tabol et al. 2010).

\section{Permanent Supportive Housing and Housing First}

By the late 1980s, it was apparent that certain segments of the homeless population were ill suited to the transitional "treatment first" approach to housing (Ridgeway and Zipple 1990, Tabol et al. 2009). For many members of the chronically homeless population, mental illness and substance abuse are chronic conditions that require long-term or permanent support systems in order to maintain housing. Furthermore, treatment and sobriety requirements have presented a barrier to housing for those with active additions and mental illness. In response to these challenges, an alternative to emergency and transitional homelessness programs has emerged that places a dual emphasis on the needs for long-term housing and the services needed to maintain housing. This approach, known as permanent supportive housing, has been used to address the needs of some of the hardest to serve of the population (Tsemberis 2000). 
Supportive housing models feature core principles including community mainstreaming, tenant empowerment, and flexibility of services. Rather than creaming for clients that will likely achieve the best outcomes, permanent supportive housing programs tend to give priority to those at greatest risk of victimization or health problems, and other barriers that have impeded success in other programs such as substance abuse or incarceration (Tsemberis 2000).

Using criteria set forth by the Substance Abuse and Mental Health Services Administration, Rog (2004) described eight specific elements of the permanent supportive housing model:

- The individual owns the housing (has a lease in his or her own name, rather than a lease tied to an agency or program) and the housing is considered permanent.

- Housing and service agencies are legally and functionally separate.

- Housing is integrated into the community.

- Housing is affordable (no more than 40 percent of adjusted gross income).

- Involvement is voluntary.

- The individual has choice of housing and services

- Services are community-based and there are no live-in or regular in-house staff.

- Crisis services are available 24 hours a day, seven days a week.

These characteristics define much of the Housing First model, a derivative of the permanent supportive housing model that has gained much recognition for its ability to address the needs of the chronically homeless. This approach was originated in the early 1990s by New York City's Pathways to Housing Inc., which set forth a new way of providing housing and other services to homeless individuals. Based on the philosophy that securing safe, decent, and affordable housing is the first step to meaningful recovery for homeless persons suffering from substance use or mental health disorders, Housing First presents a consumer driven approach that places individuals in independent housing, 
provides them with case management, and offers unmandated access to substance abuse and mental health treatment (Tsemberis 1999, 2000). In other words, while mental health and substance abuse treatment are offered and encouraged, they are in no way a precondition or requirement for obtaining or maintaining housing. Consumers are generally required to participate in case management. However, the case manager is intended to serve as an advocate, facilitator, and partner in determining and pursuing recovery options rather than a dictator of treatment compliance.

To promote its consumer driven nature, Housing First is based on the premise that homeless individuals should be treated as any other paying tenant in the community. Unlike many permanent supportive housing programs in which housing is contingent on sobriety and compliance with treatment, Housing First separates housing and treatment requirements; although supportive services and treatment options are available to clients, they are not a requirement for housing. The consumer can only lose his or her housing for the same reasons that any tenant in the rental market would be evicted: failure to pay rent or violating the conditions of his or her lease. While some programs may operate their own housing units, the Housing First model strongly encourages that housing be provided through privately-owned scattered-site apartments. Housing and treatment services are thus provided by separate agencies, with apartments rented from landlords in the community who have no direct relationship with the treatment agency (Tsemberis 1999).

Since being first implemented by Pathways in 1992, Housing First has become known as a new paradigm in addressing the needs of the chronically homeless. Pathways' Housing First Program is included as an evidence-based practice on 
SAMHSA's National Registry of Evidence-Based Programs and Practices (NREPP), which notes that at least 27 sites have implemented the Housing First program since its inception in 1992 and an estimated 6,800 individuals have participated in the program in the U.S. and several other countries. Today, more than 100 cities have developed programs based on the Housing First model (Tsemberis 2010). A considerable amount of research has been published on Housing First and its effectiveness (Tsemberis and Eisenberg 2000, Greenwood et al. 2005, Tsemberis et al. 2003, 2004, Padgett 2007). A 1996 SAMHSA-funded study randomly assigned 225 homeless individuals to either a Housing First unit or to a housing program that required treatment or sobriety. The study confirmed that a person's mental health or substance use was not related to his or her ability to maintain independent housing (Patterson 2008). Analysis of data from this study reported on four primary outcomes: residential stability, consumer choice, use of support services, and cost of supportive housing and services. Research addressing each of these outcomes as well as other studies addressing the effectiveness of Housing First is described below.

One of the most important objectives of Housing First is that homeless individuals find and maintain long-term stable housing. Housing First participants have been found to be housed more rapidly and stay housed longer than those homeless individuals participating in treatment oriented programs (Patterson 2008). While only 30 percent of the control group maintained housing over a two-year period, 80 percent of Housing First tenants remained stably housed after two years (Moran et al. 2003, Tsemberis et al. 2004). Utilization of substance abuse treatment was higher for the treatment first group, but no differences were discovered in substance use or psychiatric symptoms between the 
two groups. When comparing the Pathways to Housing program to a linear model, Pathways was found to achieve a housing retention rate of 84.2 percent over a three year period, while the linear program maintained a retention rate of only 59.6 percent.

A study of over 3,000 residents found that tenants in Housing Fist achieved a housing-retention rate of 84 percent over a three-year compared to a rate of 60 percent for residents of a comparison program tracked over a period of only two years (Tsemberis 1999). Pearson et al. (2007) found that 85 percent of participants remained in housing remained housing at the end of their first year in the program. Perlman and Parvensky (2006) found that 80 percent of participants in a Denver Housing First program maintained their housing for six months and 68 percent maintained housing for at least one year. A study of 260 individuals in permanent housing found that Housing First programs moved individuals into housing quicker than non-Housing First programs. After 47 months, 68 percent of Housing First residents had maintained housing while only one individual in the control group had moved from homelessness to independent housing (Stefanic and Tsemberis 2007).

\section{Use of Support Services}

Tsemberis et al. (2004) examined the longitudinal effects of the Housing First model for mentally ill homeless individuals concerning those individuals' consumer choice, housing stability, substance use, treatment utilization, and psychiatric symptoms. Housing First clients reported significantly less use of substance abuse treatment and less time in psychiatric hospitals. There were no significant differences in alcohol or drug use found between the two housing groups and Housing First clients showed a decrease in 
psychiatric symptoms (Gulcur et al. 2003, Moran et al. 2003, Tsemberis et al. 2004, Greenwood et al. 2005). A study of 80 individuals in permanent housing found that those in Housing First programs had a more positive reaction to housing, had a greater sense of safety, had fewer housing challenges, and reported fewer problems fitting into the community (Yanos et al. 2004). A qualitative study of a Housing First program in Massachusetts found that residents demonstrated improved health status, improved selfesteem, and a greater sense of independence and a normal life (Meschede 2006). Another qualitative study found that individuals in the Housing First program experienced greater personal security, including constancy in daily routines and privacy (Padgett 2007).

In addition to examining the outcomes of Housing First, research has also begun to raise questions about the potential cost savings of this approach. Participants in Housing First incurred fewer costs after two years than those in more traditional permanent supportive housing programs (Gulcur et al. 2003). An analysis of the health and emergency service records of a sample of participants for the 24-month period prior to entering the program and the 24-month period after entering the program found that emergency-related costs declined by 73 percent, an average savings of $\$ 31,545$ per person. Use of emergency rooms, inpatient medical and psychiatric care, detoxification services, incarceration, and emergency shelters were all significantly reduced by participation in the program (Perlman and Parvensky 2006). Stefanic and Tsemberis (2007) also found that the annual cost of housing a person in Housing First was less than housing in an emergency shelter.

Proponents of Housing First and other independent housing programs suggest that these approaches can potentially decrease costs because housing placement should reduce 
the need for other more cost intensive services (Culhane et al. 2002, Gulcur et al. 2003, Harkness et al. 2004, Barber et al. 2008, Larimer et al. 2009). Homeless persons with serious mental illness or substance abuse disorders tend to be among the heaviest users of a number of public services, including transitional and emergency shelters, psychiatric hospitals, detoxification facilities, emergency rooms, and correctional facilities (Barber et al. 2008). Research has also shown that the costs of supportive housing are largely offset by reduced utilization of hospitals, shelters, and incarceration facilities (Culhane et al. 2002, Rosenheck et al. 2003). A cost study in Louisville found that hospitals and correctional facilities accounted for 75 percent of system costs for homeless persons (Barber et al. 2008). By shifting the primary emphasis of treatment to housing rather than abstinence and treatment compliance, homeless persons gain immediate access to the independent housing that they need and desire.

Because individuals obtain and maintain housing, they no longer rely on more costly emergency and transitional shelters. Housed individuals are more likely to use outpatient psychiatric services in lieu of much more costly inpatient treatment (Culhane et al. 2002, Gulcur et al. 2003). Supported housing can also help to shift homeless individuals out of emergency room and inpatient hospital facilities by removing the health risks of street life, providing better access to preventive outpatient services, and reducing the required duration of inpatient services (Rosenheck 2000, Culhane et al. 2002). Further, while substance abusers may still choose to use, they can do so in a safe environment that allows them to avoid being arrested for public intoxication and makes them less susceptible to street violence and other injury. From this viewpoint, Housing 
First programs have the potential to reduce public expenditures for homeless persons while at the same time offering an enhanced quality of life.

Because of its two-fold nature, Housing First presents a framework that addresses both the individual and structural causes of homelessness. By placing emphasis on the imminent need for housing, the model directly addresses the structural issue of limited housing affordability and the permanence of such programs address the long-term problem of chronic homelessness. Meanwhile, the supportive services element addresses those individual factors that contribute to homelessness and strives to give individuals the resources and skills necessary to remain successfully housed.

\section{Scattered-Site Housing and Housing First}

Scattered-site voucher based housing has been the most common type used in Housing First programs (Tsemberis 1999). In fact, the Pathways to Housing model recommends that no more than 10 percent of units in an apartment building be rented to Housing First participants (Tsemberis 1999, 2000). This principle of Housing First is intended to integrate participants into the community as opposed to placing them in a congregate setting where they may feel separated from mainstream society (Yanos et al. 2007). It also reinforces Housing First's emphasis on consumer choice as it allows participants to choose the housing and neighborhood that best fit their needs and preferences. However, consumers are limited in their housing choice to those properties that accept such vouchers and these often consist of apartments in low-income neighborhoods (Tsemberis 2000).

As housing itself is considered the primary treatment within a Housing First project, the type of housing and its location should be considered a critical element for 
evaluating the program's effectiveness. However, studies that explore Housing First and other homeless programs in this context are limited to a small number of works (Thompson et al. 2004, Yanos et al. 2004, Yanos et al. 2007, Pearson et al. 2009, Tsai et al. 2012). Since there is limited research in this area, this review will consider literature pertaining to a more general discourse on scattered-site housing, existing work pertaining to homelessness and Housing First, and related studies from the mental health field.

According to Galster and Zobel (1998), the purpose of dispersed or scattered-site housing is to enhance opportunity and choice for subsidized housing recipients by spatially deconcentrating poor inner-city residents and socially integrating them into middle-class suburban communities. From the standpoint of social influence theory, proximity to non-poor neighbors may provide low-income households with positive role models and reduce the occurrence of social problems commonly associated with poor neighborhoods, such as unemployment and high crime rates (Kleit 2001).

For Kleit (2001), interaction is the key ingredient for subsidized housing recipients to absorb the benefits of mixed-income neighborhoods, but few studies have taken into account how the poor interact with non-poor residents. For this reason, she focuses her study on the differences between the experiences of scattered-site tenants and those living in more concentrated areas. Residents of clustered housing were found to be less likely to have social networks that reached beyond their public housing development. However, these individuals were more likely to feel emotionally close to their neighbors compared to those living in scattered housing. For scattered-site participants, being located in close proximity to a more affluent population did not necessarily mean that they interacted with more affluent groups on a meaningful level. Kleit also suggests that 
deconcentration of subsidized housing may cause low-income groups to lose important ties to place based support systems.

In their extensive literature review, Ellen and Turner (1997) identify six ways that neighborhood conditions may influence individual outcomes (with changing levels of importance throughout various stages of life): quality of local services, socialization by adults, peer influences, social networks, exposure to crime and violence, and physical distance and isolation. The majority of these studies have focused on the impacts of neighborhood environment on children and young adults. For families and children, the effects of neighborhood were generally found to be smaller than that of observed family characteristics such as parent's income, socioeconomic status, or educational attainment (Ellen and Turner 1997). As children age into teenagers and young adults, the influence of the immediate family is gradually replaced with that of peers and adults who become more influential in the shaping of values and behavior (Bronfernbrenner 1979). For adults, neighborhood is found to more likely affect individuals through access to services, information, and economic opportunities (Ellen and Turner 1997). However, because an individual's knowledge about and access to social networks and economic opportunities likely depends on established networks of acquaintances, the deconcentration of subsidized housing recipients may inflict an isolating effect (Ellen and Turner 1997).

Ellen and Turner (1997) state that understanding the relative importance of neighborhood attributes has been a difficult task with few definitive conclusions. They identify three major methodological challenges to discerning the effects of neighborhood: 
1. It may be difficult to identify and measure the neighborhood conditions that actually play the most important role in shaping outcomes.

2. Neighborhood effects may be non-linear and therefore may not be easily discernible.

3. It is difficult to separate the effects of neighborhood from the effects of individual or family characteristics (Ellen and Turner 1998, p. 843).

While scattered-site housing is the most common type of housing found in Housing First, some variations do exist. For example, in Seattle, Washington, the Downtown Emergency Service Center (DESC) developed four individual housing facilities which are able to accommodate up to 300 participants at one time (Pearson et al. 2009). Pearson et al. compared housing stability outcomes for 25 participants in this program to those of 26 participants in the Pathways to Housing Program in New York City. Over a 12-month period, 80 percent of DESC participants retained housing, while 92 percent of Pathways participants maintained housing. While the authors considered other program variations such as level of services and flexibility in their analysis, neighborhood characteristics and other features made these two types of housing different from each other in ways that were not considered in detail.

Yanos et al. (2004) studied the process of community integration for Housing First Participants in New York's Pathways to Housing program. Through in-depth interviews with 80 subjects, the authors found that, for the majority of participants, entry into housing was associated with improvements in community integration. While the study did not study specifically address neighborhood characteristics, many interview responses were found to relate social integration to neighborhood characteristics. Many participants were found to have derived a sense of "fitting in" that was related to the racial and ethnic composition of their neighborhoods, with some indicating they felt most 
comfortable in neighborhoods of predominantly the same racial and ethnic background as themselves. Others indicated that mixed neighborhoods created a more welcoming atmosphere. For a smaller group, the transition to housing presented challenges to social integration. This was found to be especially true for those entering housing directly from institutional settings. For these participants, challenges arose from separation from peers and service providers, learning to live independently, and adjusting to a non-secured environment (Yanos et al. 2004).

Yanos et al. (2007) explored how project-based versus scattered-site housing affects community integration, and how neighborhood characteristics relate to psychological integration. Using survey data paired with zip code-level demographic data, the authors examined a number of factors pertaining to social cohesion in the neighborhood, social functioning, and psychological integration. Socioeconomic disadvantage, immigrant concentration, and residential stability were used as measures to assess neighborhood environment. Socioeconomic indicators include proportion of households receiving public assistance, proportion of households receiving Supplemental Security Income, proportion of households at or below poverty, proportion of individuals in the labor market who are unemployed, and proportion of households receiving Section 8 subsidies.

Through qualitative analysis, the authors derive the concept of "locus of activity" to capture how respondents' relationships to their living environment are conditioned by an understanding of the primary location of their meaningful activities. This may occur at the neighborhood, building, or apartment level depending on the participant's response (Yanos et al. 2007). According to the authors, indication of a locus of meaningful 
activity in one's building, neighborhood, or job implies a higher sense of fitting in than if one's locus of activity does not extend beyond his or her apartment or if there is none at all. Participants in project-based living arrangements were found to experience greater opportunity for fellowship but diminished meaningful activity outside of their living arrangements. Participants living in apartments evidenced higher social functioning than those living in congregate arrangements. For some of these individuals, living in an independent apartment setting facilitated adjustment into normal social routines and a sense of belonging in a community. However, for others it led to isolation and difficult adjustment when participants did not feel a part of the immediate neighborhood (Yanos et al. 2007). Neighborhood characteristics were found to be only weakly related to the community integration outcomes. The authors note that this may have been partially due to the fact that zip codes covered areas too broad to capture activity within the immediate community. No significant associations between ethnic identification and community integration were found.

Thompson et al. (2004) explore what processes of change enhanced housing stability for formerly homeless persons with mental illness. Twelve individuals who had successfully maintained housing for at least 24 months were interviewed about their experiences of becoming housed and the role of significant life relationships. Positive relationships with family, friends, and service providers were identified as being most critical to housing stability. These relationships were found to help strengthen personal responsibility and decrease feelings of marginalization of homeless persons. Connections to community institutions, such as churches and other social groups, were also deemed as an important component of building relationships that help reinforce housing stability. 
Tsai et al. (2012) studied whether improvements in social integration occurred for 550 chronically homeless individuals participating in permanent supportive housing programs in 11 different cities. Subjects completed surveys at housing entry, six months after entry, and again one year after entry to determine their level of integration in terms of housing, work, social support, community participation, civic activity, and religious faith. While subjects demonstrated substantial improvements in the realm of housing, they were found to have remained socially isolated in terms of the other five domains assessed in this study (Tsai et al. 2012).

\section{Mental Health Studies}

While there are a limited number of studies that consider the role of housing type and neighborhood for Housing First projects, a substantial number of studies have considered the implications of residential environment for persons suffering from mental illness (Segal and Aviram 1978, Hull and Thompson 1981, Coulton et al. 1984, Depp et al. 1986, Cournos 1987, Davies et al. 1989, Newman et al. 1994, Newman 2001, Thompson et al. 2004, Zippay and Thompson 2007). These studies have examined how environmental factors such as number of occupants, neighborhood characteristics, and urban or rural setting have impacted personal trajectories (Newman 2001, Leff et al. 2009). One of the most important aspects of this dynamic to consider is how individual characteristics interplay with housing and neighborhood characteristics. Coulton et al. (1984) discuss the concept of "person-environment congruence" stating that interactions between individuals and their environments are a more powerful determinant of outcomes than either individual or environmental differences on their own. Persons with chronic mental illness may have particular impairments or disorders that some 
environments may exacerbate. When wide discrepancies exist between perceptions of need and what the environment provides, functioning is likely to be affected negatively (Coulton et al. 1984).

Leff et al. (2009) conducted a meta-analysis of 30 previous studies of housing models for persons with mental illness to determine if outcomes, such as housing stability and psychiatric status, varied across models. Four categories of housing and service models are specified: residential care (supervised housing), residential continuum (transitional model), permanent supportive housing, and non-model (streets, shelters, or "treatment as usual") housing. The three housing models showed significantly greater housing stability than the non-model housing, with permanent supportive housing showing the greatest effect. However, Leff et al. note that differences between the housing models was statistically insignificant. They also found some significant variation in housing stability amongst population sub-groups; studies with majority white and female populations demonstrated greater residential stability than programs serving a majority of non-whites and males.

In their study of schizophrenic patients living in project-based settings, Davies et al. (1989) found that urban patients were more likely to experience substandard housing and adverse neighborhood conditions, and received less practical support than patients living in rural areas. These urban patients were also found to exhibit more psychopathologies, lower relationship functionality, and poorer global functioning than their rural counterparts. However, psychological and social well-being were found to be attributable to neighborhood settings rather than dwelling condition (Davies et al. 1989). Findings have indicated that despite housing deficiencies, the independence afforded to 
persons living in outpatient settings has provided persons with mental illness greater life satisfaction than institutional settings (Segal and Aviram 1978, Cournos 1987, Davies et al. 1989).

Depp et al. (1986) tested the impact of housing subsidies on the provision of affordable quality housing to patients discharged from psychiatric facilities. Structured interviews were conducted with 46 subjects, including both housed participants and those wait-listed for housing. Housed participants identified the ability to live alone as the most important outcome of receiving the housing subsidy. The housed group was also found to have increased its utilization of outpatient mental health services. Subjects were found to exhibit more participation in community activities such as work, volunteerism, organized activities, and church services. Interestingly, this increase of formal supports was accompanied with decreased contact with informal networks and placed subjects were in this regard found to be more socially isolated than those that were waitlisted.

Newman et al. (1994) studied the impacts of housing attributes for mentally ill persons living in independent subsidized housing (Section 8). This work explored whether or not housing characteristics such as affordability, physical condition of housing units, and neighborhood condition were associated with changes in rates of hospitalizations, residential stability, and service needs. Over a three-year period, the authors conducted periodic interviews with individuals living in Section 8 housing in the Baltimore, Maryland, and Cincinnati, Ohio, metropolitan areas. Participants were asked questions about service utilization, clinical status, and quality of life as well as their housing conditions. Pre- and post-test results were used in a series of simultaneous equation models to test the impact of housing and neighborhood characteristics on the 
measures described above. Surprisingly, neighborhood quality was shown to actually increase the duration of hospital stay for participants. Based on prior literature, the authors posit that this unexpected outcome may be the result of less tolerance for persons with mental illness in neighborhoods of higher socioeconomic status. Affordability did however have the impact of decreasing length of hospital stays for participants. Increases in housing quality resulted in a significant improvement in housing stability (as measured by number of moves) as well as a reduction in service needs.

\section{Conclusion}

This literature review has considered a wide breadth of works pertaining to homelessness, covering its causes, prevalence, and impacts as well as policy responses. Theories of the causes of homelessness suggest that this phenomenon is caused by both structural and individual factors. From this perspective, the complexities of homelessness are attributed to both a lack of affordable housing and other factors such as mental illness and substance abuse. These individual problems are especially prevalent amongst the chronically homeless, a group that has proven exceptionally difficult to serve. Since the 1980s, homeless policy has evolved considerably in its efforts to address the diverse needs of the homeless. While emergency and transitional services have largely been considered sufficient for meeting the needs of the temporarily homeless, the chronically homeless and, to a lesser extent, the episodically homeless have not fared as well in such programs.

In response to the challenges of serving the chronically homeless, Housing First emerged as a new model intended to remove barriers for this population and move them 
directly from streets and shelters into their own homes within the community. A number of studies have demonstrated this approach to not only promote housing stability but to also to promote recovery and diminish the use of costly public services. Housing First's primary mode of providing housing has been to offer participants vouchers that allow them to obtain scattered-site housing throughout their communities. A smaller number of Housing First projects have implemented project-based housing or a mix of scattered-site and project-based. While there has been abundant literature on the impacts of Housing First programs, there is much less understanding of how the actual communities that participants live in contribute to their success in the program. While community integration is commonly viewed as a primary goal of scattered-site housing (Kleit 2001), only a very limited scope of work has addressed how this program component impacts Housing First participants (Yanos et al. 2004, Yanos et al. 2007, Tsai et al. 2012).

Qualitative work by Yanos et al. (2004) found that neighborhood characteristics such as racial composition helped ease the transition for Housing First participants moving into scattered-site housing. Yanos et al. (2007) expanded on this work by pairing zip code-level data with individual survey data but found no strong connections between neighborhood and community integrations. While these two works provide insight into how neighborhood may impact the social integration process, they do not directly address how it impacted other outcomes such as housing stability. Thompson et al. (2004) take a more direct look at what processes affected housing stability for formerly homeless persons with mental illness. While this study found that social connections and ties to community services and institutions mattered for participants, the authors do not directly explore this relationship within a spatial context. This study is intended to expand this 
base of knowledge by making a more specific examination of the relationship of housing type and neighborhood attributes to the success of Housing First participants.

Studies from the mental health field provide additional insight to how environment may affect persons in our population of focus. These studies demonstrate that housing and community influence a participant's trajectory in a number of ways including formal and informal support networks, use of public service systems, and general social functioning (Depp et al. 1986, Davies et al. 1989, Newman et al. 1994). It is likely that housing and neighborhood will have complex impacts upon participants and that these interactions will likely be contingent upon the unique characteristics and circumstances of the individuals being housed (Coulton et al. 1984). Therefore, an effective study of the impacts of housing and neighborhood will need to consider personal attributes as well.

The methodology proposed in the following chapter is designed to specifically assess the outcome of housing stability in terms of whether participants remain in or move from their housing placements. Research on housing stability for Housing First projects has looked primarily whether or not a person exited the program (Tsemberis 1999, Perlman and Parvensky 2006, Pearson et al. 2007, Stefanic and Pearson 2007). While program exits are of valid consideration, it is also pertinent to explore housing stability for those participants that remained in the program. For some participants, a move from a housing placement was directly attributable to the actions of the client such as evictions, incarcerations, or program terminations. In the case of evictions, some participants may have the opportunity to seek a new housing placement depending on the circumstances of the exit. However, other involuntary movers are likely to reenter 
homelessness either temporarily or permanently. Another group of participants may have moved voluntarily to seek better or housing or a nicer neighborhood or due to some situation beyond their control such as the condemnation of their building. While the circumstances of these movers are different from those of the first group, multiple moves for any participant will likely hinder their ability to build social ties and pursue goals for their recovery from homelessness, addiction, and mental illness. Therefore, the current work will explore moves in terms of both involuntary and voluntary moves with the goal of understanding of how the aspects of housing type and neighborhood affect the likelihood of each of these types of moves. 


\section{CHAPTER 3}

\section{METHODOLOGY}

The primary focus of this study is to explore the role of neighborhood and housing type (project-based-site versus scattered-site) within the context of two Housing First projects. To do this, both qualitative and quantitative methods will be used. The key outcome to be explored is housing stability, which will be measured based on whether or not participants remained in their original housing placements, electively moved to new housing placements, or were forced to move from their residences for reasons such as eviction, program termination, or incarceration. To explore the question of how housing type (scattered-site versus project-based) impacts these outcomes, the 25 Jimmy Heath House units provided by GCBH allow for project-based housing to be considered as a variable. The five research questions outlined in Chapter 1 are divided into three categories: process (questions 1 and 2), outcomes (questions 3 and 4), and implications (question 5). This categorization refines the framework to first examine how housing placements are made, then discern the outcomes of these placements, and finally conclude with a discussion of how these findings can be applied to the administration of future and current Housing First projects.

\section{Overview of Project Sites}

This study includes an evaluation of two Housing First projects: Louisville Housing First Project at Family Health Centers-Phoenix Health Care for the Homeless 
(FHC-Phoenix) in Louisville, Kentucky, and Paths to Recovery at Greater Cincinnati Behavioral Health $(\mathrm{GCBH})$ in Cincinnati, Ohio. These two programs provide an appropriate means of comparison for a number of reasons. Both are located in mid-sized cities located at the cusp of the southern Midwest. While the U.S. Census Bureau designates Louisville as being located in the East South Central Division of the Southern Region and Cincinnati in the East North Central Division of the Midwestern Region (U.S. Census Bureau 2011), the two cities are located only 100 miles from one another. As demonstrated in Table 3.1, the two cities and their corresponding counties are also relatively similar in terms of geography, demographics, and economics. The Cincinnati/Hamilton County Metropolitan area is the larger of the two, ranking as the 27th largest metropolitan area in the country. The Louisville Metropolitan Area ranks as the 42nd largest. While the Cincinnati Metropolitan Area is larger, the Louisville Metropolitan Area experienced a slightly higher rate of population growth during the years between 2000 and 2010. Despite their differences in size, the two cities, along their corresponding Counties and Metropolitan Areas, possess very similar demographic and socioeconomic characteristics. 
Table 3.1. Demographic Characteristics

\begin{tabular}{|c|c|c|}
\hline & $\begin{array}{l}\text { Louisville/Jefferson County, } \\
\text { KY }\end{array}$ & $\begin{array}{l}\text { Cincinnati/Hamilton County, } \\
\mathrm{OH}\end{array}$ \\
\hline $\begin{array}{l}\text { Central City } \\
\text { population } \\
(2010)\end{array}$ & 597,011 & 800,362 \\
\hline $\begin{array}{l}\text { Population of } \\
\text { Metropolitan Area } \\
\text { (2010) }\end{array}$ & $1,283,566$ & $2,130,141$ \\
\hline $\begin{array}{l}\text { Metropolitan } \\
\text { population growth } \\
\text { rate }(2000-2010)\end{array}$ & $10.5 \%$ & $6.0 \%$ \\
\hline Black persons (2010) & $22.9 \%$ & $25.8 \%$ \\
\hline $\begin{array}{l}\text { Persons of Hispanic } \\
\text { or Latino origin } \\
(2010)\end{array}$ & $4.5 \%$ & $2.7 \%$ \\
\hline $\begin{array}{l}\text { High school } \\
\text { graduates }(2011)\end{array}$ & $85.5 \%$ & $87.7 \%$ \\
\hline $\begin{array}{l}\text { Median household } \\
\text { income (2011) }\end{array}$ & $\$ 49,142$ & $\$ 50,196$ \\
\hline $\begin{array}{l}\text { Home ownership rate } \\
(2006-2010)\end{array}$ & $63.5 \%$ & $61.2 \%$ \\
\hline $\begin{array}{l}\text { Unemployment rate } \\
\text { (September 2012) }\end{array}$ & $7.6 \%$ & $6.4 \%$ \\
\hline
\end{tabular}

Sources: U.S. Census Bureau and U.S. Bureau of Labor Statistics.

These two cities also contain comparable homeless populations. Despite

Cincinnati's larger size, estimates suggest the extent of homelessness is similar if not greater in Louisville. As discussed in Chapter 2, discerning the actual number of homeless persons in a city is a difficult task. One of the most commonly used measures is the HUD Homeless Assistance Program's required annual Point-in-Time count, conducted by local Continuums of Care in January of each year. Table 3.2 contains estimates for both the Louisville/Jefferson County and Cincinnati/Hamilton County COCs for the years 2006 through 2012. The January 2012 Point-in-Time count identified a combined total of 1,532 sheltered and unsheltered homeless individuals in Louisville. Some 152 of those individuals were unsheltered and 166 were considered chronically homeless (U.S. Department of Housing and Urban Development 2012). During the same 
month, a count of Cincinnati's homeless population identified 1,654 homeless individuals, 46 of whom were unsheltered and 234 were chronically homeless. It is important to note that differences in the methods applied for finding homeless individuals and levels of compliance with HUD reporting standards can compromise the consistency and reliability of homeless counts (U.S. Department of Housing and Urban Development 2012). Other factors, such as weather, time of day, number of volunteers, and sites outreached, may also account for differences in the number of homeless individuals. Examination of past Point-in-Time data reveals a degree of variation for each year. However, with the exception of 2012, Louisville has continually reported the higher incidence of homelessness.

Table 3.2. HUD Point-in-Time Homeless Population Estimates (2005-2012)

\begin{tabular}{|l|c|c|c|c|c|c|c|c|}
\hline Continuum of Care: & $\mathbf{2 0 0 5}$ & $\mathbf{2 0 0 6}$ & $\mathbf{2 0 0 7}$ & $\mathbf{2 0 0 8}$ & $\mathbf{2 0 0 9}$ & $\mathbf{2 0 1 0}$ & $\mathbf{2 0 1 1}$ & $\mathbf{2 0 1 2}$ \\
\hline $\begin{array}{l}\text { Louisville/Jefferson } \\
\text { County }\end{array}$ & 1,473 & 2,067 & 2,587 & 2,682 & 1,515 & 1,626 & 1,628 & 1,532 \\
\hline $\begin{array}{l}\text { Cincinnati/Hamilton } \\
\text { County }\end{array}$ & 1,344 & 1,344 & 1,046 & 1,116 & 1,140 & 1,006 & 1,275 & 1,654 \\
\hline
\end{tabular}
Source: U.S. Department of Housing and Urban Development (2013).

\section{Housing First in Louisville and Cincinnati}

As both HUD and SAMSHA have emphasized preferences for Housing First and permanent supportive housing in recent years, both FHC-Phoenix and GCBH have implemented their own Housing First projects. For fiscal year 2009, SAMHSA funded the Grants for the Benefit of Homeless Individuals (GBHI) initiative to provide treatment and prevention services for vulnerable homeless or newly housed adults, families, and youth with substance abuse, mental health, or co-occurring disorders (SAMHSA 2011). FHC-Phoenix and GCBH were among 25 entities to receive these grants. Per SAMHSA's funding requirement to follow practices listed in its Registry of Evidence 
Based Practices, both projects have chosen to operate on Housing First principles, which include separation of housing and supported services, a commitment to maintaining longterm housing, and encouragement of substance abuse and mental health recovery and community integration (Tsemberis 1999).

The Louisville Housing First Project is administered by FHC-Phoenix, which is a federally designated Health Care for the Homeless provider. The agency was founded in 1988 and operates as part of Family Health Centers of Louisville, a multisite Federally Qualified Community Health Center that serves individuals throughout the Louisville Metropolitan Area. FHC-Phoenix provides medical, dental, mental health, and social services to more than 5,000 homeless individuals per year and is the only Health Care for the Homeless project in the city. For 2009, the agency received a five-year \$2 million GBHI grant which was used to assist with the implementation of the Louisville Housing First project. Operating in tandem with HUD Permanent Supportive Housing (PSH) and Shelter Plus Care $(\mathrm{S}+\mathrm{C})$ vouchers for scattered-site housing, this project partners with a number of agencies that have jointly provided housing and supportive services to 142 formerly homeless individuals. Per SAMHSA requirements, all participants are disabled by a mental health or substance abuse disorder with the majority experiencing both (cooccurring disorder). While the GBHI grant does not require participants to be chronically homeless, most vouchers utilized by this program do require participants to be chronically homeless and 97 percent of participants fit the HUD criteria for chronic homelessness. ${ }^{1}$

\footnotetext{
${ }^{1}$ HUD defines chronic homelessness as a) having been homeless for the past one year or longer or b) having experienced four or more incidences of homelessness in the past three years.
} 
Paths to Recovery is administered by Greater Cincinnati Behavioral Health (GCBH) Services, a mental health service provider serving over 4,000 individuals in the Cincinnati Metropolitan Area each year. Like FHC-Phoenix, GCBH works with a number of providers in its community to provide for the behavioral health and housing needs of Cincinnati's homeless. The organization operates a transition from homelessness project, leads Hamilton County's largest homeless outreach initiative, and is involved in a number of other activities to serve homeless individuals. Like the Louisville Housing First Project, Paths to Recovery became a SAMHSA GBHI grantee in 2009. It has used the grant funds to house and provide services for 70 individuals identified as public inebriates experiencing chronic homelessness (SAMHSA 2011). The project operates similarly to its Louisville counterpart and provides scattered-site housing through Shelter Plus Care vouchers as well as 25 project-based units provided at Jimmy Health House (JHH). This inclusion of project-based units allows this study to compare outcomes between project-based and scattered-site Housing First projects.

\section{Interviews and Qualitative Analysis}

\section{Question 1: What factors determine the location/housing type of a Housing First placement? What housing and neighborhood characteristics are most desired by the project and its participants?}

To construct a context for evaluating the locational component of Housing First, the study first seeks to describe the interplay between the various factors that determine the housing placement. The factors that determine the placement of housing can be quite complex and require an understanding of the processes that shape a Housing First project, including its availability of resources and guiding policies. The evaluation is achieved through a series of in-depth interviews and surveys with administrative staff, direct services staff, and project participants at GCBH and FHC-Phoenix. The interview 
questions were constructed using insight obtained through observation, surveys, interviews, and focus groups conducted by the author in his role as FHC-Phoenix's project evaluator from 2010 to 2013 .

Within the Housing First model, the participant ultimately selects the available unit that best meets his or her needs and preferences (Tsemberis 1999). However, before exploring the question of what characteristics are valued by participants, it is important to consider what factors determine the stock of housing from which participants choose. As with any housing search, availability is determined by a number of political, economic, and social forces. For participants entering a Housing First project, these choices are further constricted by the resources available to the project and policies and procedures of the operating agency.

The allocation of resources will ultimately determine the type of housing (projectbased or scattered-site) and the amount of subsidy provided. These resources are most commonly allocated by a governmental agency such as HUD, a state or local housing authority, or to a much smaller extent by nongovernmental entities. These resources are then harnessed by the agency staff implementing the Housing First project through activities such as advocacy and grant writing. These individuals assume the responsibility of program design and implementation and most often best understand the operations of a project from the ground up. For these reasons, this analysis begins at the agency level. Project directors from each of the two Housing First projects are interviewed for their insights on securing housing resources and establishing policies. Interview questions for these administrative staff members are provided in Appendix 3.1. 
The second subset of stakeholders to be interviewed are the direct services staff that assist participants in securing housing. This group includes case managers, supervisors, and housing provider staff. These individuals are responsible for assisting participants in identifying available housing options, locating units, prioritizing choices, and negotiating lease terms. This is a larger group consisting of approximately 10 individuals within each of the two organizations. Due to time constraints, not all direct services staff can be interviewed. Instead, a stratified random sample of two staff members per project is selected for these interviews. These individuals are interviewed about the process of locating housing, client housing and neighborhood preferences, and barriers to obtaining housing in desired locations. Interview questions for staff are provided in Appendix 3.2.

The final group of stakeholders to be considered consists of the housing participants themselves. With a combined total of approximately 200 individuals across both samples, this group is much too large to interview the entire population. Thus a random sample of five to six participants per project is selected to be interviewed. Once again, this sample is stratified so that it proportionally captures both participants living in scattered-site as well as those living in project-based housing. The participant interview includes questions similar to those of direct services staff, focusing on the factors that influenced their housing placement and the barriers that stood in the way of obtaining desired housing. However, in addition to asking questions about the housing placement process, this group is also asked about the housing characteristics they most value, whether they were able to obtain housing with those characteristics, and how they feel that it impacted their success in the project. This includes both open ended questions as 
well as closed ended questions designed to capture the importance that participants place on the housing characteristics used in later parts of the study. Interview questions for participants are provided in Appendix 3.3.

\section{Mapping and Descriptive Analysis of Neighborhood Characteristics}

Question 2: What are the characteristics (social, economic, etc.) of the neighborhoods in which Housing First participants live? Do these characteristics match the preferences of the program and its participants?

The qualitative methods described above addressed the aspects of housing that are most valued by project staff and participants. Question 2 asks whether or not these housing and neighborhood characteristics were attained. This is answered in part through the participant interview questions discussed above in response to which participants discuss whether they were able to find and secure housing with their desired amenities. However, the analysis goes beyond the self-reported findings of this small sample to ascertain the neighborhood characteristics of all participants. This is achieved through spatial analysis using Geographic Information Systems (GIS) software.

The first step in this process involves geocoding the addresses of each participant to create a map of housing locations. Administrative data provides the addresses of each housing participant which can be mapped through GIS. It is important to note that some participants have lived in multiple housing placements and have more than one address on file. Because this study is interested in whether or not an individual stayed in his or her original and subsequent housing placements, all placements are considered as their own unique cases. These addresses are geocoded to create a map layer depicting the housing placements of each subject. For the purposes of this research, neighborhood refers to the census tracts inhabited by Housing First participants. Census tracts are 
geographic units that are designated to capture areas of homogenous population characteristics, economic factors, and living conditions for which extensive data have been collected through both the U.S. Census (2010) and American Community Survey (2011). This availability of data allows the census tract to serve as an appropriate proxy for neighborhood in this analysis.

Once housing placements have been geocoded into a GIS layer, they can be mapped alongside characteristics of interest including demographics, socioeconomic conditions, crime rates, and proximity to needed services. This will be achieved by overlaying the geocoded participant addresses of participants with their corresponding census tracts as specified by U.S. Census Tiger data (geographic files). The American Community Survey (ACS) provides data on a number of measures within these tracts and this data can be merged with Tiger data to provide an analysis of the demographic and socioeconomic factors that shape the residential environment of each of these participants. Data on crime rates will be calculated using statistics for each city which provide the address of the incidents that is geocoded to census tracts. Because proximity to public services is also a variable of interest, the distance from each housing placement to the central business district (CBD) is calculated. While not a perfect measure of proximity to services, the centers of both cities represent the approximate locations of a number of vital service centers including clinics, hospitals, social security and food stamp offices, and treatment centers for substance abuse and mental health services. Once all of these data elements are synthesized within a GIS database, maps can be constructed depicting the characteristics of neighborhoods in which participants live. Descriptive 
statistics are used to analyze whether desirable neighborhood characteristics were realized and whether this varied between single-site and scattered-site projects.

\section{Empirical Models}

Questions 3 \& 4: How do housing stability outcomes in a scattered-site Housing First project differ from those of a single-site project? How do neighborhood characteristics impact the success of a Housing First project in meeting its housing stability goals?

The first part of this study addresses the process of housing placement. This next part turns to an outcomes evaluation of whether and how the aforementioned neighborhood characteristics affected residential stability for participants in the two programs. Scattered-site housing offers the advantage of community integration, which is believed to increase stability in housing by allowing a participant to locate in a neighborhood with the characteristics that best meet his or her needs and preferences. Thus, this study first addresses the question of how the role of neighborhood characteristics affected housing retention at the neighborhood level. Additionally, the presence of the Jimmy Heath House (JHH) project-based housing in Cincinnati allows for the study to make comparisons between scattered-site and project-based housing. From one perspective, project-based would be considered an inferior alternative as housing choice and community integration may be diminished. Conversely, it may offer the advantage of more readily available services and proximity to peers may allow for more social interaction than scattered-site placements. These considerations suggest that it would be desirable to test whether or not housing outcomes vary between scattered-site and project-based housing.

For the purposes of this study, housing stability will refer to the participant's ability to remain in housing. Thus, the dependent variable will be defined as whether a 
participant remained housed or exited his or her housing placement. Since we are interested in the probability that a move occurred, binary logistic regression models will be constructed to explain the dependent variables of forced moves and other moves. Binary logistic regression modeling functions similarly to linear regression but accounts for the fact that the dependent variable is categorical rather than continuous (Tranmer and Elliott 2008). Whereas continuous variables can take any value between plus or minus infinity, dichotomous categorical variables are bounded by values of 0 and 1 and the model must account for this to avoid predicted values that exceed those limits. In this analysis, 0 represents a participant remaining in his or her housing placement and 1 represents an exit from the placement (forced move or other move).

Logistic techniques allow for the odds of the exit occurring to be tested through a logistic (logit) transformation that allows the dependent and explanatory variables to be linked by changing the scale of probability to plus or minus infinity. This transformation can be specified in the following form where the term in brackets represents the odds of the move occurring (Tranmer and Elliott 2008):

$$
\operatorname{logit}(\mathrm{P})=\log \left[\frac{P}{1-P}\right]
$$

This function become the dependent variable of our binary models as specified below:

$$
\log \left(\frac{P_{i}}{1-P_{i}}\right)=\operatorname{logit}\left(P_{i}\right)=a+b_{1} x_{1}+b_{2} x_{2}+\cdots+b_{j} x_{j}
$$

In this model, the explanatory variables are represented by $x_{1} \ldots x_{j}, a$ is a constant term, and $b_{1} \ldots b_{j}$ are coefficients to be estimated. All explanatory variables are listed in 
Table 3.3 and further explained and justified in the following section. $P_{i}$ is the probability that an exit from a housing placement will occur. Models will be estimated using Statistical Package for Social Sciences (SPSS) software. The equation estimates for these logistic models will be interpreted as both the factor change in the odds $\left(\exp \left(b_{j}\right)\right)$ and the percent change in the odds $\left(100\left[\exp \left(b_{j}\right)-1\right]\right)$. Therefore, the first interpretation will explain how the odds of an exit (dependent variable) will be affected by each unit of change in our explanatory variables, holding all other variables constant (Carini 2008). The second interpretation explains how much the percent change in the odds of a move an exit occurring will increase or decrease, holding all other explanatory variables constant (Carini 2008).

While binary logistic regression models test the likelihood that an exit from a housing placement will occur, they do not allow us to determine whether or not the length of time in housing affects this outcome. To account for this, time censored survival models (Cox regression modeling) are used for addressing questions of how housing and neighborhood affects housing tenure. This method is specifically designed for the modeling of longitudinal data not well suited for conventional statistical methods (Trussell 1992). Because survival analysis has the ability to disentangle the effects of several explanatory variables on the risks that an event will occur, it serves a very appropriate means of analysis for this study.

The major benefit of using survival analysis is that it allows the study to account for data that do not neatly fit into a specific observation period and for events that have not yet occurred, otherwise known as "censored" cases (Allison 1984, Courgeau and Lelievre 1992). This is important because the most successful cases will have remained 
in their housing placements at the end of the observation period (right-censoring) and the Housing First participants observed in the study enter housing at various times throughout the observation period (staggered entries). Survival analysis allows us to systematically account for and control these censored cases in ways that other statistical methods do not allow.

Survival models are estimated using continuous-time methods where the hazard rate serves as the fundamental dependent variable. Unlike discrete-time methods, such as binary logistic regression, which account for an event occurring in a set period of time, continuous-time methods account for fact that the probability of an event occurring at an exact time $(t)$ diminishes over time (Allison 1984). In order to address the exact lengths of time spent in a housing placement before exit, continuous methods will be used for this study and the dependent variable will be the unobserved rate at which exit from housing occurs as denoted by the equation:

$$
h(t)=\lim P(t, t+s) / s
$$

In this equation, we consider the probability $(P)$ than an individual will exit housing during the interval between housing entry $(t)$ and the length of the observation $(t+s)$, given that the individual was at risk at a certain time $t$. The probability is divided by $s$, the length of the interval, and becomes smaller and smaller until the ratio reaches a limit which is the continuous-time hazard $(h(t))$ (Allison 1984).

Once a continuous-time hazard has been calculated, regression methods can be utilized to evaluate the dependence of housing exit upon time and the explanatory variables $\left(x_{1} \ldots x_{1}\right)$ indicated below. We allow the log of the hazard to increase or 
decrease linearly with time (ct) (Allison 1984). Therefore, the model is specified as follows:

$$
\log h(t)=a+b_{1} x_{1}+b_{2} x_{2}+\ldots+b_{j} x_{j}+c t
$$

In this model, the explanatory variables, constant term, and estimated coefficients are defined as for the logistic model.

The procedure is estimated using SPSS. The dependent variable is entered in two parts: a dummy variable indicating whether or not an exit from housing occurred and a variable giving the duration of housing stay before the exit occurred and, if not, the time that censoring occurred. The model estimates are interpreted similar to unstandardized regression coefficients. For each unit increase in a continuous explanatory variable, the percentage hazard of exiting housing is $100[(\exp (b)-1)]$ (Allison 1984).

\section{Variable Specification}

The explanatory variables described in Table 3.3 are used to specify the proposed models for this analysis. The selection of these variables is intended to a) control for personal attributes (demographics, diagnosis, etc.), b) discern the impact of programmatic components (project site, type of housing), and c) explore whether or not neighborhood characteristics (crime, economic conditions, proximity to amenities) have any bearing on the ability of Housing First participants to maintain housing. 
Table 3.3. Independent Variables and Data Sources

\begin{tabular}{|c|c|c|}
\hline Personal Attributes & Variable Description & Data Source \\
\hline Age & Age of participant at intake & GPRA \\
\hline Gender & Dummy $(1=$ female, $0=$ male $)$ & GPRA \\
\hline Race & Dummy $(1=$ non-white, $0=$ white $)$ & GPRA \\
\hline Participant income (intake) & Monetary income for prior 30 days & GPRA \\
\hline Depression & $\begin{array}{l}\text { Number of days of depression in } \\
\text { month prior to housing entry }\end{array}$ & GPRA \\
\hline Anxiety & $\begin{array}{l}\text { Number of days of anxiety in month } \\
\text { prior to housing entry }\end{array}$ & GPRA \\
\hline Hallucinations & $\begin{array}{l}\text { Number of days of hallucinations in } \\
\text { month prior to housing entry }\end{array}$ & GPRA \\
\hline Impaired brain function & $\begin{array}{l}\text { Number of days of impaired brain } \\
\text { function in month prior to housing } \\
\text { entry }\end{array}$ & GPRA \\
\hline Violent behavior & $\begin{array}{l}\text { Number of days of violent behavior } \\
\text { in month prior to housing entry }\end{array}$ & GPRA \\
\hline Alcohol use & $\begin{array}{l}\text { Number of days of alcohol use in } \\
\text { month prior to housing entry }\end{array}$ & GPRA \\
\hline Drug use & $\begin{array}{l}\text { Number of days of illegal drug use in } \\
\text { month prior to housing entry }\end{array}$ & GPRA \\
\hline Arrests & $\begin{array}{l}\text { Number of arrests in month prior to } \\
\text { housing entry }\end{array}$ & GPRA \\
\hline Incarceration & $\begin{array}{l}\text { Number of days incarcerated in } \\
\text { month prior to housing entry }\end{array}$ & GPRA \\
\hline \multicolumn{3}{|c|}{ Housing and Neighborhood Characteristics } \\
\hline Project site & $\begin{array}{l}\text { Dummy }(1=\text { Cincinnati, } 0= \\
\text { Louisville })\end{array}$ & Administrative \\
\hline Housing type & $\begin{array}{l}\text { Dummy }(1=\text { project-based, } \\
0=\text { scattered-site })\end{array}$ & Administrative \\
\hline Density & $\begin{array}{l}\text { Percentage of persons per square } \\
\text { mile within the census tract }\end{array}$ & ACS 2011 \\
\hline Vacancy rate & $\begin{array}{l}\text { Percentage of abandoned residential } \\
\text { units in census tract }\end{array}$ & ACS 2011 \\
\hline Poverty rate & $\begin{array}{l}\text { Percentage of households in poverty } \\
\text { in census tract }\end{array}$ & ACS 2011 \\
\hline Median household income & $\begin{array}{l}\text { Average median household income } \\
\text { in census tract }\end{array}$ & ACS 2011 \\
\hline Proximity to CBD & $\begin{array}{l}\text { Distance (in miles) from participant } \\
\text { address to CBD) }\end{array}$ & GIS \\
\hline Proximity to public transit & $\begin{array}{l}\text { Distance (in feet) from participant } \\
\text { address to nearest bus stop }\end{array}$ & $\begin{array}{l}\text { Administrative } \\
\text { transit data } 2013\end{array}$ \\
\hline Crimes per capita & $\begin{array}{l}\text { Number of per capita crimes within } \\
\text { census tract }\end{array}$ & $\begin{array}{l}\text { City crime } \\
\text { statistics } 2013\end{array}$ \\
\hline
\end{tabular}

Acronyms: GPRA - Government Performance Results Act, ACS - American Community Survey, GIS Geographic Information Systems 
While the housing and program variables are the primary interest of this study, it is important to include personal attributes to control for the individual factors that may influence a person's success in achieving stable housing. Causal relationships between housing and neighborhood characteristics and project outcomes are unclear when individual differences such as gender, age, education, and income are not included as control variables (Nelson et al. 1998). Thus, standard demographic characteristics, including age, gender, and race will be included in the equation. This data will be obtained from the GPRA (Government Performance Results Act), an interview tool that must be administered by all SAMHSA grantees to participants at intake and again six months after entry. ${ }^{2}$ This data is stored in SAIS (Substance Abuse Information System), an online data management website specifically for the entry and processing of GPRA data. Additionally, the GPRA collects data on income in the form of both wages and transfer payments (housing subsidies, food stamps, etc.) in the previous 30 days.

In addition to controlling for demographic data, the models will also control for other personal characteristics often associated with homeless populations. A high number of homeless persons have generally been found to be experiencing substance use disorder, mental illness, or both (North et al. 2012). Diagnoses for these conditions have been used in previous studies on supportive housing to control for mental illness in studies of the impacts of housing and neighborhood (Newman et al. 1994, Tsai et al. 2012). As SAMHSA grantees, participants in both projects are required to be experiencing substance use or mental health disorder, and many experience both. The

\footnotetext{
${ }^{2}$ A sample copy of the GPRA tool is provided in Appendix 3.4.
} 
GPRA captures the severity of these behavioral health problems through a number of questions about mental illness, criminal activity, and substance abuse. While the 30-day period assessed by GPRA limits a complete understanding of the participant's behavioral health, it provides a measure of whether or not a participant was actively struggling with substance abuse and/or mental health symptoms at the time of project entry, which is a proxy for ongoing problems with these issues.

Another factor likely to impact housing retention is involvement with the criminal justice system. Research has shown a high prevalence of criminal histories and incarceration in homeless populations as millions of individuals exit jails and prison each year with uncertain prospects of housing (Metraux et al. 2007). Estimates suggest that as much as 49 percent of the homeless population has spent time in jail and 18 percent has been incarcerated in a state or federal prison (Burt et al. 1999). Former inmates experiencing homelessness are particularly vulnerable to returning to jail or prison. GPRA data captures involvement with the criminal justice system through questions asking about number of arrests and days of incarceration in the 30 days prior to project entry.

The remaining explanatory variables used in the study will pertain to dimensions of program administration, housing type, and neighborhood environment. A dummy variable (Cincinnati) will be specified to differentiate the GCBH's Housing First project from FHC-Phoenix's so that differences between the two programs can be accounted for. Housing type (scattered-site or project-based) will also be considered in the analysis through a dummy variable specified to indicate project-based housing. It has also been suggested that housing quality can have an impact on the progress of participants with 
mental illness and other disabilities (Nelson et al. 1998). Taking these factors and the nature of Housing First into consideration, the study seeks to develop variables that allow us to explore the following four areas: quality of living conditions, access, socialization, and exposure to crime. Because many measures of neighborhood quality are highly correlated, it may be extremely difficult to differentiate their effects (Ellen and Turner 1997). Therefore, it is important to choose a limited number of variables to represent each of these concepts and caution must be exercised in choosing the most relevant variables possible.

Population density is one aspect of neighborhood that will be measured in the proposed models. While some individuals may prefer to live in dense urban areas, others may prefer more suburban or rural settings and thrive better in those environments. For example, some studies that settings with fewer residents to be associated with less psychological distress and greater self-sufficiency (Hellman et al. 1985, Kruzich and Berg 1985, Nelson et al. 1998). To determine whether density has an impact on housing stability for Housing First participants, it will be included as an independent variable in the models. This variable will be specified as the number of persons per square mile will be calculated for each census tract using U.S. Census 2010 data and included as a continuous variable in the model.

An additional measure of neighborhood quality is the number of vacant units in the census tracts. Vacant buildings have been associated with poor environmental conditions including increased incidence of crime and personal isolation (Wilson and Kelling 1982, Ellen and Turner 1997). Vacancy rates are obtained from ACS 2011 data and calculated as the percentage of total residential units that are vacant. The 
concentration of poverty is also an important measure of neighborhood quality as it serves as an indicator of economic opportunities. A neighborhood may be considered to have a high rate of poverty when the number of persons in poverty is 20 percent are higher (Zippay and Thompson 2007). To capture this aspect, household poverty rates (percent of households below the poverty line) and median household income will also be taken from ACS data and included as continuous variables.

Access to local services and amenities is a locational attribute likely to affect outcomes for Housing First participants. Participants are challenged by mental illness, substance use, and extreme poverty. In light of these challenges, access to other services including primary medical care, mental health treatment and rehabilitation, substance abuse treatment, and resources, such as food and clothing banks, are all likely important locational factors. Of all neighborhood characteristics to be explored in the literature, access has been found to have one of the strongest impacts on outcomes for adults (Ellen and Turner 1997). Visits to neighborhood destinations, such as banks, grocery stores and other shops, or friends, can be considered as proxies for social integration within the community (Tsai et al. 2012). Further, persons isolated in poor neighborhoods with limited access to public transit experience diminished opportunities to seek out jobs in more prosperous areas (Ihlanfeldt and Sjoquist 1989, Ellen and Turner 1997).

To capture access to services and amenities, two distance variables will be calculated using GIS: distance to the CBD and distance to public transportation. While not a perfect proxy for proximity to services, the centers of both cities represent the approximate location of a number of vital services, including clinics, hospitals, social security and food stamp offices, and treatment centers for substance abuse and mental 
health services. Because it is also important to consider access by transportation, distance to public transportation (bus stops) will be calculated using a GIS layer depicting the location of transit stops for the two cities.

As stated above, a large number of homeless individuals have experienced prior criminal involvement and exposure to high crime areas may have the impact of increasing the chances of recidivism. Further, living in a high crime neighborhood increases the odds of being victimized compared to living in a neighborhood with a low rate of crime and also the likelihood of leading a more sheltered, isolated life, and spending less time outside of the home (Ellen and Turner 1997). Exposure to neighborhood crime could have an impact on housing retention either by perpetuating recidivism or causing decreased emotional or financial stability as a result of victimization. To determine whether or not crime has a bearing on housing stability, the number of per capita crimes per census tract in 2013 is considered. This variable is constructed with the use of city crime statistic databases that list the address and date of incidence for crimes reported within the city. Because both violent and less severe crimes may contribute to recidivism, all crimes per capita are considered within the model.

Once constructed, each of these variables will be compiled into a comprehensive dataset that allows all variables to be included in the proposed models. The creation of this dataset involves merging program data with the GIS database in order to test the impacts of neighborhood and housing characteristics on housing stability. First, administrative data for each of these programs was collected from FHC-Phoenix and GCBH. This includes databases compiled directly by the organizations to track intake 
dates, exit dates, housing exits, number of days in housing, number of housing placements, and reason for discharge. This data comprises the dependent variables of forced and other exits. Also, this administrative data provides data pertaining to participant demographics, the type of housing (scattered-site or project-based), and the addresses of residence for scattered-site housing participants. Once compiled, this administrative data was merged with the GIS database created to answer question 2. This provides a dataset that links neighborhood characteristics and housing provided to the participant to the housing stability characteristics described above.

\section{Conclusion}

\section{Question 5: What are the implications of this evaluation for designing and implementing future Housing First projects?}

This chapter has provided a detailed description of the methods used in this study and how they address the research questions presented in Chapter 1 . The following three chapters will discuss the findings gathered from the analyses proposed in this chapter. Chapter 4 will include a summary and analysis of the qualitative portion of the study. Chapter 5 will provide detailed descriptions of data collected on the individual characteristics of Housing First participants and the neighborhoods where they live. Chapter 6 covers the results of the empirical models constructed to test the influence of neighborhood on housing stability. Chapter 7 summarizes these findings and discusses policy implications so that question 5 may be addressed. Findings from this study should provide insight on how GCBH, FHC-Phoenix, and other Housing First projects may improve the housing placement process to promote greater stability in housing. The findings also offer suggestions for future research pertaining to the relationship between Housing First and neighborhood environment. 


\section{CHAPTER 4}

\section{QUALITATIVE FINDINGS}

What factors determine the location and housing type of a Housing First placement? What housing and neighborhood characteristics are most desired by project participants?

This first research question is intended to gain a better understanding of 1) how housing placements are made in Housing First programs in Louisville and Cincinnati and 2) staff and participant perceptions of the role that neighborhood plays in the participant's trajectory of housing stability. To answer this question, staff and participants in both Louisville and Cincinnati were interviewed about their experiences with their respective Housing First programs. Between August and September of 2013, the researcher conducted these interviews in staff offices, Cincinnati's Jimmy Heath House, and the homes of Louisville participants. This chapter summarizes the responses gathered through these interviews and identifies common themes in the responses of both staff and participants. The first section of the chapter provides a detailed description of responses gathered in staff interviews. The remainder of the chapter discusses responses provided by project participants. As discussed below, a number of common themes was found among staff and clients as well as some variations in perceptions of the relationship between housing and neighborhood. These themes provide insight and a conceptual framework for the variables explored in later chapters. 


\section{Staff Interviews}

Staff interviews were conducted at both projects to better understand how the two programs were implemented and how the housing placement process works.

Additionally, these interviews included questions regarding staff perceptions of the tradeoffs between scattered-site and project-based housing, how neighborhood affects a participant's success in the program, and what neighborhood and housing characteristics are most important to participants. In Louisville, the agency director and project supervisor were interviewed along with two case managers. In Cincinnati, the program manager, a case manager, and a clinical counselor with case management experience were interviewed. It is important to note that the differences in administrative staff titles between the two agencies are due to the structure of each organization. At FHC-Phoenix, a project director is over the entire agency and fulfills administrative duties of the agency's Housing First project. FHC-Phoenix's project supervisor oversees case management and other day-to-day operations of the program. At GCBH, a project manager is dedicated solely to the agency's Housing First project and oversees both administrative duties and day-to-day operations. Staff members at both agencies were interviewed in their offices and no compensation was provided. Administrators interviewed were asked 13 open-ended questions. Direct services staff were asked 10 open-ended questions. While the two sets of questions are very similar, administrator interviews focused more heavily on program implementation and direct services staff interviews were directed towards more detailed information about the housing placement process. 


\section{Program Implementation}

The agency director at FHC-Phoenix and the project manager at GCBH both provided insight on how their programs came to fruition. Both projects began as multiagency initiatives to bring Housing First to their communities. In both cities, this initiative was augmented by the award of supportive services grants from the federal Substance Abuse Mental Health Services Administration (SAMHSA). Both agencies relied heavily on the Pathways to Housing model as a template for structuring their programs. Both administrators discussed receiving consultation from the agency's founder, Sam Tsemberis. FHC-Phoenix's project director talked about consulting directly with Mr. Tsemberis during a speaking engagement in Louisville. The project manager of GCBH traveled to New York City to visit the Pathways program as his agency was planning the implementation of its project.

Both individuals recognized a strong preference for a scattered-site approach that replicated the Pathways model in their visions for Housing First programs in their community. To provide this type of housing, the agencies secured supportive services housing vouchers from HUD. FHC-Phoenix receives HUD Permanent Supportive Services vouchers allocated through Louisville's Continuum of Care and Shelter Plus Care vouchers allocated through the city. ${ }^{1}$ These vouchers operate similarly to the Section 8 program, where a low-income individual or family receives a voucher that they can use to rent a housing unit at fair market value from a private landlord. ${ }^{2}$ However,

\footnotetext{
${ }^{1}$ Continuum of Care or COC refers to a HUD mandated local coalition of homeless providers that direct the allocation of HUD homeless grants in each city.

${ }^{2}$ FHC-Phoenix also began receiving Section 8 vouchers through the Louisville Metro Housing Authority in 2011. However, participants housed under this program are not included in this study.
} 
unlike more conventional vouchers, these vouchers are designed specifically for the needs of the chronically homeless and have a requirement for the recipient to receive case management as part of his or her housing. Under this arrangement, agencies generally have to find their own funding for case management and other supportive services through local, state, and federal grants. For both of these projects, such funding has primarily been provided through their SAMSHA supportive services grants.

Like FHC-Phoenix, GCBH also receives vouchers to allow participants to obtain scattered-site housing. According to the project manager at GCBH, the program utilizes only Shelter Plus Care vouchers allocated through their local Continuum of Care. The most substantial difference in GCBH from FHC-Phoenix is the presence of a 25 unit project-based facility, the Jimmy Heath House (JHH). These units are owned and operated by Over the Rhine (OTR) Community Housing which has been a developer of affordable housing in the community for more than 20 years. OTR Community Housing was allocated Shelter Plus Care vouchers specifically for this project that are attached to each of the 25 units. Like scattered-site participants, JHH participants use vouchers to subsidize rent payment for units. However, unlike scattered-site voucher recipients who can use their housing subsidy to move at the end of a lease, JHH tenants cannot take their vouchers with them when they leave. GCHB's project manager pointed out that this system makes moving very difficult and participants exiting JHH must often become homeless again for a period of time before moving into a new housing placement.

According to GCBH's project manager, this dual approach of providing both scattered-site and project-based housing was the product of a compromise between differing preferences among the involved community interest groups. While GCBH 
strongly preferred the scattered-site Pathways model, other community interests

expressed their preference for project-based housing. OTR Community Housing became involved as a community partner with their visions set on a renovation project to turn existing housing in Over the Rhine into a congregate facility, the Jimmy Heath House. The GCBH project manager noted that representatives from OTR project traveled to Seattle to visit the East Lake project-based Housing First project. By pulling a diverse array of community resources together, GCBH, OTR Community Housing, and other community characters were able to implement a housing program offering both types of housing and theoretically expanding the options available to program participants.

\section{Scattered-Site vs. Project-Based Housing}

At both agencies, staff at all levels were asked which form of housing best addressed the needs and preferences of project participants. Respondents identified positive and negative aspects of each approach. Administrators particularly focused on the pros and cons of each approach. Reflecting on his experience with using both modes of housing, the project manager of GCBH saw tradeoffs between the two approaches and stated that the best model often depended on the circumstances of the participant.

I think they both have their positives. Scattered-site, the problem is honestly getting to and from your clients all of the time. It's just ... let's say they don't answer the door ... you know, just keeping that connection is difficult. The advantage is that there is a little more flexibility in location and if there's a problem with the landlord, we can move folks very quickly without issue. I think most private landlords work with us pretty well. You don't have the fact that you have 25 other alcoholics hanging around your hallways and occasionally causing a ruckus. You've got some personal space ... . Congregate site, the positive is that we are literally onsite so folks in our congregate site tend to have higher rates of counseling and higher rates of showing up at appointments. It just makes sense. They get more services. We see them every day. Now, the negative 
side of congregate housing is that you are in a building that is quote unquote a "damp house" and we have problems especially at the beginning of the month. We have 25 guys living in the building at one time. We have seven or eight that drink absolutely beyond capacity every day so we have fights. We have bizarre behaviors. We have arrests. The police are called here fairly regularly at the beginning of the month (referring to when participants generally receive monthly disability benefit payments). You can predict it. You can predict who is going to do it and we don't get that with scattered-site. Our scattered-site folks for the most part tend to not have problems with the neighbors.

The project director at FHC-Phoenix reflected on the experiences of his program and how project-based housing may have provided different advantages and disadvantages compared to a program dedicated 100 percent to scattered-site housing.

Scattered-site works really well for us. I think that there are benefits of project based and I think that is because they tend to have 24 hours staff. One of the things I hear from my clients is that they get lonely and I think that issue is lessened when you have project-based housing because participants are nearby. The downside to that is that you can argue that it continues to stigmatize folks because you really ... [have] a bunch of formerly homeless folks with substance abuse or mental health issues all in one place so you're not really normalizing per se. So, I think there are certainly pros and cons with both.

I don't know if I've seen any research comparing scattered-site vs. projectbased. There might be some reasons that housing stability would be better in project-based because folks have easier access to their services and their case managers and the program has more control over their clients because they see their clients on a regular basis. So, if they see that their client is getting out of control, they can surround them with more resources. On the other hand, I can also see clients not liking that more controlled environment because for some it may continue to seem like a shelter atmosphere because everyone is like them and formerly homeless so I don't know. I think there are probably (some clients) better suited to project-based and some more suited to scattered-site.

The housing supervisor at FHC-Phoenix stated that if he was a participant in his program that he would definitely prefer to live in scattered-site housing as it offers more opportunities for a "normal" life. However, he also expressed a strong preference for 
Louisville to expand its range of Housing First projects to include project-based housing particularly for high-need participants.

I think that generally speaking that the best approach for housing options in a community is a menu because it depends on the client, right? I think the best option would be for a menu and if you only offered scattered-site, it's my opinion that that is a limitation. I would love for Phoenix to own and/or operate or at least sign a master lease with a particular property for all of the units to be our units. That is a better fit for a lot of people. If there's a front desk or you can gain control to the front door, you can let in or not let in whoever you want. You can make people sign-in. You can record who comes and goes. You can even hire the front desk worker so if a person with severe mental illness come in and they're symptomatic, it's not the end of the world. Then the housing is less at risk because the people at the front desk won't freak out. So yeah, it could offer advantages for people who are very symptomatic.

Other direct services staff at the two agencies had more mixed responses regarding the advantages or disadvantages of scattered-site versus project-based housing. One FHC-Phoenix case manager stated that, while she had never seen true project-based housing, her experience with having multiple participants in one apartment complex made her feel that project-based housing may present problems such as participants not understanding how the service needs of their peers may differ from their own. The other FHC-Phoenix case manager also expressed a preference for scattered-site saying that it just seemed "a lot more normal to have people in apartments in communities with other people and private landlords."

The case manager interviewed at GCBH presented a more impartial approach based on her experiences with the program. Like administrators, she discussed seeing both pros and cons and provided more detail on how participants may be directly impacted. 
I think they both have advantages and disadvantages. In scattered-site, it is easier to place a client in the community and not have constant triggers and friends and alcohol surrounding them. So, in that way, it is a little bit easier for them to blend in and it is easier for them to see what other people in the community are doing and model some of that. Here at the house $(\mathrm{JHH})$ though for our higher need clients, it's very convenient as a case manager to kind of "live with" your clients. You know they are right onsite so we can address problems immediately.

When asked which she felt that participants preferred, she responded that scattered-site seemed to be the more liked of the two types of housing.

Gosh. I think they prefer scattered-site because there is just less supervision you know. They can do more of their own thing and not have the front desk looking over their shoulder or barring out their guests or a case manager going "why did you leave the stove on and fall asleep?" and all that stuff.

The third staff member at GCBH had experience in providing both counseling and case management and provided a more clinical perspective of the tradeoffs between the two approaches. This individual talked about how he saw project-based housing as a more advantageous way of promoting recovery.

Well, as a counselor, I notice that people who live here [at JHH] have the most likelihood of getting sober simply because they have more access and there are more chances for us to intervene or to speak with them or help them to put things into perspective so I'd say convenience wise this would be the advantage.

However, he also discussed how the bureaucratic structure of the JHH housing facility limited choice because participants were not allowed to use their vouchers to find other housing if they desired to move. He described them as being "locked in" to their housing.

Overall, staff at all levels identified tradeoffs to the two approaches. This was most true at the administrative level where respondents provided macro level insight on the pros and cons of each approach. Scattered-site housing was identified as a means for helping to normalize individuals who have been stigmatized by long histories of 
homelessness, mental illness, and substance abuse disorders. However, staff at all levels of both agencies discussed how scattered-site housing limited access to services and supervision which could be particularly problematic for high-need participants. Projectbased housing, in this regard, was seen by all respondents to offer more opportunities for providing services and intervention that could help mitigate problems before they got out of control. Although he saw scattered-site housing as his preference, FHC-Phoenix's housing supervisor particularly expressed that his community were missing opportunities to better serve high-need individuals by not having project-based housing. The GCBH case manager was able to provide the most detailed comparison of how the two types of housing impacted the project's ability to serve participants. Her comments supported the majority opinion about the tradeoffs between both approaches. The consensus of staff at both projects identified scattered-site as the most conducive to the Housing First model, particularly in regard to consumer choice. However, the majority of respondents felt certain segments of their target population may be better served by a project-based approach.

\section{Choices and Barriers}

Staff at both agencies were asked to describe the process by which participants attain their housing placements, including the extent they have a choice in selecting their placements and what factors might constrain those choices. Overall, staff stated that they felt participants had a lot of choice over their housing placements but a number of constraints existed to keep participants from finding housing placements in their desired neighborhoods. When asked which criteria most influence a participant's housing choice, staff at all levels and both agencies mentioned that, when coming off the streets, 
homeless persons are likely to choose whatever option will most quickly house them.

According to GCBH's project manager, "They're so desperate that they just want to take what we have so most people say I'll take it."

The FHC-Phoenix housing supervisor talked about housing choice and how program staff helped them to secure housing placements.

Their first apartment is 100 percent client choice so we often will ask what neighborhoods they might not want to live in. If they're from Louisville, where they grew up, would they like to be back in the neighborhood that they grew up in? If there's a neighborhood they like to spend time in and felt comfortable back when they had their own housing and would like to return there. We ask those type of questions in terms of figuring out where to start. And then in terms of finding an apartment, we will be like normal people. They'll get on the internet and look for available rental units, sorting by zip and neighborhood. So, a lot of internet searches. The Housing Authority does have a list of available units where you already know the landlord already accepts a voucher. I encourage folks to get that list. And, then clients can bring options to the table on their own and then if we're still having trouble, we'll just get in the car and go that neighborhood and just like anyone else we'll just drive around if there's for rent sign, you just call and inquire.

When asked about barriers to housing placements, staff most commonly reflected on the difficulties of finding housing in more desirable neighborhoods due to factors such as higher than fair market rents, a much higher demand for their units, and NIMBYism.

Since all housing at FHC-Phoenix is scattered-site, participants theoretically have complete choice over their housing placement. However, administrators and case managers both discussed how housing choices were limited by the local housing market. According to the housing supervisor at FHC-Phoenix:

So, in theory, they have 100 percent choice but there are neighborhoods where it is hard to find affordable rental units and I think we should admit it. So, there are certain neighborhoods in Louisville that it's hard for our clients to lease up and so on paper the clients have 100 percent choice but 
on the other hand there are some community dynamics. Certain neighborhoods are less accessible.

The housing supervisor added that the individual circumstance of a participant, such as criminal history or a poor credit rating, can make it difficult to obtain certain housing placements. He also discussed how voucher regulations can impact a participant's access to certain neighborhoods in two ways. First, he identified the fact that properties in more desirable neighborhoods were less likely to make modifications to make their apartments conform to housing inspection standards because they knew that they could always rent their property to someone else. ${ }^{3}$ Second, he discussed how fair market rent was based on a citywide standard although some neighborhoods were more expensive than others. He noted that his agency worked with a number of housing voucher programs and that some vouchers offered more flexibility for participants in determining the rent they were able to pay.

If we're just talking about neighborhood choice, then the Housing Choice (Section 8) voucher with LMHA is our best one because they can pass up to 110 percent of FMR [Fair Market Rent] and all of the others I believe are 100 percent of FMR. If the FMR says $\$ 60$, and all of a sudden you can do $\$ 660$, that a big difference that opens up a lot of doors. They also have an option where participants instead of paying 30 percent, they can pay up to 40 percent of their income as rent. Maybe that's how they pay 110 percent but anyway it makes their voucher more flexible and they can essentially choose a lot more housing if they choose to and it opens doors to neighborhoods and just nicer apartments.

Case managers at FHC-Phoenix provided similar feedback emphasizing the most common barriers were difficulties in finding landlords willing to accept vouchers and the

\footnotetext{
${ }^{3}$ This refers to the fact that all government subsidized housing units must pass a Housing Quality Standards inspection before a lease can be executed between the landlord and participant.
} 
high cost of rent in the most desirable neighborhoods. One case manager explained it as

having choices within the bounds of certain programmatic restriction and market realities.

I think they have a lot of choice but I think there's a lot of choice within certain boundaries so there are a lot things that get in the way of their choice but considering, within those parameters, they have a lot of choice. There's things like some landlords don't accept vouchers. The amount of vouchers really, really restricts choice but within that limit, I show them a lot of places.

Both case managers talked about the importance of finding landlords that are willing to work with the program. One stated "The more we work with landlords, the more opportunities that are available to the clients. I've never heard of a person saying they felt like they had to live in a certain place or couldn't go where they wanted."

Staff at GCBH offered similar reflections on difficulty in finding units in certain neighborhoods. The project manager gave a very reflective response as to how the agency had become so accustomed to lack of access to more desirable neighborhoods that he rarely thought of it as a problem. Initially he responded:

Finding a geographic area and then finding landlords in that area, that's probably a small barrier but that's not a big deal. I think for the most part, landlords have heard of us. Our agency has been around for 50 years. They know us. They know we're going to pay the bill. They're not that worried about it even though they see the client's record and they know it's a pain in the ass client, they're still going to take them because they know that they're going to get paid. A lot of times, you work in these buildings that suck or in an area that not everyone wants, you have a lot of landlords who are like "you are going to pay the bill, that's a good thing." I'd say that one problem we have is that if there is a nice area that you want, it's difficult. Cincinnati is very conservative and it's very difficult ... there are certain communities that have been sued by HUD in Cincinnati because they refused to allow Shelter Plus Care, not Shelter Plus Care, but Section 8 in general.

After reflecting on this statement, he added: 
It's ridiculous but you know it is maybe that I need to sit back and look at that as a barrier because we've just adjusted. We've been doing this for 20 years so I just know that I'm not going to put someone with substance abuse and a criminal record in Hyde Park which is the nice area [laughs] so we've adjusted to it. But if a client really wants Hyde Park, that's going to be a struggle.

The other I guess is the limits of Shelter Plus Care. There's a top limit (rental amount). So, like Hyde Park, which is a nice area, you're just not going to go there because they're not going to pay for it. Even though its market rent in that area, it's above fair market rent of Section 8.

Staff at GCBH offered similar reflections on difficulty in finding units in certain neighborhoods. The housing case manager interviewed stated that while participants have options, many of the options are actually very similar to each other.

They do have a lot of options but a lot of the options are very similar to each other so there are specific neighborhoods that we tend to look in. We have certain communities in Cincinnati that don't allow any kind of Section 8 housing. They are very kind of restricted to certain areas like Price Hill, Westwood, some places in Norwood, but it's usually specific communities that we stay inside because it's easier to find landlords that will accept our housing voucher.

The project director at $\mathrm{GCBH}$ also talked some about the challenges of offering participants true choice in a program that is partially project-based. Due to the lengthy renovation project to complete $\mathrm{JHH}$, project-based housing was not available until nine months after GCBH's original scattered-site housing placements were made. According to GCBH's project manager, this delay dictated how housing placements were determined in the early years of the program. Those entering the program in the beginning only had the option of scattered-site vouchers and all of these vouchers had been allocated by the time JHH was completed. Participants entering the project at that point in time were more likely to be presented with $\mathrm{JHH}$ as the only option for housing. Thus, according to GCBH's project manager, placements were decided primarily based on circumstances at the beginning of the project. He went on to add now that the project 
is in its fourth year of implementation, incoming clients are more likely to have a choice of housing type.

\section{Importance of Neighborhood}

Staff at all levels were asked how they felt neighborhood factors impact a participant's success in housing. Project staff most commonly identified case management and services as the primary determinants of housing success. The Housing First approach itself was identified as a key element of being able to keep people housed. According to the project director at FHC-Phoenix:

I think removing the barriers to both to get into housing so that we can move folks in quickly and they don't have to prove that they are housing ready. We understand that most anybody is capable of living in their own apartment and then not creating barriers once they enter because our number one goal is to keep folks in housing as long as possible.

Direct services staff interviewed at FHC-Phoenix all expressed that individual needs and preferences had a strong interaction with the impacts of neighborhood. All staff members talked about the importance of access and proximity to shopping, laundry, and services. All three also stated that familiarity with a neighborhood could have a positive or negative trajectory for the participant's success depending on their previous relationship to the area and their neighbors. The housing supervisor discussed how he felt that the two most important things for the participant was that he or she had access to services and were in an area where he or she felt at home. However, he also strongly emphasized that what "feels like home" varies from individual to individual and that he didn't feel that there were any criteria that could be used to define a "good neighborhood" or a "bad neighborhood." 
The two case managers at FHC-Phoenix also expressed that neighborhood was important but emphasized that what was important varied from participant to participant. One described it as being a "big deal" but not the "biggest deal." She added that neighborhood could serve as both a conduit and a barrier to success. She emphasized that what she had found most important was to be attuned to the individual needs and preference of the participant.

I just think that it's really, really, really important to listen to the client and try to accommodate them as best possible when they tell you what is important to them because when they tell you what is important to them, like transportation or a certain neighborhood, but then you find yourself maybe pushing them toward something else because maybe it's available or you know the landlord or something, it is less likely to work out because they told you what they needed and you ignored it.

The second case manager also emphasized the importance of pairing participants with neighborhoods in which they felt comfortable. According to her, "It makes them feel better about themselves, their futures, and their happiness so I think that overall wellbeing is going to be affected when they live in a neighborhood that they feel safe and comfortable."

The project manager at GCBH provided examples of both positive and negative implications of neighborhood. On the positive side, he felt that access to services, public transportation, and shopping had helped people to be successful. On the negative side, he talked of two participants whose housing stability was adversely affected by neighborhood quality.

I think neighborhood is a factor. I don't know if it's the single factor. There are neighborhoods that have affected people's positive outcome. For example, there's a place about five minutes from here. It's called Price Hill and its rough, prostitution and drugs. And we had two gentlemen that their apartments were taken over by crack dealers. 
When asked what aspects of neighborhood are most important for a client, GCBH's case manager provided a response similar to that of FHC-Phoenix staff. She stated that proximity to bus stops, being connected to resources, and being in neighborhoods that they are familiar and comfortable with were what she saw as some of the most important factors. In describing how she thought neighborhood could impact a participant's success in the program, she emphasized that participants all had their own characteristics that made certain neighborhoods a better fit for some than others.

Some of our clients are older and low-key and they need just a quiet place without a lot of traffic because if they have the opposite then it upsets them and they start acting out. So, I think just matching the right environment to the right personality. Sometimes, we need a little bit of a rougher place for our rougher clients because they are going to engage in things like knocking on people's doors and asking for money or they're going to play loud music. I think just kind of matching the environment to the personality is a big thing to me just to make it last because we don't want to constantly move people.

The program's clinical counselor talked about neighborhood and housing type in terms of how it could impact participants in terms of recovery.

I don't know because neighborhood cuts both ways. It's where they find support and it's also where they drink and where they find enabling systems so we have groups, people are pretty consistent, they complain about the incidents of trouble or illegal activity breaking up their serenity, their feeling of being safe in their own home. So, because they're kind of isolated from broader society and they tend to congregate with each other and with similar folks, they are in that vulnerable realm of the normal spectrum that leaves themselves vulnerable. So, many of our people are in high risk neighborhoods and the anomaly of the Jimmy Heath House, they are in a high risk neighborhood but they are more isolated than others because they have a collective space here that they can occupy without going out. So, it's really ambivalent. I can't give a firm one way or the other answer but I see both sides. I see resources. I see how community is formed. I also see risks that are inherent in that community when people are living close to or around constant illegal activity and violent activity is going on. 
At both agencies, staff at all levels agreed that neighborhood was an important factor to consider when making placements. However, neighborhood quality was rarely identified as a determining factor in a participant's program success. Other factors, such as access to services, were considered to be more crucial influencers of success. While most staff identified how neighborhood may be an important factor, no one interviewed was able to identify any certain criteria to define what would be a good or bad neighborhood. Instead, it was deemed more of a factor that depended on individual circumstances. Staff responses would suggest that while a certain neighborhood may help one participant thrive in the program, the same neighborhood may be seen as detriment to the success of another participant.

\section{Participant Interviews}

In total, 11 participant interviews were conducted: five with Louisville participants (all scattered-site), three with participants in Cincinnati's project-based housing (Jimmy Heath House), and three with participants in Cincinnati's scattered-site housing. Participants at both programs were chosen at random. To ensure that both project-based and scattered-site housing was represented, participants in Cincinnati were chosen through a stratified random sample generated by staff at GCBH. Program participants at both sites received a $\$ 10$ grocery store gift card in return for their time. They agreed to a face-to-face interview consisting of eight open ended questions and a short survey that asked them to rate how much they valued specific housing and neighborhood amenities. A copy of this interview tool is provided in Appendix 4.1. Four FHC-Phoenix participants were interviewed in their homes; the fifth was interviewed in his case manager's office. All six GCBH participants were interviewed at JHH. 
Four of the five interviews with Phoenix participants took place in their homes and the fifth took place at the program's office site. All five interviewees were males between ages 41 and $63 .{ }^{4}$ Three were Caucasian and two were African American. In Cincinnati, three residents of JHH were interviewed; all of whom were males between the ages of 50 and 62. One JHH participant was African American and the other two were Caucasian. Of the scattered-site residents interviewed in Cincinnati, two were Caucasian males and one was a Caucasian female. The range of ages of these participants fell between 40 and 48. Demographics of this sample closely matched those of the two programs as well as the general population of chronically homeless individuals.

\section{Description of Housing}

Participants were first asked to describe their housing. This general question was intended to probe for what participants saw as the most important aspect of their housing placement. Participants responded initially with either 1) a description of their neighborhood or 2) a description of their apartment and its amenities.

One GCBH scattered-site participant talked first about amenities and then location. Another scattered-site participant mentioned location and the importance of being close to his sister who also lives in the neighborhood. A third talked about his housing in terms of building upkeep and apartment amenities: "It's a pretty sweet deal because I've got free cable, air conditioning, and [the landlord] keeps building pretty up to date and up to par" (GCBH3).

\footnotetext{
${ }^{4}$ Demographics were obtained from client records collected as part of the GPRA intake interview.
} 
Participants at Jimmy Heath House provided similar descriptions but their answers were less focused on location. One JHH participant provided a very positive reflection saying "The place is pretty clean and it's safe. It's convenient" (JHH3). One JHH participant simply described it as being "excellent housing (JHH1)." When probed about why he felt this way, he responded "It's a roof over my head. It beats staying at drop-ins [shelters]" (JHH1). Another had a similar response saying "I love this place. I was on the streets for awhile. This place was a godsend" (JHH2). Participants in JHH were also more likely to talk about program staff when initially describing their housing. One joked that the only thing that he didn't like about it was that program staff members are "too nice" (JHH3). Another talked about the care received by staff when asked what he liked most about his housing: "These people care about you so much. They're like family. If you need anything and they can do it, they will do it for you" (JHH2).

Participants at FHC-Phoenix described their housing primarily in terms of neighborhood characteristics. One Phoenix participant said that the neighborhood and having a one bedroom apartment were his favorite aspects of his housing. Another said that he was comfortable and when probed more about what he liked about it, he stated "It beats the damn streets" (PHC3). Another described his housing in terms of having a peaceful neighborhood and its demographic characteristics, saying:

It's quiet. The neighbors are friendly. Everybody minds their own business. And there are working people around here, my neighbors, either working or get SSI, some kind of income, monthly, but mainly working people (PHC5).

Participants were additionally asked about what they liked most and least about their housing. Similar answers were given by participants in both programs. Four 
participants reported neighborhood convenience as what they liked most about their housing. Two of these responses were from Phoenix scattered-site residents, one from JHH, and another from GCBH's scattered-site program. Two respondents elaborated to say that it was convenience to shopping and transit as most important. Another also added that they liked that their housing was clean and safe. Four other participants (two at Phoenix and one at JHH) indicated that they most liked the people in their neighborhood. Another Phoenix participant remarked "I like the peace. It's a nice quiet neighborhood" (PHC1). Two respondents, one Phoenix participant and one JHH participant, simply indicated that being housed was better than being homeless. Only one respondent provided an answer that was directly related to the quality of the housing, stating, "They're just really nice apartments" (GCBH2).

When ask about what they liked least about their apartments, two of the three participants at JHH responded that it was in bad neighborhood. The three other GCBH participants also indicated problems with the neighborhood, including location and problems with actual neighbors themselves. Only one Phoenix participant described neighborhood as being what he liked least, stating that the neighbors in general were bad influences. Three other Phoenix participants discussed problems with housing amenities and condition as their least liked aspects of their housing. The remaining Phoenix participant was unsure of what he liked least about his housing. The main likes and dislikes expressed by the interviewees are summarized in Table 4.1. 
Table 4.1. Most and Least Favorite Housing Characteristics

\begin{tabular}{|c|c|c|}
\hline Program & Like Most: & Like Least: \\
\hline $\begin{array}{l}\text { Jimmy Heath House } \\
(n=3)\end{array}$ & $\begin{array}{l}\text { - "Roof over my head, beats } \\
\text { drop-ins." } \\
\text { - "These people care so much } \\
\text { about you. They're like } \\
\text { family." } \\
\text { - "Clean, safe, convenient." }\end{array}$ & $\begin{array}{l}\text { - "The area that it's in. It's a } \\
\text { bad area." } \\
\text { - "Least, the actual } \\
\text { neighborhood (laughs). I'd } \\
\text { love it even more if it were in } \\
\text { a better area." } \\
\text { - "None. I like everything." }\end{array}$ \\
\hline $\begin{array}{l}\text { GCBH scattered-site } \\
(n=3)\end{array}$ & $\begin{array}{l}\text { - "It's convenient to shopping } \\
\text { and real close to public } \\
\text { transit." } \\
\text { - "They're just really nice } \\
\text { apartments." } \\
\text { - "I get along with the people. } \\
\text { They get along with me." }\end{array}$ & $\begin{array}{l}\text { - "It's housed with mental } \\
\text { patients. I was not aware of } \\
\text { that." } \\
\text { - "The location." } \\
\text { - "People that don't live there } \\
\text { are always in the parking lot." }\end{array}$ \\
\hline $\begin{array}{l}\text { Phoenix scattered- } \\
\text { site }(n=5)\end{array}$ & $\begin{array}{l}\text { - "The neighborhood itself is } \\
\text { really convenient to groceries } \\
\text { and bus routes and all of that." } \\
\text { - I like the peace. It's a nice } \\
\text { quiet neighborhood." } \\
\text { - "It's my home. It beats the } \\
\text { damn streets." } \\
\text { - Convenience." } \\
\text { - "The people. They're } \\
\text { friendly, respectful. That's a } \\
\text { good thing." }\end{array}$ & $\begin{array}{l}\text { - "Too many neighbors, too } \\
\text { many bad influences } \\
\text { individually. My neighbors are } \\
\text { all nice enough but people in } \\
\text { total are drunks, alcoholics, } \\
\text { and pill heads. All sorts of } \\
\text { other people that are just not } \\
\text { very character building." } \\
\text { - "I have one door. I don't } \\
\text { have a back door." } \\
\text { - "The bugs. I get all kinds of } \\
\text { critters in here." } \\
\text { - "Don't know." } \\
\text { - "I wish the plumbing was a } \\
\text { little better." }\end{array}$ \\
\hline
\end{tabular}

When asked if they were happy with their housing placement, seven of the 11 participants responded that they were pleased. Two of the three GCHB scattered-site participants reported that they were happy with their housing placements. The third responded that, while he was happy with the program, he was not happy with his housing placement. Two out of three participants at JHH also reported being happy with their housing placement, with the third saying that he was somewhat happy with his placement. Three of the five Phoenix participants reported that they were happy with 
their housing placements. The two others reported initially being happy with their housing placements but property management, neighborhood deterioration, and other factors had resulted in them becoming dissatisfied with the placement: "Just everything. From the management, the change in management, the deterioration of the environment here. And then again, the type of people that are living here" (PHC1). One GCBH participant and one Phoenix participant attributed any dissatisfaction with their housing to their own choices.

I'm happy with this program absolutely but the choice was mine and I made the wrong choice. I wasn't aware of the other residents in the building (GCBH1).

Well, I'm happy with the placement because I'm the one that suggested this area and stuff like that. Maybe, I made a bad decision (PHC4).

\section{Description of Neighborhood}

When asked to describe their neighborhoods, participants most commonly commented on neighborhood safety and convenience. One participant at JHH referred directly to neighborhood safety as a concern, stating:

This neighborhood is no joke [laughing]. You only hear about it like every other day on the news. People either getting shot or killed. You've got a lot of dope boys and drug dealers in the area and stuff. Like I said, I love this place (referring to JHH building), but I wish that it was located in a different area and you could walk down the street and not accidentally get shot by a drive-by ( $\mathrm{JHH} 2)$.

The other two participants also commented on the population of the neighborhood in their descriptions of the neighborhood. One referred specifically to the presence of persons with substance abuse issues both inside and outside of the building.

A lot of people that live here have been drinking. There's a lot of alcoholics out there. There's a lot of alcoholics in here. And, sometimes 
it gets kind of hectic. Trying to get into that store over there. People begging and acting like they're going to fight or something like that. What you're trying to go into the store and you come out, you've got the same problems. Therefore, there needs to be a little bit more of police outside (JHH3).

The remaining JHH resident gave a general answer, saying that the "neighborhood was fair but fine" (JHH1). When probed further about what he liked most and least about it, the participant remarked that while he liked the building itself, he least liked the people that hung around the OTR neighborhood.

GCBH scattered-site participants also talked about their neighborhood in terms of their concerns about safety and other residents in the neighborhood. One participant remarked that "it could be dangerous for people that don't know any better I guess" $(\mathrm{GCBH} 2)$. Another discussed safety and neighborhood decline as a result of redevelopment in another part of town: "When they cleaned up downtown with 3CDC [Cincinnati Community Development Corporation], it had to move somewhere so with the problem came people and the problem" (GCBH3). The third GCBH scattered-site participant stated that he was happy with the neighborhood itself but not the other tenants in his building. In areas lacking close proximity to shopping and resources, access to public transportation was shown to play a pivotal role for participants. One GCBH participant felt that distance to the bus line was a major problem stating "The location ain't too good because of the bus. It's really about a mile, mile and a half from any bus service" (GCBH2).

Phoenix participants also discussed their neighborhoods in terms of safety and neighborhood composition. One Phoenix participant initially described his neighborhood in a mostly negative light. He laughed as he said "Well, I don't know how to explain this 
one. It's okay. It's iffy. You just have to watch your back" (PHC3). Another participant described his neighborhood in terms of its racial, ethnic, and socioeconomic characteristics. This participant identified himself as an immigrant and saw the presence of other immigrants in the neighborhood as being a positive attribute: "We have Mexicans, Cubans, Africans, not that many blacks and whites in this neighborhood and not within this section here, a lot of immigrants which is good" (PHC5). Another Phoenix participant described his neighborhood as being in a constant state of flux: “There's a whole lot of traffic through here and you've got to many people moving out and you really don't have a chance to know anyone" (PHC4). Two other Phoenix participants described their neighborhood in a more positive light including talking about its convenience to amenities:

First is the convenience and there's some trees around this portion of the neighborhood. That's nice and the subdivision across the street here. I can walk my dog in peace (PHC1).

It's in the East End. I think they call it Smoke Town. I'm across the street from a nice church. So, it's a nice neighborhood (PHC2).

Overall, participant descriptions of neighborhoods focused primarily on convenience and safety. Most participants identified convenience as being relatively good and either indicated having needed services nearby or good transit access for reaching those services. The majority of participants expressed negative views of safety in their neighborhoods, particularly Cincinnati participants at both JHH and in scatteredsite housing. In both programs, individuals talked about issues of declining neighborhoods and a transient flow of neighbors making it difficult to find meaningful relationships with neighbors. While nearly all participants expressed strong opinions on what they did and did not like about their neighborhoods, only one FHC-Phoenix 
participant discussed neighborhood with reference to his success in the program. According to this participant, the presence of a large number of drug users in his apartment building led him to start using again and he had to move to escape this negative influence.

\section{Housing Choice}

The interview also included questions about how involved participants were in finding and choosing their housing placements. Because JHH is project-based, participants expressed that their only involvement in finding their housing was applying to the program. In these instances, the participants also did not officially have a case manager until they entered their housing. One JHH participant described his entry into housing almost as something that he just stumbled upon: "I was looking. I wouldn't exactly say searching but I was looking for housing and just happened to look up and find it. They had what I was looking for" (JHH3).

The three GCBH scattered-site participants reported being highly involved in identifying the neighborhood and housing of their choice. Unlike the JHH participants, scattered-site participants began working with a case manager as part of their housing search process. All three stated that they already had neighborhood preferences in mind when they began their housing search. Participants responded that staff asked them about their neighborhood preferences and then helped them to select units in their preferred neighborhoods. One responded that he was given a list of landlords affiliated with the program. One added that he received transportation assistance from staff in his apartment 
search: "Actually, I found it on my own but the transportation. You know, Greg (staff member) provided the transportation to go look at places" (GCBH3).

Participants in FHC-Phoenix scattered-site housing reported having less involvement in their housing searches, with all of them stating that they received some degree of assistance from staff in the process. Two Phoenix participants stated that their involvement was " $50 / 50$ " with program staff being equally active in the process. The other three stated that they had little involvement in finding their own housing. Instead, the case manager was largely responsible for taking the initiative and being responsible for choosing the placement. As also indicated in staff interviews, interviews with FHCPhoenix participants suggested that they would often choose the first apartment shown to them by their case manager.

I wasn't very involved. My old case worker found it for me but I knew exactly where the apartment was (PHC1).

My case worker pretty much did all of the leg work (PHC2).

Not very because when my case manager came over, she brought me over here, right? To the one on Goldsmith Lane and over here and each time, I was happy with it (PHC3).

Participants were also asked if the neighborhood that they live in was their first choice. One GCBH participant stated that while the neighborhood was his first choice, he was not satisfied with his apartment building and the surrounding vicinity. Two of the three GCBH participants stated that it was not their first choice. One respondent indicated that staff steered her away from her first choice in the housing search: "I wanted to live over here in Over the Rhine but they thought it was better that I get out of here ... . Location, everything down here is what I need. All of your appointments are down here anyway" (GCBH2). Another also expressed that his first choice would have 
been to have had more convenience. "Convenience, I was close down here at the path and I was close to things like the grocery store" (GCBH3). At JHH, one participant stated that the neighborhood was his first choice, another stated that it was not, and a third expressed mixed feelings about the placement. In each instance, convenience appeared to be the major factor in whether or not JHH was the participant's first choice. The participant who said that OTR was his first choice expressed that it was convenient to the area where he had already spent most of his time, stating that he just had to go "across the street and the building was there" (JHH1). The participant expressing mixed feelings stated that the location and convenience of the neighborhood made it his first choice in that regard. However, the third JHH participant expressed that he felt another neighborhood would have been more convenient.

Colorado Avenue ... well, it's close to everything. It's close to stores and to restaurants. I'm totally blind in my right eye so I'm never going to be able to get my driver's license so I used to live there and I could walk to everything that I needed to get to ( $\mathrm{JHH} 2)$.

Three of the five FHC-Phoenix participants reported living in the neighborhood of their first choice. One said that his neighborhood was his second choice. The fifth participant said that while his neighborhood was not his first choice, he did not know where he wanted to live. Of the participants stating their neighborhood was their first choice, factors that made it their first choice included accessibility, peacefulness, and having friends nearby.

\section{Multiple Housing Placements}

Six of the 11 participants interviewed reported having lived in multiple housing placements since entering their housing program. Five of these were FHC-Phoenix 
participants and one was a GCBH scattered-site participant. However, another GCBH participant was in the process of looking for his second housing placement. None of the JHH participants had moved since entering the program. All participants reporting multiple placements had lived in two different housing placements since entering their programs. One FHC-Phoenix participant was in the process of looking for his third housing placement due to the fact that his landlord had decided to stop accepting housing vouchers. All FHC-Phoenix participants with multiple housing placements reported that they moved to a new neighborhood for their second housing placement. The one participant preparing for his third placement stated that he desired to remain in a nearby neighborhood. Conversely, the one GCBH participant with multiple placements reported remaining in the same neighborhood and the one preparing to move also said that he wanted to remain in the same general neighborhood as it was the area where he grew up.

Participants reported moves to be both voluntary and involuntary. The GCBH participant with multiple placements moved due to incarceration and having to find a new place upon release. The participant planning to move stated that he was moving voluntarily due to his dissatisfaction with neighbors in his building. Of the FHC-Phoenix participants, one reported moving because he wanted to quit using drugs and felt it would be beneficial to get away from neighbors that used drugs in his old neighborhood. One reported moving to avoid eviction at his prior housing placement. Another reported his motivation was to get away from a crime ridden area in favor of a more peaceful area. The remaining PHC-Phoenix participant to move reported that it was due to accessibility issues and his declining health: "It was just that I was doing a lot of walking up and down 
hills and it was really starting to wear on my knees and arthritis. So, that was a big thing here. It's flat" (PHC1).

\section{Social Interaction}

Participants were also asked about how they interacted with their neighbors and other participants within their program. Participants reported varying degrees of social interaction with others in their neighborhood. JHH participants appeared to remain the most connected to their previous social ties. One participant at JHH stated that he had known all of the other residents in the building for at least 15 years.

I interact with everybody. They all got a nickname for me. They call me Ponytail. Most of the time I've got my hair pulled back in a ponytail. One guy started calling me Ponytail and caught on like wildfire (JHH2).

He also discussed staying connected to the community through volunteering at the Homeless Coalition and other organization saying "Man, I've volunteered at so many places that it ain't even funny" (JHH2).

The other two JHH participants reported social involvement with others in the neighborhood and in their building but to a lesser extent. One participant remarked that he interacted with other participants when he first moved in but now avoids them because he is trying to quit drinking. The other JHH participant stated that he enjoyed playing chess, cards, and other games with staff and residents in the building. However, he also discussed avoiding neighbors at times because he either did not feel like interacting with others or wanted to avoid getting into trouble.

Yeah, I think I do (interact with others). However, I'm not the type of person that is real go-out friendly. If I have something I need from you or I'm just feeling real good one day, I'm very friendly but other than that, I 
usually just stick to myself because it's so easy to get into stuff around here, even in this building getting into a whole bunch of trouble ... (JHH3).

Among GCBH participants living in scattered-site housing, social circles appeared to extend beyond other program participants. One participant stated that, while she is a loner and does not interact much with other participants, she does sometimes play with the neighbors' children. Another said that he avoided people in his building but had regular interaction with 15 or 20 friends as well as his sister and two nieces that live nearby. He also said that he attended services at a neighborhood church. While he attends weekly meetings and program functions, he otherwise does not interact with other participants in his program. The third participant reported interacting with three other participants that lived nearby and most others in his neighborhood. According to this participant, "Everybody that lives in my building knows me. Just when I walk down the street I say hi to everybody. I'm neighborly" (GCBH3).

FHC-Phoenix participants also reported various levels of social interaction with their neighbors and other program participants. One participant said that he regularly interacted with others in his neighborhood but not other program participants. One said that while he did not regularly interact with participants in his program that he had a neighbor with whom he enjoyed spending time, talking and laughing. Another participant said that he regularly interacted with about five people from his building, a couple of whom were also program participants. He added that outside of the building that the only people he knew were the employees at the neighborhood gas station.

Two other Phoenix participants talked primarily about interacting with other program participants. One said that while he regularly spoke to neighbors he did not 
regularly spend time with them because many of them had jobs or other daily activities to keep them busy. However, he said that he often spent time with one other participant. When asked what they usually do together, he responded that usually they drank beer together. He stated that he did not see that as a positive thing as he struggles with trying to change his drinking habit. Another participant talked about mostly interacting with other participants. When asked what kinds of things they do together, he also responded that when together they "party and drink" (PH3).

\section{Neighborhood Satisfaction}

At the conclusion of the open-ended segment of the interview, participants at both programs were asked to rate certain aspects of their housing and neighborhood. The participants were asked to first rate how much importance they put on certain housing and neighborhood amenities on a scale of 1 to 5 with 1 being "not important at all" and 5 being "very important." These items were separated into three domains: housing/neighborhood quality, safety, and accessibility. For amenities, they were then asked to indicate "yes" or "no" as to whether or not their housing placement had that amenity. For each neighborhood safety item, they were asked to indicate how safe they felt on a scale of 1 to 5 with 1 being "not safe at all" and 5 being "very safe." For accessibility, they were asked rate how accessible each item was to them on a scale of 1 to 5 with 1 being "not at all accessible" and 5 being "very accessible." The tables below indicate the presence of these housing and neighborhood amenities as well as the average score for each of the items. 
As shown in Table 4.2, the amenities offered by housing placements varied among participants. Four participants lived in smaller buildings such as a duplex or fourplex. The other seven lived in larger apartment complexes. In either case, participants placed little importance on the building size. Most participants felt that they lived in buildings with plenty of square footage and all participants had private bedrooms, meaning that they did not live in studio apartments. Most respondents reported living close to other project participants but the importance placed on proximity to peers was neutral. Most participants reported living in neighborhoods with sidewalks that were easy to get around on foot. As all of the participants interviewed did not have personal vehicles, this item scored of high importance. Only six participants lived in a downtown area but value placed on living downtown was relatively low. Most participants felt that they lived in buildings that were kept in good shape and placed a high importance on this item. Participants also placed a high importance on living in pleasant or beautiful neighborhoods as well as in neighborhoods with outdoor space such as parks. However, less of half of participants interviewed felt that their housing placement offered this amenity. 
Table 4.2. Summary of Responses to Question 9. (For each item, please respond yes or no as to whether you feel that your housing provides that amenity. Then, rate its importance on a scale of 1-5.)

\begin{tabular}{|c|c|c|}
\hline Item: & $\begin{array}{l}\text { Amenity? } \\
\text { (frequency) }\end{array}$ & $\begin{array}{l}\text { Importance? } \\
\text { (mean) }\end{array}$ \\
\hline $\begin{array}{l}\text { a. Living in a small building with just a few } \\
\text { units (duplex, four-plex)? }\end{array}$ & $\begin{array}{l}\text { Yes }-4 \\
\text { No }-7\end{array}$ & 3.2 \\
\hline $\begin{array}{l}\text { b. Living in a large building with many units } \\
\text { (apartment complex)? }\end{array}$ & $\begin{array}{l}\text { Yes }-7 \\
\text { No }-4\end{array}$ & 2.0 \\
\hline $\begin{array}{l}\text { c. Living in a unit with lots of space (square } \\
\text { footage)? }\end{array}$ & $\begin{array}{l}\text { Yes }-8 \\
\text { No }-3\end{array}$ & 3.1 \\
\hline $\begin{array}{l}\text { d. Living in a unit with your own bedroom } \\
\text { (non-studio apartment)? }\end{array}$ & $\begin{array}{l}\text { Yes - } 11 \\
\text { No }-0\end{array}$ & 4.4 \\
\hline e. Living close to other project participants? & $\begin{array}{l}\text { Yes - } 9 \\
\text { No }-2\end{array}$ & 3.1 \\
\hline $\begin{array}{l}\text { f. Living in a neighborhood that has } \\
\text { sidewalks and is easy to walk around? }\end{array}$ & $\begin{array}{l}\text { Yes }-9 \\
\text { No }-2\end{array}$ & 4.4 \\
\hline g. Living downtown? & $\begin{array}{l}\text { Yes }-6 \\
\text { No }-5\end{array}$ & 2.8 \\
\hline $\begin{array}{l}\text { h. Living in a neighborhood that you feel is } \\
\text { generally in good condition (buildings } \\
\text { kept in nice shape)? }\end{array}$ & $\begin{array}{l}\text { Yes }-8 \\
\text { No }-2 \\
\text { Neutral - } 1\end{array}$ & 4.5 \\
\hline $\begin{array}{l}\text { i. Living in a neighborhood that you feel is } \\
\text { pleasant or beautiful to look at (attractive } \\
\text { buildings and landscape)? }\end{array}$ & $\begin{array}{l}\text { Yes - } 4 \\
\text { No - } 3 \\
\text { Neutral - } 4\end{array}$ & 4.0 \\
\hline $\begin{array}{l}\text { j. Living in a neighborhood with lots of } \\
\text { places for you or your guests to park a } \\
\text { vehicle? }\end{array}$ & $\begin{array}{l}\text { Yes - } 8 \\
\text { No }-3\end{array}$ & 3.5 \\
\hline $\begin{array}{l}\text { k. Living in a neighborhood with lots of } \\
\text { outdoor space like lawns, forests, and } \\
\text { parks? }\end{array}$ & $\begin{array}{l}\text { Yes }-4 \\
\text { No }-6 \\
\text { Somewhat }-1 \\
\end{array}$ & 4.5 \\
\hline
\end{tabular}

Table 4.3 depicts average scores for how safe participants rated their neighborhood and how much importance they placed on this safety. These scores show that participants uniformly place a high value on safety. However, high safety scores are not recognized in most instances. Neighborhood safety items (a) and (b) ranked in the neutral range on average. While participants scored safety when walking alone at night the lowest at 2.7, they scored their feeling of safety when walking alone during the day much higher at 4.0. 
Participants also indicated higher safety scores for their apartment unit itself. This suggests that while they may not feel particularly safe in the neighborhood, they did feel relatively safe while inside their homes. Participants placed a neutral score on the safety of leaving their apartments unattended for both short and long periods of time.

Table 4.3. Summary of Responses to Question 10. (Now, I'm going to ask about how safe you feel in your housing and neighborhood. For each item, please respond on a scale of 1-5 how safe you feel and how important you rank that safety item.)

\begin{tabular}{|c|c|c|}
\hline Item: & $\begin{array}{l}\text { How safe? } \\
\text { (mean) }\end{array}$ & $\begin{array}{l}\text { Importance? } \\
\text { (mean) }\end{array}$ \\
\hline a. Your neighborhood in general? & 3.5 & 4.6 \\
\hline b. The people who live in your neighborhood? & 3.1 & 4.5 \\
\hline c. Your apartment in general? & 4.0 & 4.9 \\
\hline d. Being alone in your apartment at night? & 4.2 & 4.9 \\
\hline e. Walking alone in your neighborhood? & 4.0 & 4.9 \\
\hline $\begin{array}{l}\text { f. Walking alone in your neighborhood after } \\
\text { dark? }\end{array}$ & 2.7 & 4.7 \\
\hline $\begin{array}{l}\text { g. Leaving your apartment unattended for a } \\
\text { short period of time like just a few hours? }\end{array}$ & 3.3 & 4.9 \\
\hline $\begin{array}{l}\text { h. Leaving your apartment unattended } \\
\text { overnight or for longer periods? }\end{array}$ & 3.2 & 4.8 \\
\hline
\end{tabular}

Table 4.4 depicts how participants scored in response to questions regarding how they rated their access to certain services and amenities. For most items, participants indicated a relatively high score. This was especially true for places they needed to go to meet basic needs such as obtaining food, medications, clothing, laundry, program services, and other services such as banking and medical care. Access to opportunities for education and employment received average scores of 3.4 and 3.7 respectively. Access to recreation also received an average score in the neutral range of 3.5, but access to dining and entertainment scored the lowest at 2.2. This consistently low ranking led the researcher to ask participants why they felt these services were inaccessible. Responses suggested that that participant did in fact have access to dining and 
entertainment in most cases but could not personally access it due to not having the monetary resources. Therefore, it is important to note that for many of these items, responses may be influenced more by personal circumstances than by actual proximity.

Table 4.4. Summary of Responses to Question 11. (Now, I'm going to ask about the places that you may need or want to go. Please indicate on a scale of 1-5 how accessible each of the following is to you and the importance that you place on having access to that item.)

\begin{tabular}{|c|c|c|}
\hline Item: & $\begin{array}{l}\text { Access? } \\
\text { (mean) }\end{array}$ & $\begin{array}{l}\text { Importance? } \\
\text { (mean) }\end{array}$ \\
\hline $\begin{array}{l}\text { a. Places to shop for necessities like grocery } \\
\text { stores and pharmacies? }\end{array}$ & 4.2 & 4.9 \\
\hline $\begin{array}{l}\text { b. Places to go for resources like food and } \\
\text { clothing banks? }\end{array}$ & 4.1 & 4.3 \\
\hline $\begin{array}{l}\text { c. Place to go for needed services like a bank } \\
\text { or post office? }\end{array}$ & 3.9 & 3.9 \\
\hline $\begin{array}{l}\text { d. Places to go for medical care like a clinic or } \\
\text { doctor's office? }\end{array}$ & 4.3 & 4.5 \\
\hline $\begin{array}{l}\text { e. A laundromat or other place to wash } \\
\text { clothes? }\end{array}$ & 4.3 & 4.7 \\
\hline $\begin{array}{l}\text { f. Places to go out to eat or for other } \\
\text { entertainment like a restaurant or movie } \\
\text { theater? }\end{array}$ & 2.2 & 3.6 \\
\hline $\begin{array}{l}\text { g. Public transportation to downtown or } \\
\text { another place that you need to go? }\end{array}$ & 3.8 & 4.6 \\
\hline $\begin{array}{l}\text { h. Places to go for recreation and exercise like } \\
\text { a park or gym? }\end{array}$ & 3.5 & 4.3 \\
\hline $\begin{array}{l}\text { i. Places to go for learning like a library or } \\
\text { educational center (voc rehab, college, } \\
\text { etc.)? }\end{array}$ & 3.7 & 4.0 \\
\hline j. Employment opportunities? & 3.4 & 4.1 \\
\hline $\begin{array}{l}\text { k. Program services like case management, } \\
\text { support groups, or treatment centers? }\end{array}$ & 4.1 & 4.5 \\
\hline
\end{tabular}

\section{Conclusion}

This chapter has summarized the findings of interviews of staff and participants at both FHC-Phoenix and GCBH's Housing First programs. Interview questions were intended to learn more about what how participant housing placements are made, what 
participants most value about their housing and neighborhoods, and if housing type (scattered or project-based) and neighborhood affects their success in the program. Interviews with staff also focused on comparisons between scattered-site and projectbased housing. Not surprisingly, GCBH participants living in JHH described their housing as being more intertwined with services and project staff. Staff at both programs expressed similar opinions in their discussions of how project-based housing is likely to bring participants in more direct contact with case management and other services. Most staff indicated that project-based housing was likely to hinder social integration with the mainstream community. However, participants in both scattered-site and project-based housing talked much less about socialization as being an issue. Regardless of the housing type, participants indicated few responses to suggest new friendships or ties with neighbors. Most socialization discussed was with previously established friendships with other homeless or formerly homeless individuals or in fewer instances with family.

Staff and participant interviews both suggested that neighborhood is important to participants but not necessarily in terms of determining participants' success in remaining housed. The majority felt that participants largely lived in subpar neighborhoods in terms of housing quality, safety, and amenities. Both staff and participant respondents at JHH stated that the project-based facility offered superior housing quality but the facility was surrounded by one of the city's most dangerous neighborhoods. All staff and all but one participant agreed that that program housing placements were in areas that offered good access to services and transportation. Regardless of satisfaction with housing and neighborhood quality, participants expressed satisfaction with the program as a whole and a feeling that any housing placement would be better than homelessness. 
For most interviewed, it was services and individual determination that were identified as vital factors to success in the program. These interviews suggested that while neighborhood is important, it is secondary to other factors. However, everyone interviewed expressed strong opinions about neighborhood and community as being important to the well-being and satisfaction of housing participants. Of the 11 participants interviewed, six moved at least once during their tenure in the program. It is also important to note that of those six, none were JHH residents. Therefore, six out of eight scattered-site residents either voluntarily or involuntarily left their housing placement. For voluntary moves, the reason was often associated with dissatisfaction with the housing or neighborhood. For involuntary moves, the reason for the move was identified as individual behaviors which were often perpetuated by neighbors. Therefore, while the location of a housing placement did not necessarily impact the ultimate success of the participant in the program, it did in fact very likely have an impact on housing stability in that participants were much less likely to remain in neighborhoods for which they expressed dissatisfaction. It is important to emphasize that the limited number of interviews does not allow us to infer any strong conclusions about the influence of neighborhood. However, these interviews do provide a richer context for understanding the dynamic relationship between Housing First participants and their surrounding environments. This understanding will be used in following chapters to guide discussion of how neighborhood characteristics affect housing stability for all Housing First participants. 


\section{CHAPTER 5}

\section{DATA}

The previous chapter addressed the process of placing homeless individuals in Housing First placements through an analysis of in-depth interviews with a small sample of staff and project participants in Louisville and Cincinnati. These interviews also provided insight to the factors respondents felt were important in regard to housing and neighborhood and how these factors may impact a participant's success in achieving housing stability. This chapter builds on this insight by using quantitative data collected for all participants and their housing placements. This data is used to examine the housing and neighborhood characteristics of Housing First placements through an analysis of descriptive statistics. In addition, this chapter also reviews the independent variables that describe the participants themselves.

\section{Dataset}

As described in Chapter 3, the dataset was designed to capture both demographic and other personal characteristics of Housing First placements and the neighborhood characteristics of each of their housing placements. It was created using administrative records and demographic data from the U.S. Census Bureau (Census 2010 and American Community Survey 2011), public transit data collected by the transportation authorities of the two cities, and annual crime report statistics collected by the Louisville and Cincinnati police departments. Administrative data collected from project administrators 
at both agencies provided the address, dates of tenure, and reason for leaving (if applicable) of each housing placement made in these programs. The database includes 227 participants: 89 of whom were participants at GCBH (51 in scattered-site and 38 at $\mathrm{JHH}$ ) and 138 of whom were participants at FHC-Phoenix. Because the study is interested in actual housing placements, each record represents an individual stay in housing for a participant. Thus, more than one record exists in the dataset for individuals with multiple placements. This data was used to create 312 unique records, each representing a participant's stay in one or more housing placements.

Demographic data from both cities were obtained at the census tract level through mapping TIGER data files from the U.S. Census Bureau. Addresses provided through the administrative database were then mapped into a GIS database and merged with census tracts using the overlay geographic processing tool. This merging of data allowed each housing record to be paired with detailed information for the census tract including neighborhood poverty, median income, population density, residential vacancy rates, crime rates (as measured by crimes per capita), as well as distance to the central business district and public transportation stops. The following sections provide descriptive statistics detailing these characteristics and the distribution of Housing First placements throughout the cities of Cincinnati and Louisville.

\section{Housing Placements}

Figures 5.1 and 5.2 present maps depicting the housing placements of Housing First participants in GCBH's Pathways to Housing and FHC-Phoenix's Housing First projects. In total, 197 housing placements were made during years 2008 through 2013 in Louisville. A total of 115 housing placements were made in Cincinnati during the same 
Figure 5.1. Housing First Placements, GCBH, Cincinnati/Hamilton County, Ohio

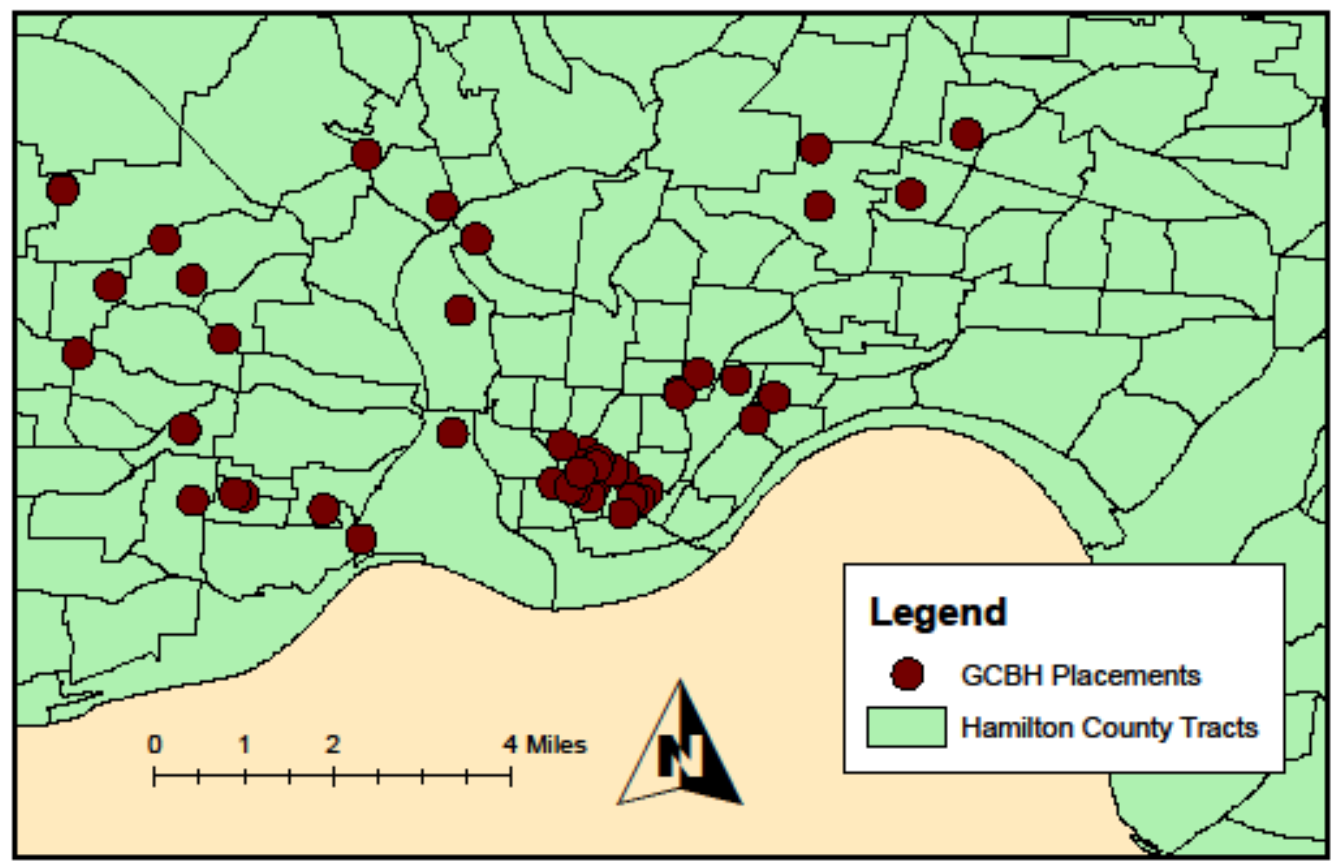

Figure 5.2. Housing First Placements, FHC-Phoenix, Louisville/Jefferson County, Kentucky

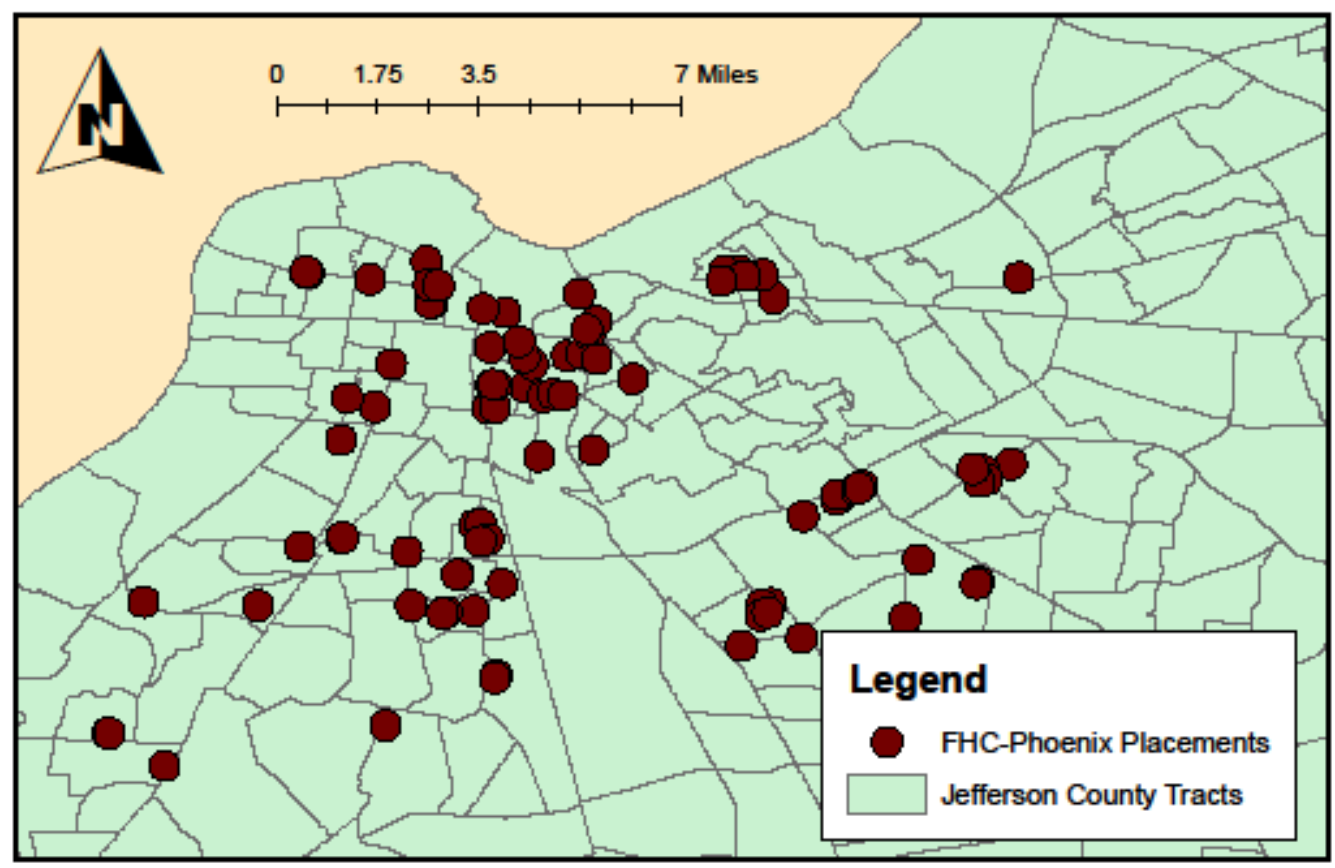


period. Of the latter placements, 77 were in scattered-site units and 38 were at the Jimmy Heath House project-based residential facility.

The 197 housing placements in Louisville were spread out over 43 different census tracts with the highest number of placements in a single tract being 22. Seventeen of the Louisville census tracts had only a single Housing First placement. The mean number of housing placements per census tract in Louisville was five; the median number was two. The 115 housing placements made in Cincinnati were spread out over a total of 30 different census tracts. The largest number of placements in a single tract was in Census Tract 9 which is the location of the Jimmy Heath House. This tract contained the $38 \mathrm{JHH}$ housing placements as well as six additional scattered-site housing placements in the neighborhood. In Cincinnati, 15 of the census tracts contained a single housing placement. Including Census Tract 9, the mean number of placements per tract was four; the median was two.

\section{Distribution of Poverty, Median Income and Vacant Properties}

Figures 5.3 through 5.8 depict the distribution of three indicators of economic characteristics for the census tracts inhabited by Housing First participants in Louisville and Cincinnati; these three indicators are percentage of households living in poverty, median household income, and percentage of vacant residential dwelling units. As demonstrated by these maps, Housing First placements in both cities tend to be distributed among the tracts with the highest percentages of poverty, lowest median incomes, and highest percentage of residential vacancies. Table 5.1 demonstrates how the economic indicators of census tracts containing Housing First placements vary between those of the city as a whole. 
Figure 5.3. Percent of Households Below Poverty Level in Cincinnati/Hamilton County, Ohio

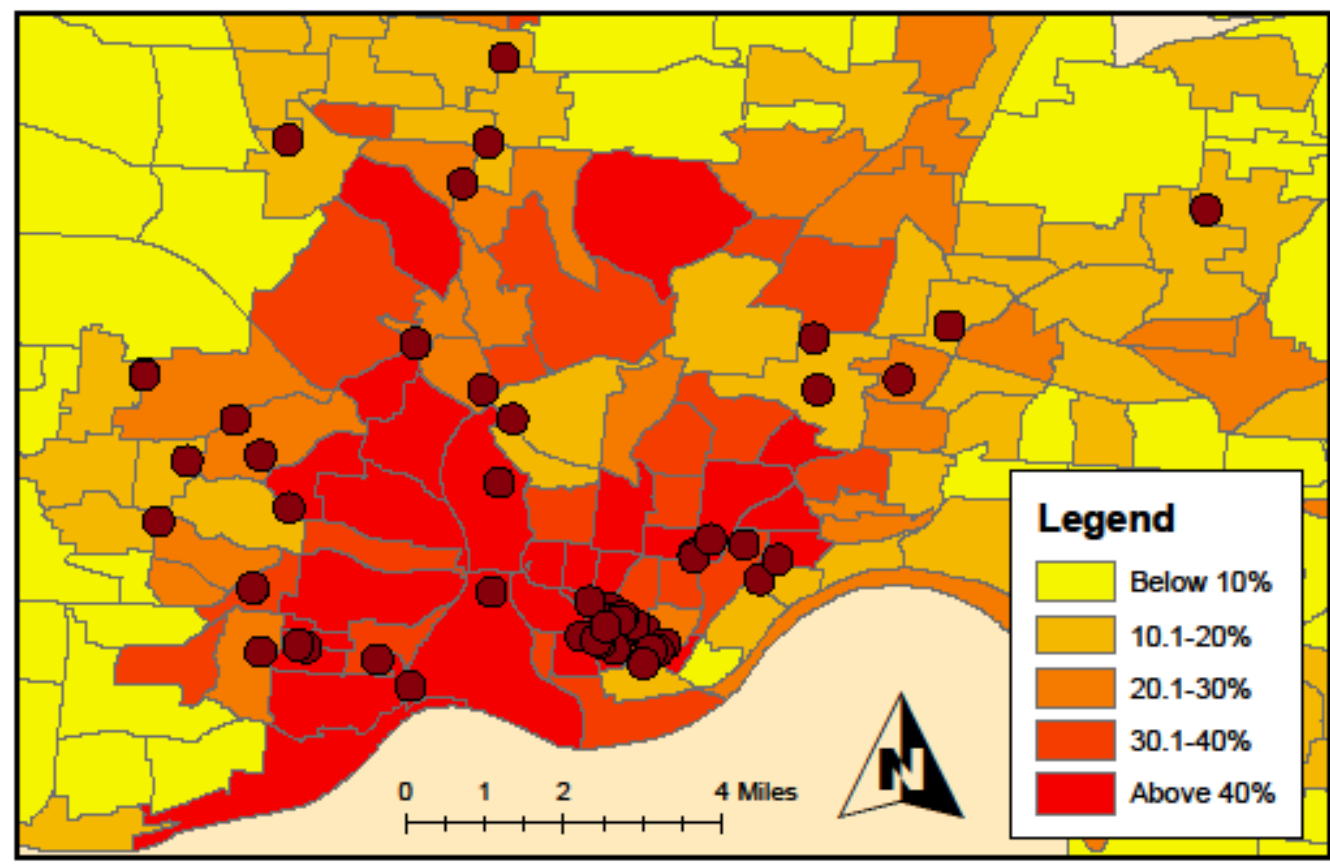

Figure 5.4. Percent of Households Below Poverty Level in Louisville/Jefferson County, Kentucky

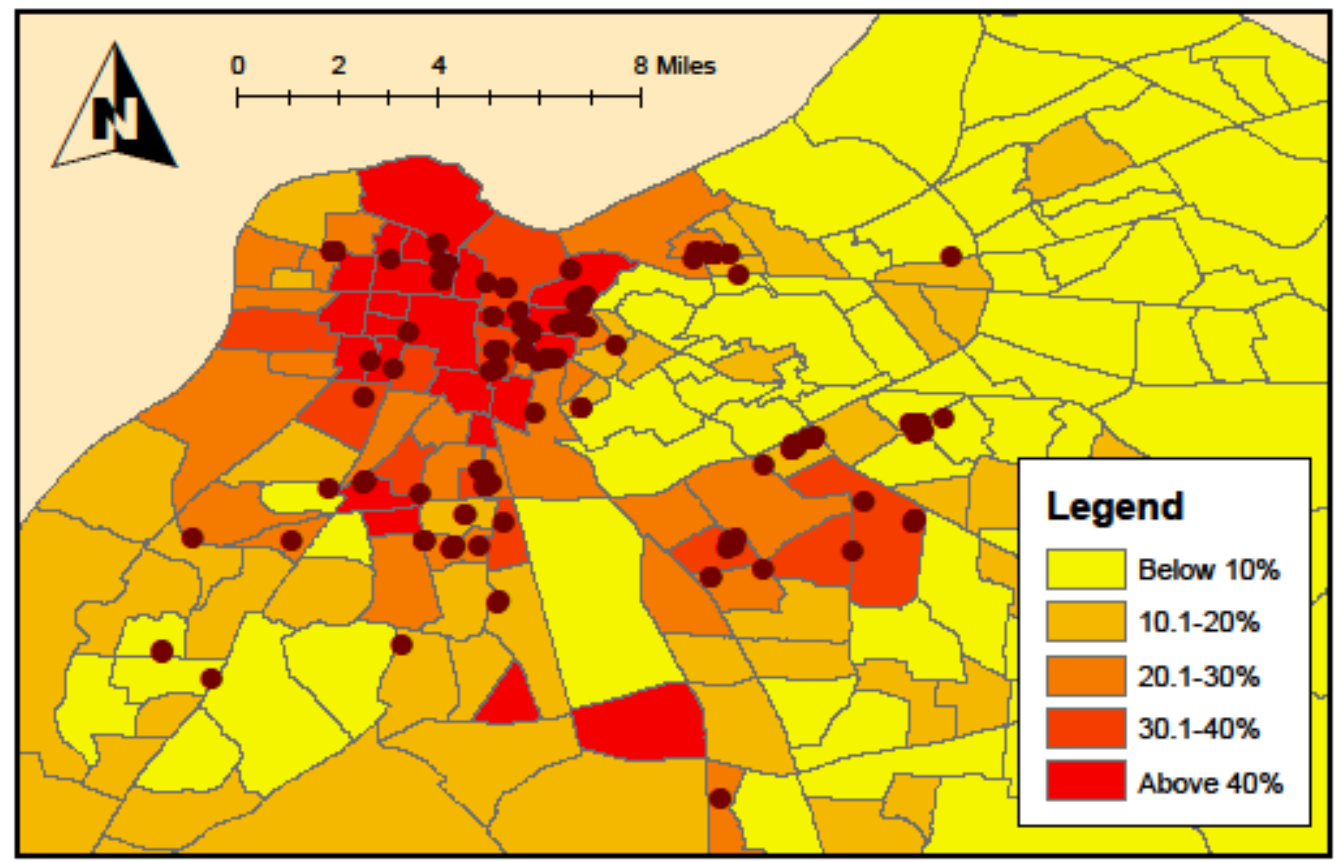

Source: 2011 American Community Survey, U.S. Census Bureau 
Figure 5.5. Median Household Income in Cincinnati/Hamilton County, Ohio

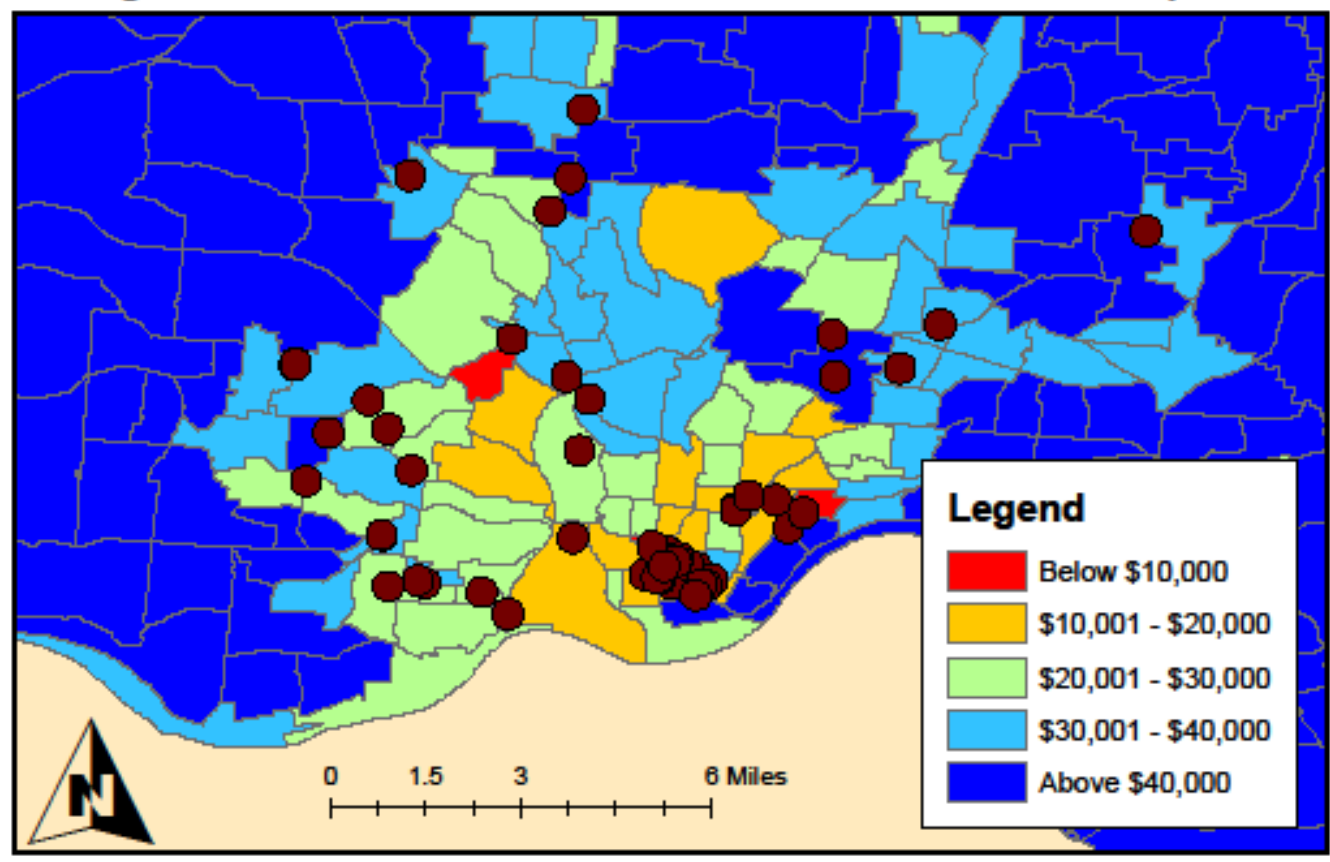

Figure 5.6. Median Household Income in Louisville/Jefferson County, Kentucky

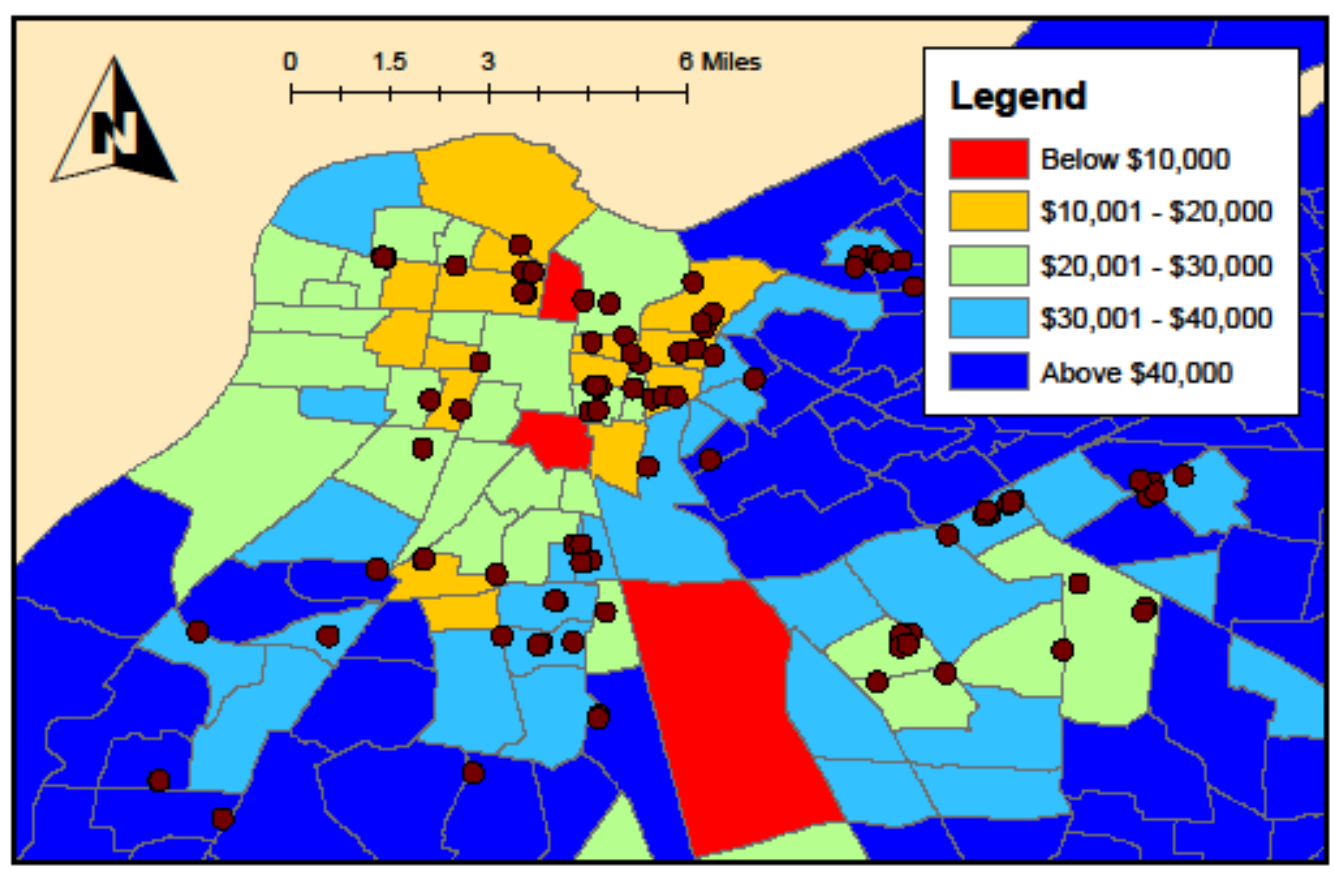

Source: 2011 American Community Survey, U.S. Census Bureau 
Figure 5.7. Percentage of Vacant Housing Units in Cincinnati/Hamilton County, Ohio

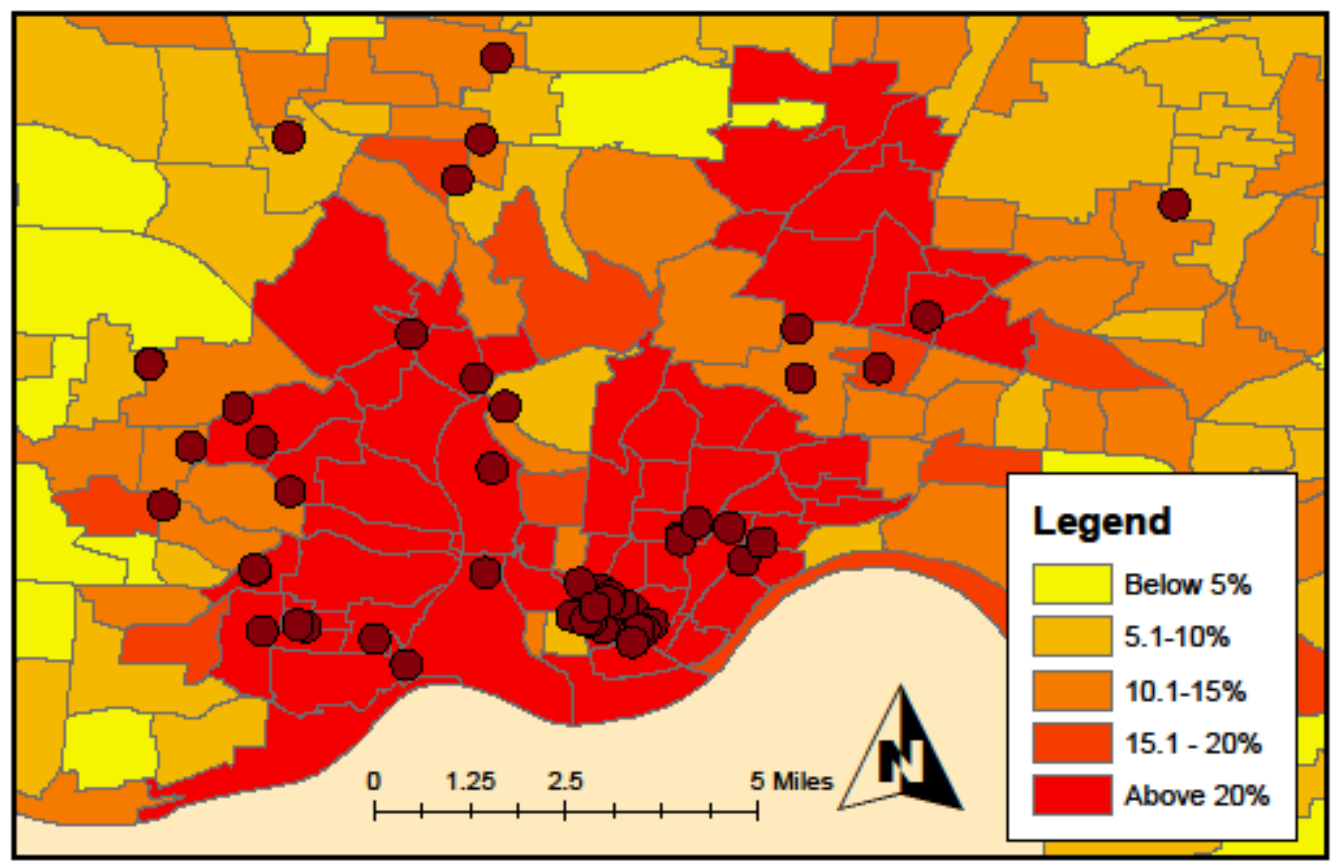

Figure 5.8. Percentage of Vacant Housing Units in Louisville/Jefferson County, Kentucky

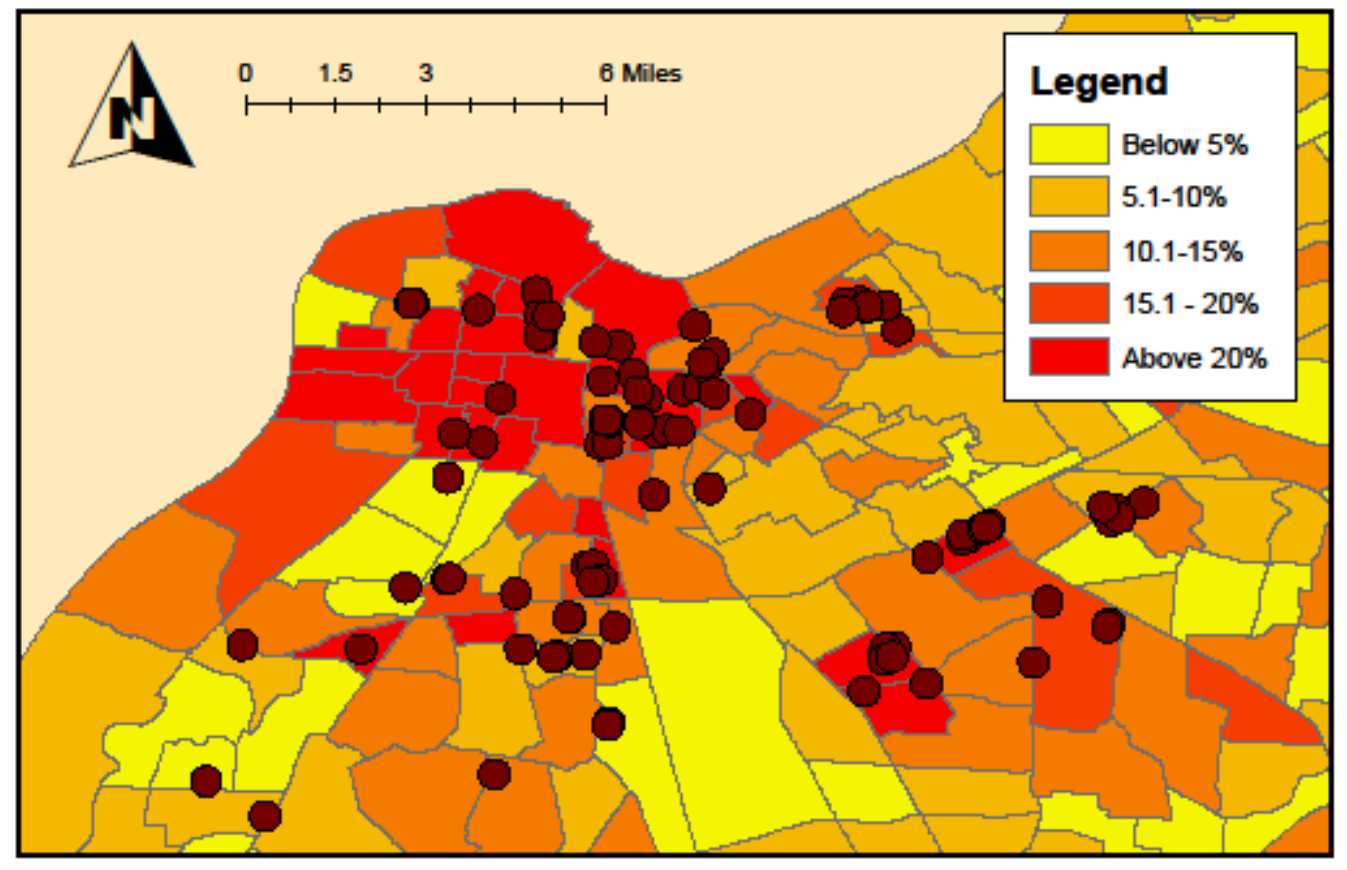

Source: 2011 American Community Survey, U.S. Census Bureau 
Table 5.1. Distribution of Economic Indicators

\begin{tabular}{|c|c|c|c|c|c|}
\hline \multirow[t]{2}{*}{ Indicator } & \multicolumn{3}{|c|}{$\begin{array}{l}\text { Cincinnati Pathways to Housing } \\
\text { Greater Cincinnati Behavioral } \\
\text { Health }\end{array}$} & \multicolumn{2}{|c|}{$\begin{array}{l}\text { Louisville Housing First } \\
\text { FHC-Phoenix }\end{array}$} \\
\hline & $\begin{array}{l}\text { Hamilton } \\
\text { County }\end{array}$ & $\begin{array}{l}\text { Scattered- } \\
\text { site }\end{array}$ & $\begin{array}{c}\text { Project- } \\
\text { based }\end{array}$ & $\begin{array}{c}\text { Jefferson } \\
\text { County }\end{array}$ & $\begin{array}{l}\text { Scattered- } \\
\text { site }\end{array}$ \\
\hline Number of tracts & 221 & 29 & 1 & 191 & 43 \\
\hline $\begin{array}{l}\text { Percent poverty } \\
\text { - Mean } \\
\text { - Median } \\
\text { - Range } \\
\end{array}$ & $\begin{array}{l}19.7 \% \\
14.0 \% \\
1-82.5 \% \\
\end{array}$ & $\begin{array}{c}40.2 \% \\
39.4 \% \\
12.2-82.5 \% \\
\end{array}$ & $53.6 \%$ & $\begin{array}{c}17.8 \% \\
13.1 \% \\
0-80.6 \% \\
\end{array}$ & $\begin{aligned} & 30.9 \% \\
& 29.4 \% \\
& 4.3-55.2 \% \\
&\end{aligned}$ \\
\hline $\begin{array}{l}\text { Median income } \\
\text {-Mean } \\
\text {-Median } \\
\text {-Range }\end{array}$ & $\begin{array}{l}\$ 50,196 \\
\$ 45,411 \\
\$ 9,071- \\
\$ 232,917\end{array}$ & $\begin{array}{l}\$ 24,710 \\
\$ 23,906 \\
\$ 9,071- \\
\$ 60,266\end{array}$ & $\$ 15,919$ & $\begin{array}{l}\$ 49,142 \\
\$ 45,643 \\
\$ 8,858- \\
\$ 123,250\end{array}$ & $\begin{array}{l}\$ 27,514 \\
\$ 27,885 \\
\$ 13,762- \\
\$ 52,500\end{array}$ \\
\hline $\begin{array}{l}\text { Percent vacant } \\
\text { - Mean } \\
\text { - Median } \\
\text { - Range }\end{array}$ & $\begin{array}{c}15.2 \% \\
11.2 \% \\
0.4-77.5 \% \\
\end{array}$ & $\begin{array}{c}36.4 \% \\
27.5 \% \\
7-77.5 \%\end{array}$ & $77.5 \%$ & $\begin{array}{c}10.7 \% \\
8.9 \% \\
0-39.0 \%\end{array}$ & $\begin{array}{l}18.2 \% \\
15.9 \% \\
1-33.4 \%\end{array}$ \\
\hline
\end{tabular}

Note: For Jimmy Heath House, characteristics are presented for the single tract surrounding the facility.

For Cincinnati, the census tract surrounding the Jimmy Heath House projectbased facility is compared to that of both scattered-site housing placements and the city as a whole. As this table demonstrates, census tracts containing scattered-site Housing First placements in both cities fared worse than each of their respective cities as a whole. In Cincinnati, the average median income in tracts with scattered-site housing placements was $\$ 25,485$ lower than the city as whole. Thus, median income in these tracts was less than 50 percent of the average. The tract containing JHH had an even lower median income of $\$ 15,919$. In Louisville, tracts with scattered-site housing placements fared slightly better than Cincinnati with an average median household income \$21,628 lower than that of the city as a whole. The distribution of poverty and residential vacancies follows similar trends for both cities, with scattered-site housing placements being located in less economically advantaged tracts. Both of these indicators fell far below the averages for both Cincinnati and tracts containing GCBH housing placements. 


\section{Density and Proximity}

In addition to economic indicators, this analysis examined three measures to serve as indicators of centrality. These include proximity to public transportation, proximity to each city's central business district, and the population density of each census tract.

Figures 5.9 and 5.10 depict the distribution of population density for Cincinnati and Louisville, respectively. Census 2010 data were used to calculate the average number of individuals per square mile for all census tracts in each city. Bus stops for each city were geocoded using data provided by the public transit authorities of Louisville and Cincinnati. Proximity to public transportation was determined by using GIS to calculate the shortest difference between each housing placement and the bus stop. Tables 5.2 and 5.3 present descriptive statistics for proximity to public transportation, proximity to the central business district, and census tract population density for scattered-site participants at GCBH and FHC-Phoenix as well as the project-based Jimmy Heath House. Proximity to the $\mathrm{CBD}$ was determined by calculating the distance from each housing placement to the center of the census tract containing each city's tallest building; Great American Tower at Queen City Square (301 East Fourth Street) in Cincinnati and AEGON Center (400 West Main Street) in Louisville. 
Figure 5.9. Persons per Square Mile in Cincinnati/Hamilton County, Ohio

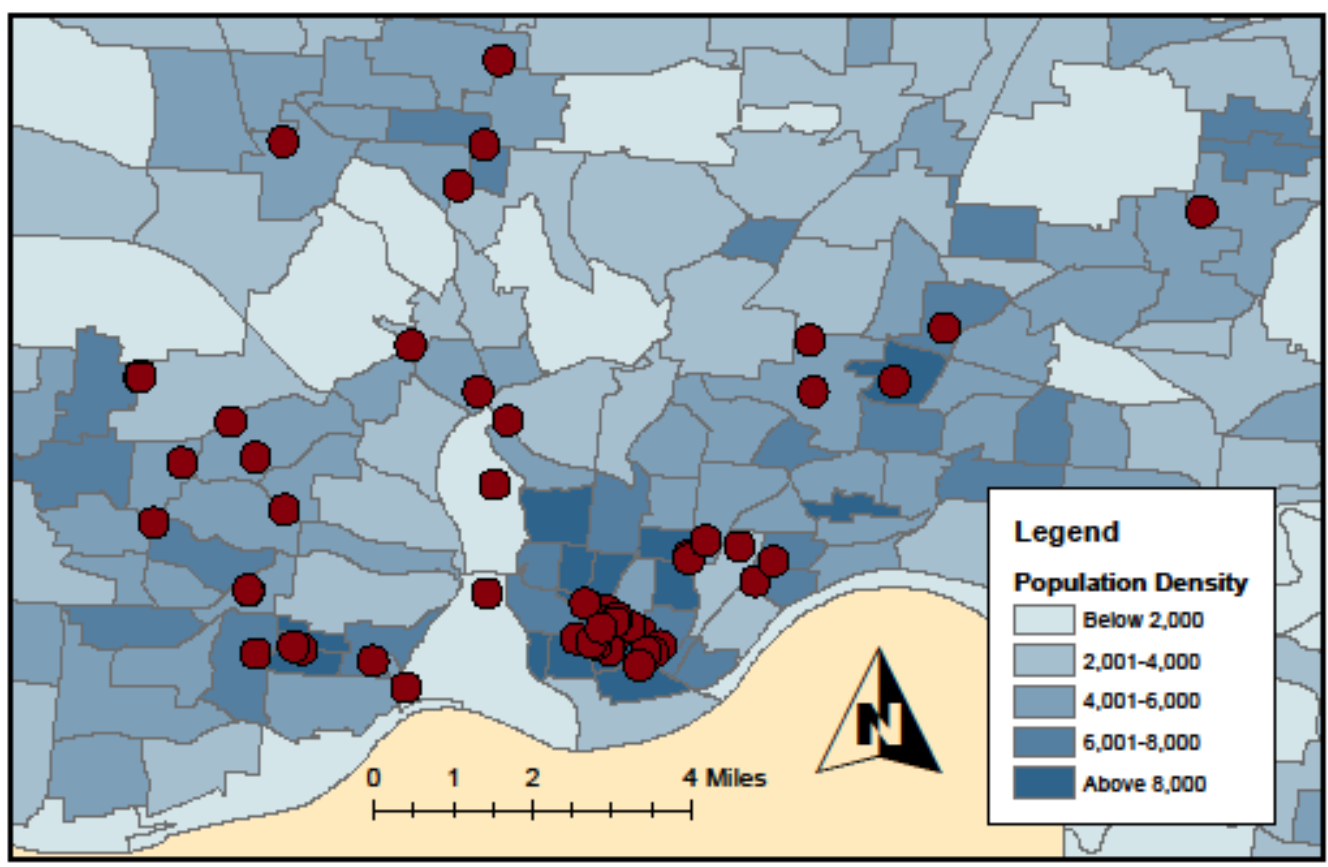

Figure 5.10. Persons Per Square Mile in Louisville/Jefferson, Kentucky

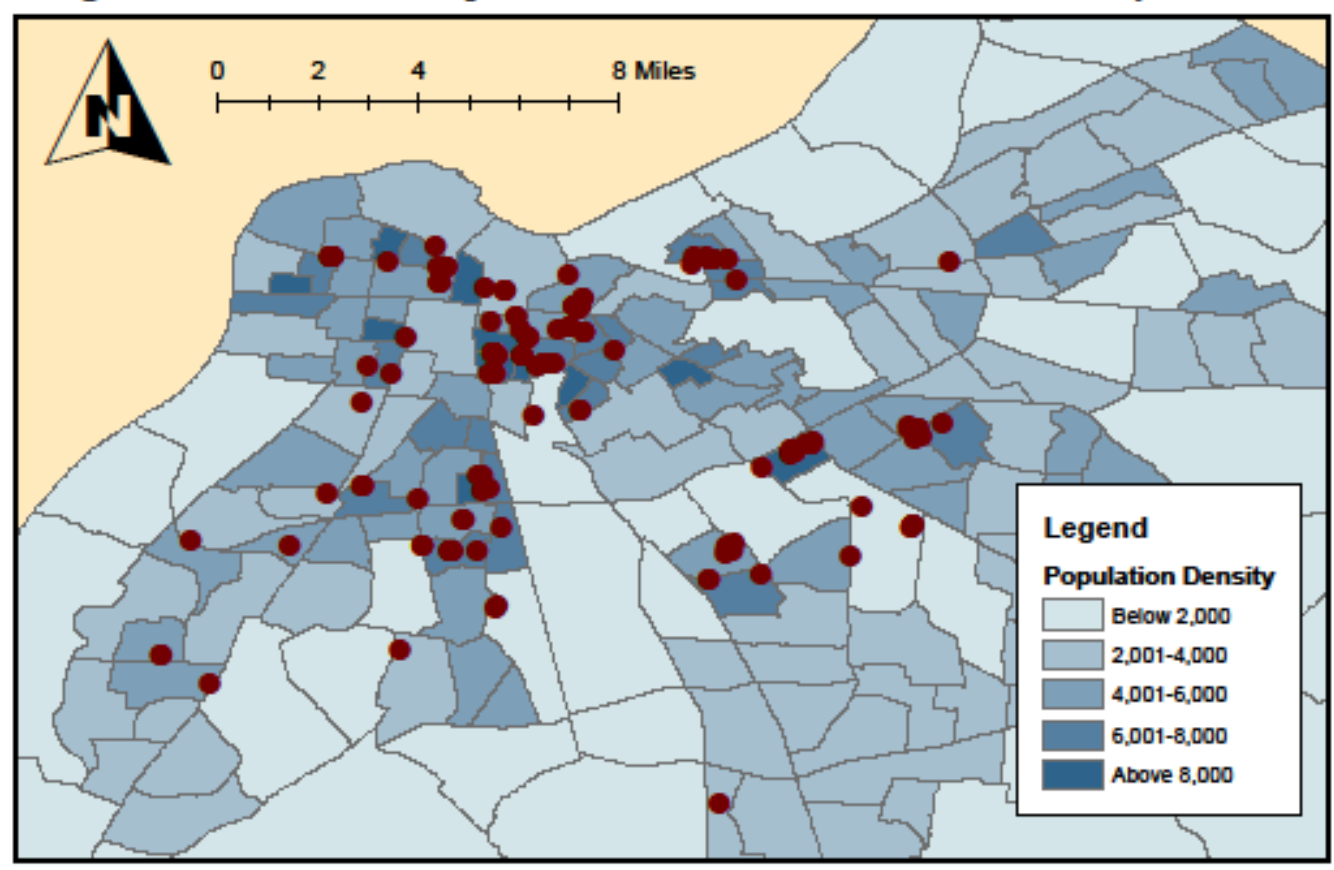

Source: 2010 U.S. Census, U.S. Census Bureau 
Table 5.2. Access to CBD and Public Transportation

\begin{tabular}{|l|c|c|c|}
\hline \multicolumn{1}{|c|}{ Indicator } & $\begin{array}{c}\text { GCBH } \\
\text { scattered-site } \\
(\mathrm{n}=77)\end{array}$ & $\begin{array}{c}\text { GCBH } \\
\text { project-based } \\
(\mathrm{n}=38)\end{array}$ & $\begin{array}{c}\text { FHC-Phoenix } \\
\text { scattered-site } \\
(\mathrm{n}=197)\end{array}$ \\
\hline Distance to CBD & & & \\
(feet) & 13,643 & 2,323 & 15,066 \\
- Mean & 8,896 & & 10,066 \\
- Median & $1,902-40,999$ & & $0-53,555$ \\
- Range & & & \\
\hline Distance to bus stop & & 280 & 409 \\
(feet) & 481 & & 291 \\
- Mean & 203 & & $9-4,638$ \\
- Median & $7-2,574$ & & \\
- Range & \multicolumn{2}{|}{} \\
\hline
\end{tabular}

\section{Table 5.3. Population Density (2010)}

\begin{tabular}{|l|c|c|c|c|c|}
\hline \multirow{2}{*}{ Indicator } & \multicolumn{2}{|c|}{$\begin{array}{c}\text { Cincinnati Pathways to Housing } \\
\text { Greater Cincinnati Behavioral } \\
\text { Health }\end{array}$} & \multicolumn{2}{c|}{$\begin{array}{c}\text { Louisville Housing First } \\
\text { FHC-Phoenix }\end{array}$} \\
\cline { 2 - 6 } & $\begin{array}{c}\text { Hamilton } \\
\text { County }\end{array}$ & $\begin{array}{c}\text { Scattered- } \\
\text { site }\end{array}$ & $\begin{array}{c}\text { Project- } \\
\text { based }\end{array}$ & $\begin{array}{c}\text { Jefferson } \\
\text { County }\end{array}$ & $\begin{array}{c}\text { Scattered- } \\
\text { site }\end{array}$ \\
\hline Number of tracts & 221 & 29 & 1 & 191 & 43 \\
\hline Density per & & & & & \\
square mile & 4,157 & 7,494 & 14,152 & 3,790 & 6,630 \\
- Mean & 3,617 & 6,023 & & 3,606 & 6,609 \\
- Median & $173-16,975$ & $634-16,975$ & & $88.5-$ & $732-10,513$ \\
- Range & & & & 10,513 & \\
\hline
\end{tabular}

Note: For Jimmy Heath House, characteristics are presented for the single tract surrounding the facility.

\section{Crime}

Finally, crime statistics were calculated for the census tracts comprising each of these cities. The Louisville Metropolitan Police Department and Cincinnati Police Department both provided datasets listing all reported crimes by address for the 2013 calendar year. Louisville provides these statistics in a downloadable format online. The Cincinnati Police Department provided a similar database upon the request of the researcher. This information was then overlaid with Housing First placement data to determine how many crimes per capita occurred in the tracts where Housing First 
placements were made in the two cities. Crimes per capita are depicted in Figures 5.11 and 5.12. These datasets were used to geocode the number of crimes reported per census tract for all tracts in the two cities. As shown in the maps, the distribution of per capita crimes differed somewhat between Cincinnati and Louisville. For Cincinnati, the highest per capita crime rates were in tracts adjacent to the central most parts of the city. In Louisville, the highest per capita crime rates were distributed primarily in the central parts of the city. During staff and participant interviews, a number of participants talked about how revitalization in Over the Rhine and other parts of the central city had pushed crime into older suburbs. The distribution of crimes displayed in the maps appears to support these claims.

Table 5.4 provides a comparison of crimes per capita for census tracts containing scattered-site and project-based housing placements to those for the entirety of each of the two cities. Similar to other neighborhood characteristics, the distribution of reported crimes and crimes per capita in both cities was greater in the tracts containing Housing First placements. In Cincinnati, the mean number of crimes per capita was .06 per census tract. For scattered-site placements, this number more than doubled to .17; for the tract surrounding $\mathrm{JHH}$, crimes per capita increased to .24. Louisville placements exhibited a smaller disparity with the mean crimes per capita being the same as Cincinnati at .06 but increasing to .10 for tracts containing Housing First placements. 
Figure 5.11. Crimes Per Capita 2013 Cincinnati/Hamilton County, Ohio

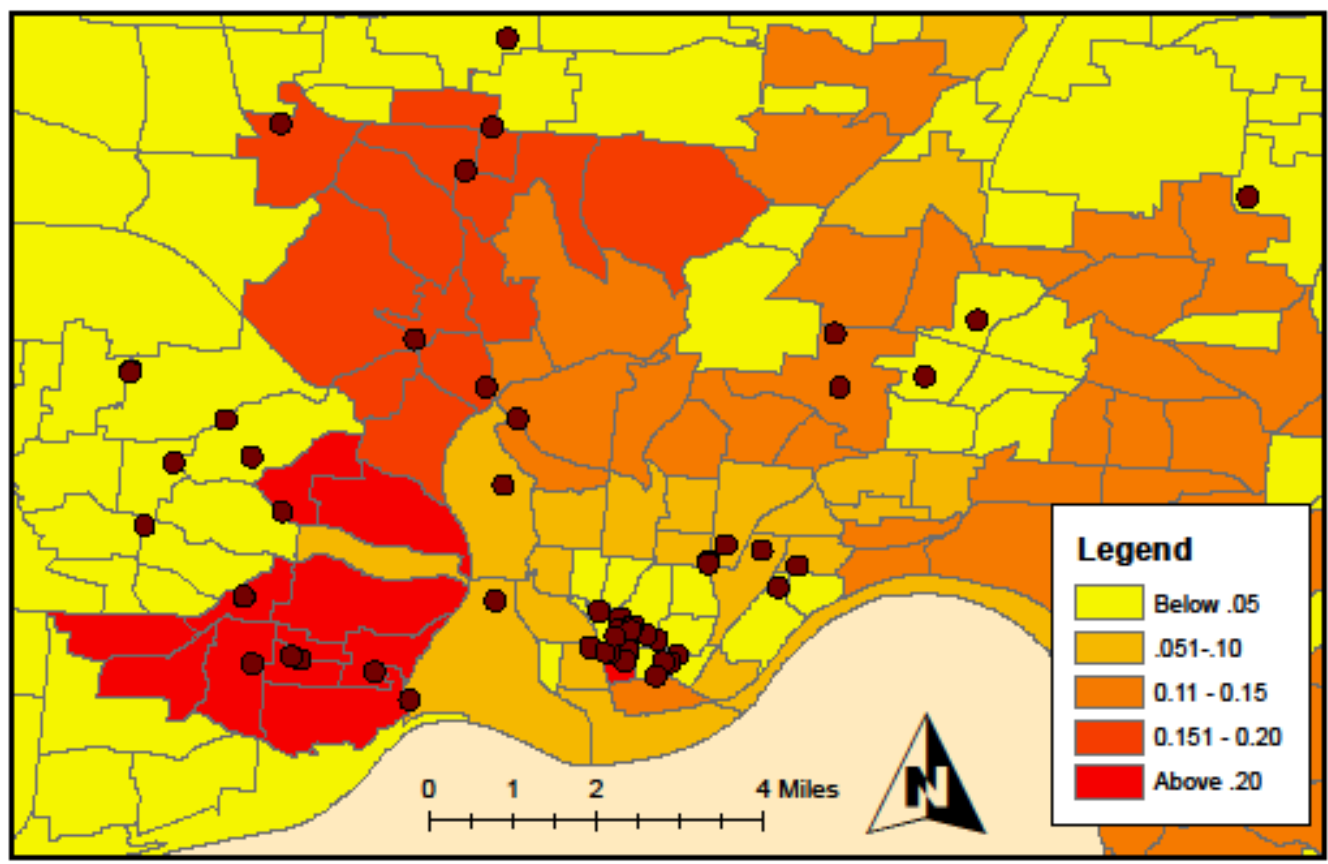

Figure 5.12. Crimes Per Capita 2013 Louisville/Jefferson County, Kentucky

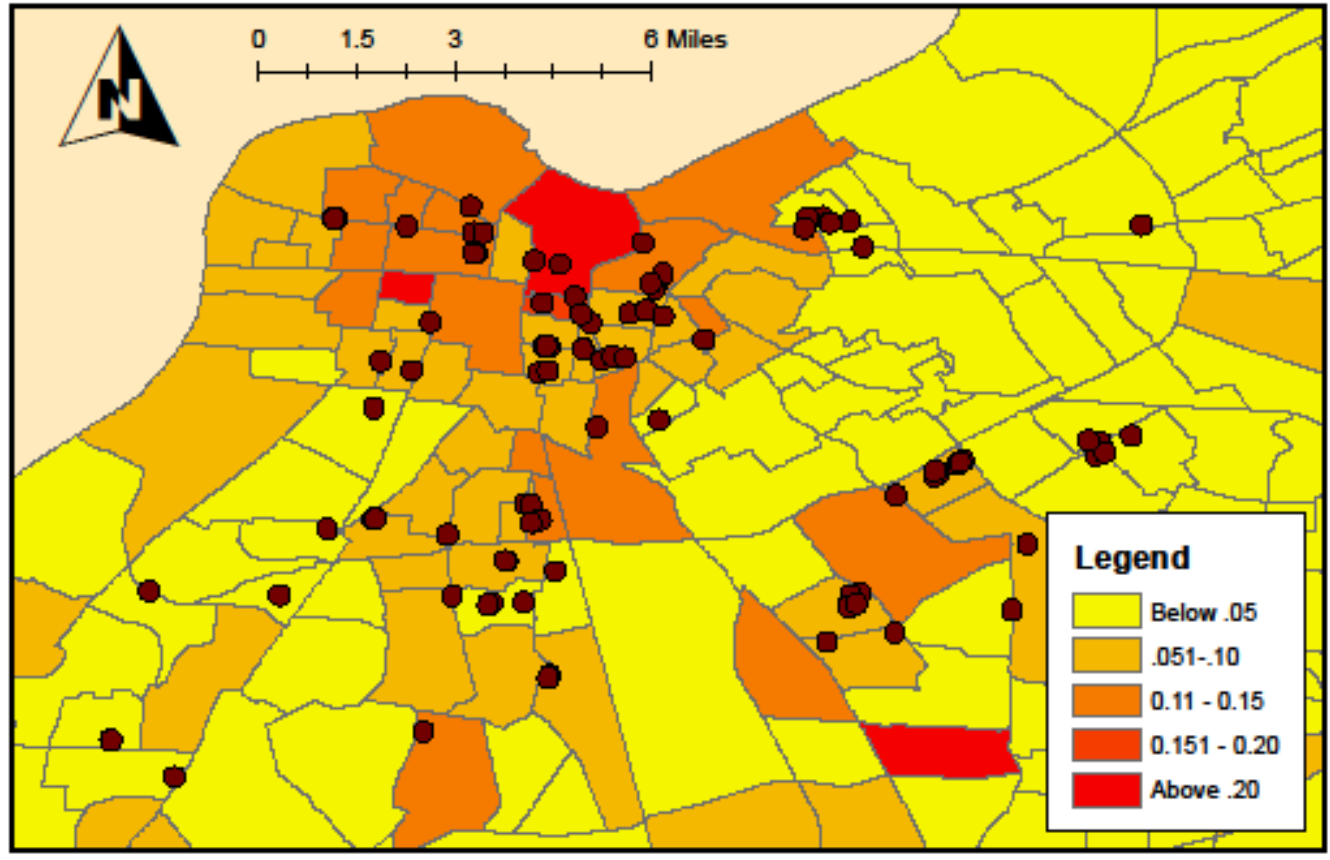


Table 5.4. Distribution of Crimes per Census Tract (2013)

\begin{tabular}{|c|c|c|c|c|c|}
\hline \multirow[t]{2}{*}{ Indicator: } & \multicolumn{3}{|c|}{$\begin{array}{l}\text { Cincinnati Pathways to Housing } \\
\text { Greater Cincinnati Behavioral } \\
\text { Health }\end{array}$} & \multicolumn{2}{|c|}{$\begin{array}{l}\text { Louisville Housing First } \\
\text { FHC-Phoenix }\end{array}$} \\
\hline & $\begin{array}{l}\text { Hamilton } \\
\text { County }\end{array}$ & $\begin{array}{l}\text { Scattered- } \\
\text { site }\end{array}$ & $\begin{array}{c}\text { Project- } \\
\text { based }\end{array}$ & $\begin{array}{c}\text { Jefferson } \\
\text { County }\end{array}$ & $\begin{array}{l}\text { Scattered- } \\
\text { site }\end{array}$ \\
\hline Number of tracts & 222 & 29 & 1 & 191 & 43 \\
\hline $\begin{array}{l}\text { Number of } \\
\text { crimes } \\
\text { reported in } 2013 \\
\text { - Mean } \\
\text { - Median } \\
\text { - Range }\end{array}$ & $\begin{array}{c}145 \\
32 \\
0-936\end{array}$ & $\begin{array}{l}353.6 \\
338.0 \\
0-705\end{array}$ & 392 & $\begin{array}{l}203 \\
155 \\
1-3,715\end{array}$ & $\begin{array}{c}402.1 \\
291.0 \\
1-3,715\end{array}$ \\
\hline $\begin{array}{l}\text { Crimes per } \\
\text { capita } \\
\text { - Mean } \\
\text { - Median } \\
\text { - Range } \\
\end{array}$ & $\begin{array}{c}.06 \\
.01 \\
0-.37\end{array}$ & $\begin{array}{c}.17 \\
.15 \\
0-.37\end{array}$ & $\begin{array}{l}.24 \\
.24 \\
.24\end{array}$ & $\begin{array}{c}.06 \\
.04 \\
0-.87\end{array}$ & $\begin{array}{c}.10 \\
.08 \\
0-.87\end{array}$ \\
\hline
\end{tabular}

The crime datasets used in this analysis capture more recent data than those used from the U.S. Census (2010) and American Community Survey (2011). Furthermore, the majority of housing placements in this study were made prior to 2010 . However, due to the small number of cases, it is unlikely that the location of placements would have affected the distribution of reported crimes. Thus, endogeneity should not be a problem in this dataset. It is also important to note that types of crime were not differentiated in this analysis. This was due to the fact that both datasets contained thousands of records and geocoding these records proved to be a very time intensive task. While it would have been beneficial to analyze this data by type of crime, constructing and geocoding separate databases for type of crime was not feasible. Furthermore, because crime at all levels can impact quality of life, all types of crime may very well be relevant indicators of neighborhood quality. Therefore, all types of crimes reported in 2013 were considered in aggregate to accommodate the time constraints of the project. 


\section{Individual Characteristics}

Demographic and behavioral health data were collected for participants at both GCBH and FHC-Phoenix to provide a description of the population being served and provide control variables for the empirical models presented in the next chapter. This information was collected from participant responses to their Government Performance Results Act (GPRA) surveys administered as part of each project's SAMHSA grants at participant intake. In addition to common demographic variables including gender, race, age, and income of participants, the GPRA also asked a number of questions about a participant's behavioral health status in the 30 days prior to project entry including questions about alcohol abuse, illegal drug use, mental health symptoms, and criminal involvement. This data proves helpful for this study because it captures the extent of behavioral health problems commonly experienced by project participants and allows for these behaviors to serve as control variables when testing the effect of neighborhood on housing placements for project participants.

Table 5.5 presents a comparison of general demographics for all participants to those in each of the three distinct programs: GCBH scattered-site, GCBH project-based (JHH), and FHC-Phoenix scattered-site). From 2008 to 2013, these programs served 227 unduplicated individuals. GCBH served 89 individuals, 51 of whom were placed in scattered-site housing and 38 at JHH. FHC-Phoenix housed 138 scattered-site participants. GCBH had a larger number of non-white participants compared to FHCPhoenix. Interestingly, while the racial composition of scattered-site participants at $\mathrm{GCBH}$ had a nearly even distribution, the majority of JHH participants were non-white. For all programs, the mean age was 48.9 years with little variation between scattered-site 
programs at GCBH and FHC-Phoenix. However, the mean age for JHH participants was slightly higher than that of scattered-site participants at both programs. Mean income in the past 30 days was $\$ 247$ for all participants with FHC-Phoenix participants reporting the highest incomes at $\$ 346$. Incomes for GCBH participants were much lower with means of $\$ 43$ for scattered-site participants and $\$ 160$ for JHH participants. One potential reason for this difference is that FHC-Phoenix also pairs participants with disabilities with a SOAR (SSI/SSDI Outreach Access and Recovery) social worker to help them facilitate disability claims so many participants may have been linked with benefits during the time they were preparing to enter housing. The mean income for FHCPhoenix was also inflated due to one participant reporting a mean monthly income of $\$ 3,000$. This participant had just received a back payment settlement as part of a disability claim at the time that he entered housing.

Table 5.5. Demographic Characteristics of Housing First Participants

\begin{tabular}{|l|c|c|c|c|}
\hline Characteristics & $\begin{array}{c}\text { All } \\
\text { Participants } \\
(\mathrm{n}=227)\end{array}$ & $\begin{array}{c}\text { GCBH } \\
\text { Scattered-Site } \\
(\mathrm{n}=51)\end{array}$ & $\begin{array}{c}\text { GCBH/JHH } \\
\text { Project-Based } \\
(\mathrm{n}=38)\end{array}$ & $\begin{array}{c}\text { FHC-Phoenix } \\
\text { Scattered-Site } \\
(\mathrm{n}=138)\end{array}$ \\
\hline Gender & $209(91.6 \%)$ & $48(94.1 \%)$ & $34(89.5 \%)$ & $126(93.1 \%)$ \\
- Male & $19(8.4 \%)$ & $3(5.9 \%)$ & $4(10.5 \%)$ & $12(8.7 \%)$ \\
- Female & & & & \\
\hline Race & $126(55.5 \%)$ & $26(51 \%)$ & $15(39.5 \%)$ & $85(61.6 \%)$ \\
- White & $101(44.5 \%)$ & $25(49 \%)$ & $23(60.5 \%)$ & $53(38.4 \%)$ \\
\hline - Non-White & & & & \\
\hline Age & 48.9 & 48.8 & 52.3 & 48 \\
- Mean & 49 & 49 & 51 & 48 \\
- Median & $28-75$ & $32-60$ & $41-65$ & $28-75$ \\
- Range & & & & \\
\hline Income in past & $\$ 247$ & $\$ 43$ & $\$ 160$ & $\$ 346$ \\
30 days & 0 & 0 & 0 & $\$ 100$ \\
- Mean & $0-\$ 3,000$ & $0-\$ 680$ & $0-\$ 985$ & $0-\$ 3,000$ \\
- Median & & & & \\
- Range & \multicolumn{2}{|r}{} \\
\hline
\end{tabular}


Table 5.6 captures participant reports of alcohol and illegal drug use in the 30 days prior to entering the program. The mean number of days of alcohol use for all participants was 14.2 and the mean number of days of illegal drug use was 6.5. The range of days of substance use across all categories and program types was 0 to 30 days. Interestingly, the mean number of days of substance use was substantially higher for GCBH participants compared to FHC-Phoenix participants. The GCBH program specifically serves homeless persons with alcohol dependency (chronic inebriates) which is likely to account for this variation. While FHC-Phoenix also has a focus on substance abuse, it does not target alcoholics and other substance users to the same extent as GCBH. Also, it is important to note that underreporting of substance use at GPRA intake has been a problem for SAMHSA grantees nationwide (Center for Substance Abuse Treatment 2013). This has been particularly problematic in Housing First projects where participants often do not believe staff when they are told that they will be allowed to remain in their housing regardless of their substance use. While it is likely participants at both agencies underreported use, those at GCBH may have been less likely to underreport because they had a stronger awareness that their program was structured to accommodate the needs of persons with active substance use.

Table 5.6. Days of Alcohol and Drug Use in 30 Days Prior to Intake

\begin{tabular}{|l|c|c|c|c|}
\hline Indicator & $\begin{array}{c}\text { All } \\
\text { Participants } \\
(\mathrm{n}=227)\end{array}$ & $\begin{array}{c}\text { GCBH } \\
\text { Scattered-Site } \\
(\mathrm{n}=51)\end{array}$ & $\begin{array}{c}\text { GCBH/JHH } \\
\text { Project-Based } \\
(\mathrm{n}=38)\end{array}$ & $\begin{array}{c}\text { FHC-Phoenix } \\
\text { Scattered-Site } \\
(\mathrm{n}=138)\end{array}$ \\
\hline Alcohol use & 14.2 & 26.1 & 22.4 & 7.5 \\
- Mean & 10 & 30 & 30 & 1 \\
- Median & 6.5 & 16.1 & 13.1 & 1.2 \\
\hline Illegal drug use & 20 & 10 & 0 \\
- Mean & 0 & & & \\
- Median & & & \\
\hline
\end{tabular}


Table 5.7 shows the incidence of mental health symptoms for participants in the 30 days prior to project entry. As the table shows, there was a slight variation in symptoms among the three programs. For all categories, the number of days of symptoms ranged from 0 to 30 days for all projects. JHH participants demonstrated the lowest incidence of symptoms. This was especially true for hallucinations, impaired brain function, and violent behavior. With the exception of trouble controlling violent behavior, FHC-Phoenix participants reported the highest incidence of mental health symptoms. Mean days of hallucinations and impaired brain function were nearly double for Phoenix participants compared to GCBH participants. Again, this may have been attributable to targeting of participants. As stated above, GCBH specifically targeted persons with alcoholism. While FHC-Phoenix did not target a specific subpopulation, many of the agency's consumers of mental health services were chosen as participants.

Table 5.7. Days of Mental Health Symptoms in 30 Days Prior to Intake

\begin{tabular}{|c|c|c|c|c|}
\hline Indicator & $\begin{array}{c}\text { All } \\
\text { Participants } \\
(\mathrm{n}=227)\end{array}$ & $\begin{array}{c}\text { GCBH } \\
\text { Scattered- } \\
\text { Site } \\
(\mathrm{n}=51)\end{array}$ & $\begin{array}{c}\text { GCBH/JHH } \\
\text { Project- } \\
\text { Based } \\
(\mathrm{n}=38) \\
\end{array}$ & $\begin{array}{c}\text { FHC-Phoenix } \\
\text { Scattered- } \\
\text { Site } \\
(n=138) \\
\end{array}$ \\
\hline $\begin{array}{l}\text { Serious depression } \\
\text { - Mean } \\
\text { - Median }\end{array}$ & $\begin{array}{c}9.8 \\
3\end{array}$ & $\begin{array}{c}9.6 \\
2\end{array}$ & $\begin{array}{c}8.6 \\
2\end{array}$ & $\begin{array}{c}10.1 \\
3.5\end{array}$ \\
\hline $\begin{array}{l}\text { Serious anxiety } \\
\text { - Mean } \\
\text { - Median }\end{array}$ & $\begin{array}{c}10.3 \\
2 \\
\end{array}$ & $\begin{array}{c}10 \\
0 \\
\end{array}$ & $\begin{array}{c}9.3 \\
0 \\
\end{array}$ & $\begin{array}{c}11 \\
4 \\
\end{array}$ \\
\hline $\begin{array}{l}\text { Hallucinations } \\
\text { - Mean } \\
\text { - Median }\end{array}$ & $\begin{array}{c}1.5 \\
0 \\
\end{array}$ & $\begin{array}{l}1 \\
0 \\
\end{array}$ & $\begin{array}{l}.3 \\
0\end{array}$ & $\begin{array}{l}2 \\
0 \\
\end{array}$ \\
\hline $\begin{array}{l}\text { Impaired brain } \\
\text { function } \\
\text { - Mean } \\
\text { - Median }\end{array}$ & $\begin{array}{c}8.9 \\
0\end{array}$ & $\begin{array}{c}6.4 \\
0\end{array}$ & $\begin{array}{c}2.4 \\
0\end{array}$ & $\begin{array}{c}11.7 \\
4\end{array}$ \\
\hline $\begin{array}{l}\text { Violent behavior } \\
\text { - Mean } \\
\text { - Median }\end{array}$ & $\begin{array}{c}1.8 \\
0\end{array}$ & $\begin{array}{c}2.3 \\
0\end{array}$ & $\begin{array}{l}.8 \\
0\end{array}$ & $\begin{array}{c}1.8 \\
0\end{array}$ \\
\hline
\end{tabular}


Table 5.8 captures involvement with the criminal justice system for participants in the 30 days prior to project entry including number of arrests and days spent in jail or prison. The mean number of arrests was .4 for all participants. JHH participants had the lowest mean number of arrests at .1; FHC-Phoenix had the highest mean number of arrests at .5. The range of number of arrests at FHC-Phoenix was also much larger with participants reporting as many as 25 arrests in one month. A similar trend is found for days in jail or prison with a mean of .7 days for all participants. JHH participants reported the lowest number of days incarcerated at .5; FHC-Phoenix participants reported the highest number of days incarcerated at .8. While the range of days incarcerated was similar for the two scattered-site programs, JHH participants exhibited a much lower range.

Table 5.8. Involvement with Criminal Justice System 30 Days Prior to Intake

\begin{tabular}{|l|c|c|c|c|}
\hline Indicator & $\begin{array}{c}\text { All } \\
\text { Participants } \\
(\mathrm{n}=227)\end{array}$ & $\begin{array}{c}\text { GCBH } \\
\text { Scattered- } \\
\text { Site } \\
(\mathrm{n}=51)\end{array}$ & $\begin{array}{c}\text { GCBH/JHH } \\
\text { Project-Based } \\
(\mathrm{n}=38)\end{array}$ & $\begin{array}{c}\text { FHC-Phoenix } \\
\text { Scattered- } \\
\text { Site } \\
(\mathrm{n}=138)\end{array}$ \\
\hline Number of arrests & .4 & .4 & .1 & .5 \\
- Mean & 0 & 0 & 0 & 0 \\
- Median & $0-25$ & $0-4$ & $0-2$ & $0-25$ \\
- Range & .7 & .7 & .5 & .8 \\
\hline Days in & 0 & 0 & 0 & 0 \\
jail/prison & $0-16$ & $0-12$ & $0-1$ & $0-16$ \\
- Mean & & & \\
- Median & & & \\
- Range & \multicolumn{3}{|c}{} \\
\hline
\end{tabular}

Table 5.9 reports administrative data on length of tenure for housing placements. This information is used to construct the dependent variables discussed in the following chapter. Of the 312 placements made, the mean number of days participants had been in their housing placement was 657 . For scattered-site participants, the average length of 
stay was similar at 631 for GCBH and 647 for FHC-Phoenix. The mean number of days housed for all JHH participants was higher at 768. As discussed in Chapter 4, participants at JHH have less mobility because their vouchers are attached to their specific units.

The second and third rows of Table 5.9 compare average length of stay in housing for non-movers versus movers. For scattered-site participants, the average length of stay in a placement was longer for non-movers than for movers. Only four JHH participants moved from their placements at the project (all forced) and their average length of stay was only somewhat shorter than that of JHH non-movers. The final two rows capture differences in the two types of moves, forced and other moves. Forced moves pertain to involuntary removals that were the direct result of the participant's actions. These included evictions, incarcerations, and termination from the project. Other moves refer to moves that were not directly attributable to adverse actions of the client, including voluntary relocation and landlord problems such as maintenance issues or a landlord's decision to no longer participate in the project. No JHH residents moved for this reason because the fixed structure of project-based site's housing subsidy does not allow participants to use their voucher to move to a new location. While the forced and other movers were almost evenly divided for GCBH participants, the number of forced moves was double that for other moves at FHC-Phoenix. For scattered-site participants at both projects, the average length of stay for forced moves was 226 days shorter than that of other movers. GCBH forced movers spent an average of 95 days less in their housing placement than other movers. At FHC-Phoenix, forced movers spent an average of 285 fewer days in their housing placement compared to other movers. 
Table 5.9. Number of Days in Housing First Housing Placement

\begin{tabular}{|l|c|c|c|c|}
\hline & $\begin{array}{c}\text { All } \\
\text { Placements }\end{array}$ & $\begin{array}{c}\text { GCBH } \\
\text { Scattered-Site }\end{array}$ & $\begin{array}{c}\text { GCBH/JHH } \\
\text { Project-Based }\end{array}$ & $\begin{array}{c}\text { FHC-Phoenix } \\
\text { Scattered-Site }\end{array}$ \\
\hline All participants & & & & \\
- Total & 312 & 77 & 38 & 197 \\
- Mean & 657 & 631 & 768 & 647 \\
- Median & 560 & 550 & 905 & 540 \\
- Range & $12-1,993$ & $60-1,343$ & $33-1,442$ & $12-1,993$ \\
\hline Non-movers & & & & \\
- Total & 194 & 53 & 34 & 107 \\
- Mean & 715 & 661 & 772 & 724 \\
- Median & 676 & 560 & 1,015 & 672 \\
- Range & $33-1,993$ & $60-1,343$ & $33-1,442$ & $34-1,993$ \\
\hline Any movers & & & & 90 \\
- Total & 118 & 24 & 4 & 554 \\
- Mean & 563 & 565 & 737 & 428 \\
- Median & 465 & 545 & 839 & $12-1,455$ \\
- Range & $12-1,455$ & $71-1,145$ & $342-929$ & 60 \\
\hline Forced movers & & & & 460 \\
- Total & 77 & 13 & 7 & 374 \\
- Mean & 484 & 521 & 737 & $40-1,307$ \\
- Median & 409 & 469 & 839 & 30 \\
- Range & $40-1,307$ & $71-1,145$ & $342-929$ & $12-1,455$ \\
\hline Other movers & & & & \\
- Total & 41 & 11 & 0 & \\
- Mean & 710 & 616 & & \\
- Median & 705 & 552 & & \\
- Range & $12-1,455$ & $335-971$ & & \\
\hline
\end{tabular}

The data presented above illustrate similarities and differences between GCBH (scattered-site and project-based) and FHC-Phoenix participants. Overall, the data show that, while the two programs served similar populations, GCBH participants were more likely to report greater use of alcohol and illegal drugs. Conversely, FHC-Phoenix participants were more likely to report higher incidences of mental health problems and involvement with the criminal justice system. Interestingly, the starkest differences in individual characteristics were for those persons living at JHH compared to scattered-site participants in both Cincinnati and Louisville. Demographically, these participants tended 
to be older and were more likely to be non-white than those in scattered-site housing placements. Behaviorally, they reported lower rates of substance use, mental health symptoms, and involvement with the criminal justice system. Their length of stay in their housing placements were longer than that of other participants which may be partly attributable to behavioral differences but also likely a result of a much lower rate of forced moves as well as policies that reduce the ease of voluntary moves for $\mathrm{JHH}$ participants.

The beginning of the chapter described the characteristics of the neighborhoods of the housing placements inhabited by these participants. Overall, the data conveyed that Housing First participants were more likely to live in lower quality neighborhoods than other residents of their respective cities. This difference was the starkest for Cincinnati participants, especially those at JHH. The following chapter will use this neighborhood data to empirically test whether these factors had an effect on the likelihood of either a forced or other move occurring. Data presented on individual characteristics show other differences between the two groups and will be used in the upcoming analysis to control for demographic and behavioral characteristics. 


\section{CHAPTER 6}

\section{QUANTITATIVE FINDINGS}

Chapter 5 provided a detailed discussion of data pertaining to the neighborhood and housing characteristics of Housing First placements in Cincinnati and Louisville as well as that of personal characteristics of project participants. The current chapter will specify a series of statistical models that will be used to test whether or not these characteristics influenced residential stability for project participants. Each of the individual and neighborhood characteristics discussed in Chapter 5 will be used to construct independent variables to be tested within both binary logistic regression and Cox (survival) regression models. As discussed in Chapter 3, residential stability will be tested in the context of two different dependent variables: Forced Moves and Other Moves. Forced Moves pertain to those moves that were directly the fault of the participant and could include eviction, failure to pay rent, incarceration or termination from the program. Other Moves include moves that were not directly attributable to problems with the participant, such as voluntary moves and property issues including maintenance problems or a landlord deciding to no longer accept housing vouchers.

Each of the models below is specified as described in the equations in Chapter 3 with the exception of the variable, $J H H$. Originally intended to identify persons living in the Jimmy Heath Housed project-based site in Cincinnati, this dummy variable turned out to be problematic because virtually all of the JHH clients are non-movers, and none fall into the category of Other Moves. As discussed in Chapter 4, interviews with GCBH's 
staff revealed that participants were locked into these vouchers and did not have the same freedom to move with their vouchers that scattered-site participants have. If a participant wishes to move to a scattered-site placement, he or she must first become homeless again. Furthermore, because of the nature of the program, JHH housing management staff are likely to be more tolerant of behavioral issues and thus less likely to evict participants. Otherwise, each of the models below follows the specifications described in Chapter 3.

\section{Principal Components Analysis}

A quick examination of the variables to be considered for these analyses leads to the logical inference that many of them will likely demonstrate a high degree of correlation. This is especially likely for two groups: 1) individual and behavioral characteristics and 2) neighborhood characteristics. Appendices 6.1 and 6.2 provide collinearity statistics, including Variance Inflation Factors and pairwise correlations (Pearson Correlations), for each of the variables and demonstrates that issues of multicollinearity should be addressed in order for the regression analyses to provide viable results. While all variables are of interest to the research questions at hand, they need to be combined in a fashion that allows their combined effect to be demonstrated. To address these issues, Principal Components Analysis (PCA) is used as a method for identifying correlations within the dataset and developing a considerably smaller set of factors that account for these intercorrelations (Carini 2008). Table 6.1 demonstrates the results of the PCA analysis when all independent variables, excluding dummy variables, are included. The Kaiser-Meyer-Olkin (KMO) statistic of sampling adequacy was .687, indicating a medium level of adequacy. Bartlett's Test of Spericity statistic was significant, allowing the rejection of the null hypothesis that all correlations are equal to 
zero. The analysis generated six components with Eigenvalue scores greater than one.

The first four of these components had particularly high Eigenvalue scores of 4.17, 2.87,

1.70, and 1.50 respectively. Each of these four components also included a number of variables with relatively high factor loadings of .5 or greater (in absolute value).

Table 6.1. PCA Analysis Component Matrix

\begin{tabular}{|l|c|c|c|c|c|c|}
\hline \multirow{2}{*}{ Variable } & \multicolumn{7}{|c|}{ Component } \\
\cline { 2 - 7 } & $\mathbf{1}$ & $\mathbf{2}$ & $\mathbf{3}$ & $\mathbf{4}$ & $\mathbf{5}$ & $\mathbf{6}$ \\
\hline Age & -.185 & .010 & .000 & .257 & -.407 & .659 \\
\hline Participant Income & .266 & .136 & -.208 & -.222 & .528 & .538 \\
\hline Days of Alcohol Use & -.244 & .462 & .633 & .339 & -.024 & -.097 \\
\hline Days of Drug Use & -.253 & .433 & .423 & .388 & .424 & -.102 \\
\hline Days of Serious Depression & .204 & .644 & -.257 & .308 & -.277 & -.089 \\
\hline Days of Serious Anxiety & .253 & .554 & -.322 & .498 & -.165 & -.073 \\
\hline Days of Hallucinations & .283 & .565 & -.217 & -.197 & .289 & .004 \\
\hline $\begin{array}{l}\text { Days of Impaired Brain } \\
\text { Function }\end{array}$ & .319 & .438 & -.556 & .136 & -.091 & -.002 \\
\hline Days of Violent Behavior & .168 & .622 & -.109 & -.138 & .371 & -.039 \\
\hline Number of Arrests & .214 & .608 & .345 & -.514 & -.265 & .022 \\
\hline Number of Days Incarcerated & .232 & .533 & .359 & -.528 & -.327 & .080 \\
\hline Population Density & -.677 & .158 & -.053 & .043 & -.002 & .299 \\
\hline Percent of Vacant Dwellings & -.796 & .215 & .144 & .143 & .106 & .183 \\
\hline $\begin{array}{l}\text { Percent of Households in } \\
\text { Poverty }\end{array}$ & -.850 & .248 & -.136 & -.112 & -.025 & .014 \\
\hline Median Household Income & .804 & -.185 & .250 & .220 & .015 & .024 \\
\hline Distance to Nearest Bus Stop & .329 & .049 & .316 & .225 & .072 & .275 \\
\hline $\begin{array}{l}\text { Distance to Central Business } \\
\text { District }\end{array}$ & .779 & -.104 & .297 & .143 & .111 & .115 \\
\hline Crimes Per Capita & & & & & & \\
\hline
\end{tabular}

As shown in table 6.1, the first component contains factors that load heavily on indicators of neighborhood quality including population density, percentage of vacant dwellings, percentage of households below the poverty line, median household income, distance to the central business district (CBD), and crimes per capita. The only neighborhood indicator to not exemplify high factor loadings was distance to bus stops. Factor loadings for density, vacancy, poverty, and crimes per capita all demonstrated 
negative factor loadings while median household income and distance to the CBD demonstrated positive factor loadings. This indicates that high factor scores are associated with higher quality neighborhoods.

The second component contains loadings heavily influenced by the behavioral health characteristics assessed through the participant's intake GPRA survey. Symptoms of mental illness, including depression, anxiety, hallucinations, and trouble controlling violent behavior, all had factor loadings greater than positive .5 , as did indicators of criminal involvement including number of arrests and days spent in jail. The third and fourth components also capture behavioral health factors. In component 3 , the variable Days of Alcohol Use had the strongest loading of .633. Interestingly, this factor also included a strong but negative factor loading for Days of Impaired Brain Function, suggesting an inverse relationship between this variable and alcohol use. The fourth component captures heavy loadings for the criminal justice factors Number of Arrests and Number of Days of Incarcerated, which also loaded heavily for component 2. Interestingly, in this component, the factor loadings for both of these indicators of criminal involvement are negative.

Components 1 through 4 demonstrate high factor loadings among multiple variables that suggest they capture an important aspect of the interplay among the independent variables. However, components 5 and 6 demonstrate less clear relationships with Eigenvalue scores of 1.2 and 1.0 respectively. Component 4 loads heavily only on one factor, income. While component 6 loads heavily on two variables, income and age, the low Eigenvalue score suggests the factor is not a good fit for the model. Instead, these variables are included independently in the analysis. Therefore, factor scores were 
generated for each of the first four components discussed above to serve as cumulative measures for the variables that loaded most heavily. Component 1 is named Neighborhood Quality as it represents all neighborhood characteristics except for distance to the nearest bus stop. Component 2 is named Behavioral Problems as it captures behavioral health problems such as mental health symptoms as well as criminal activity. Component 3 is named Alcohol Abuse as it most heavily loads on this variable. The fourth component is named Law Abiding as it is inversely related to criminal activity.

\section{Regression Modeling}

Using the principal components described above, a series of regression models was structured to test how these variables impacted housing stability. Dummy variables and continuous variables that did not load heavily on any of the first four components are specified separately in each model with the exception of Days of Drug Use. Because both Forced Moves and Other Moves are of interest to the research questions at hand, each of these outcomes was specified as a dependent variable in separate models. As described in Chapter 3, two methods of regression analysis were tested, binary logistic modeling and survival analysis (Cox regressions). Binary logistic regression was included because it tests the probability that a certain event (in this case a Forced Move or Other Move) will occur. Because time spent in a housing placement may impact whether or not these events will occur, Cox regressions were also specified and tested as well. The primary difference in these two methods is that binary models estimate the odds ratio for a move occurring while the central statistical output for the Cox model is the hazard ratio, which assesses the relationship between time in housing (survival time) and the covariates (Bian 2014). Both models will be compared below to determine 
whether or not this factor is important in the determining the likelihood of a housing turnover.

\section{Binary Logistic Regression Models}

Tables 6.2 and 6.3 show the results of the binary logistic model when specifying Forced Moves as the dependent variable. Table 6.2 (classification table) depicts the results when specifying a binary model. Since the correct number of predictions was 237 $(228+9)$, the overall proportion of accurate predictions for this model is $237 / 312=.760$. This is based on rounding predicted values of .5 or higher up to one and values less than .5 down to zero. The Cox and Snell R-Square was .105, and the Nagelkereke R-square was .156. The -2LL value (-2 time the log of the likelihood) for the model is 314.17.

Table 6.2. Classification Table for Forced Moves

\begin{tabular}{|c|c|c|c|c|}
\hline \multirow[b]{3}{*}{ Observed } & & \multicolumn{3}{|c|}{ Predicted } \\
\hline & & \multicolumn{2}{|c|}{ Forced Move } & \multirow{2}{*}{$\begin{array}{c}\text { Percentage } \\
\text { Correct }\end{array}$} \\
\hline & & .00 & 1.00 & \\
\hline \multirow{2}{*}{$\begin{array}{l}\text { Forced } \\
\text { Move }\end{array}$} & .00 & 228 & 7 & 97.0 \\
\hline & 1.00 & 68 & 9 & 11.7 \\
\hline \multicolumn{2}{|c|}{$\begin{array}{l}\text { Overall } \\
\text { Percentage }\end{array}$} & & & 76.0 \\
\hline
\end{tabular}

Table 6.3 lists the coefficients for each of the variables in the binary logistic equation. This model contains three statistically significant coefficients: Cincinnati, Behavioral Problems, and Alcohol Abuse. Statistical significance is defined for this study to be at the 10 percent level of better, based on a two-tailed test, 
Table 6.3. Binary Logistic Regression: $\mathrm{DV}=$ Forced Moves

\begin{tabular}{|l|r|r|r|r|}
\hline Variable & \multicolumn{1}{|c|}{ B } & \multicolumn{1}{c|}{ S.E. } & \multicolumn{1}{c|}{ Sig. } & Exp(B) \\
\hline Cincinnati & -.629 & .347 & .070 & .533 \\
Age & -.014 & .021 & .506 & .986 \\
Female & .123 & .488 & .800 & 1.131 \\
Non-White & .153 & .296 & .605 & 1.165 \\
Participant Income & .000 & .000 & .161 & 1.000 \\
Distance to Bus & .000 & .000 & .425 & 1.000 \\
Neighborhood Quality & .182 & .150 & .225 & 1.200 \\
Behavioral Problems & .426 & .139 & .002 & 1.532 \\
Alcohol Abuse & -.405 & .158 & .010 & .667 \\
Law Abiding & -.064 & .138 & .644 & .938 \\
Constant & -.597 & 1.017 & .558 & .551 \\
\hline
\end{tabular}

The independent variables in this model can be interpreted for their effect in terms of the anti-logarithm of the unstandardized coefficients as indicated in the last column, labeled $\operatorname{Exp}(B)$. They can also be interpreted in terms of their percent change in odds using the following formula:

$$
\text { Percent Change in the Odds }=100 *\left[\exp \left(B_{j}\right)-1\right]
$$

As expected the dummy variable Cincinnati has a negative effect on the likelihood that a forced move will occur. The coefficient for this variable can be interpreted to mean that for participants in Cincinnati, the relative risk of a Forced Move is a factor of .533 that of Louisville participants, all other variables held constant. In other words, the odds of a Forced Move in Cincinnati are 46.7 percent less than in Louisville. This finding makes sense considering that the programs have different procedures for terminating participants as previously revealed through interviews with administrative staff.

It would also appear logical that behavioral health has a positive effect on the odds of a Forced Move occurring because behavioral health problems such as mental 
health symptoms and criminal activity will likely impact an individual's likelihood of being able to maintain residential stability. However, the second behavioral health component, Alcohol Abuse, has an unexpected negative effect on the dependent variable of housing exit, suggesting that those who abuse alcohol are less likely to be move. While this may initially seem counterintuitive to logic, the nature of the program would suggest otherwise. Because GCBH and FHC-Phoenix both operate as Housing First programs, participants are not required to maintain sobriety. Thus, those with heavy alcohol use should not be any more likely than other participants to move as long as they are able to maintain rent payments and comply with the terms of their lease. All other independent variables in this equation, including the Neighborhood Quality component, are not statistically significant, suggesting that neighborhood characteristics had no influence over whether or not a forced move occurred.

As demonstrated in Tables 6.4 and 6.5, the second model specifies Other Moves as the dependent variable. The classification table depicts the results when specifying a binary model.

Table 6.4. Classification Table for Other Moves

\begin{tabular}{|c|c|c|c|}
\hline \multirow[b]{3}{*}{ Observed } & \multicolumn{3}{|c|}{ Predicted } \\
\hline & \multicolumn{2}{|c|}{ Other Moves } & \multirow{2}{*}{$\begin{array}{l}\text { Percentage } \\
\text { Correct }\end{array}$} \\
\hline & .00 & 1.00 & \\
\hline \multirow{2}{*}{$\begin{array}{l}\text { Other } \\
\text { Moves }\end{array}$} & 268 & 3 & 98.9 \\
\hline & 40 & 1 & 2.4 \\
\hline $\begin{array}{l}\text { Overall } \\
\text { Percentage }\end{array}$ & & & 86.2 \\
\hline
\end{tabular}


Since the correct predictions was $269(268+1)$, the prediction accuracy for this model is 269/312=.862. The Cox and Snell R-Square was .084 , and the Nagelkereke R-square was .156. The -2LL value for the model was 215.29 .

Table 6.5 lists the coefficients for each of the variables in the binary logistic equation. The binary model contains three statistically significant coefficients: Age, Participant Income, and Neighborhood Quality.

Table 6.5. Binary Logistic Regression: DV $=$ Other Moves

\begin{tabular}{|l|r|r|r|r|}
\hline & \multicolumn{1}{|c|}{ B } & \multicolumn{1}{c|}{ S.E. } & Sig. & Exp(B) \\
\hline Cincinnati & -.405 & .423 & .338 & .667 \\
Age & -.086 & .028 & .002 & .917 \\
Female & -.142 & .609 & .816 & .868 \\
Non-White & -.003 & .386 & .994 & .997 \\
Participant Income & -.001 & .001 & .085 & .999 \\
Distance to Bus & .000 & .000 & .320 & 1.000 \\
Neighborhood Quality & -.477 & .183 & .009 & .620 \\
Behavioral Problems & -.328 & .306 & .285 & .721 \\
Alcohol Abuse & .131 & .207 & .527 & 1.140 \\
Law Abiding & -.108 & .190 & .571 & .898 \\
Constant & 2.521 & 1.340 & .060 & 12.444 \\
\hline
\end{tabular}

In this equation, the Neighborhood Quality component's negative and significant coefficient presents the most interesting finding as it suggests that placement in neighborhoods of higher quality result in a greater likelihood that the participant will remain in the unit. For each unit of improvement in Neighborhood Quality, the odds of a participant being moved for other reasons changes by a factor of .620 holding all other variables constant. In other words, each unit of increase in Neighborhood Quality will mean that the odds of moving from the housing placement will decrease by 37.9 percent. Neighborhood Quality scores ranged from negative 3.1 to positive 2.1 with a mean of 0 
and a standard deviation of 1 . Therefore, these scores essentially represent a five-point scale with the odds of moving decreasing 37.9 percent with each increase in standard deviation. The variable Age has a negative effect on the likelihood of an Other Moves, which is logical since age is likely to impact an individual's mobility. Participant Income's negative effect can be explained by the fact that higher incomes may allow participants to remain in nicer neighborhoods.

\section{Survival Analysis}

After constructing binary logistic models to test the likelihood that neighborhood would impact residential stability in the program, survival analysis (Cox regression models) was also conducted to see if the likelihood of moving from a housing placement for either forced or other reasons would be influenced by the length of a participant's stay in his or her housing placement. The Cox regression model is similar to the binary logistic model. However, unlike the logistic model which aims to estimate the odds ratio, Cox regression aims to estimate the hazards ratio instead by taking into account the time taken before a particular event (exit from housing) happens (Sainani 2014). In the models described below, the Cox regression estimates the hazards rate for housing exits as it changes over time (days spent in housing placement). Table 6.6 shows the regression coefficients for our equation when Forced Moves is selected as the dependent variable. Unlike binary logistic regression, SPSS does not produce prediction accuracy statistics. However, SPSS does provide -2LL statistics for iterations of the model both with and without (constant only) the addition of independent variables. For Forced Moves, the 2LL value was 794.03 for the constant only and 763.08 for the model will all independent variables specified. 
Table 6.6. Cox Regression: $\mathrm{DV}=$ Forced Moves

\begin{tabular}{|c|c|c|c|c|}
\hline & $\mathrm{B}$ & SE & Sig. & $\operatorname{Exp}(B)$ \\
\hline Cincinnati & -.539 & .316 & .088 & .583 \\
\hline Age & -.020 & .018 & .258 & .980 \\
\hline Female & .069 & .419 & .870 & 1.071 \\
\hline Non-White & .075 & .243 & .757 & 1.078 \\
\hline Participant Income & .000 & .000 & .355 & 1.000 \\
\hline Distance to Bus & .000 & .000 & .278 & 1.000 \\
\hline $\begin{array}{l}\text { Neighborhood } \\
\text { Quality }\end{array}$ & .135 & .130 & .301 & 1.144 \\
\hline $\begin{array}{l}\text { Behavioral } \\
\text { Problems }\end{array}$ & .248 & .072 & .001 & 1.281 \\
\hline Alcohol Abuse & -.341 & .133 & .010 & .711 \\
\hline Law Abiding & .034 & .130 & .791 & 1.035 \\
\hline
\end{tabular}

Table 6.6 demonstrates results similar to those seen in the binary logistic model in Table 6.3. Once again, the significant independent variables for the equation are Cincinnati, Behavioral Problems, and Alcohol Abuse. These coefficients can also be interpreted as the hazard rate as identified by the value in the column headed $\operatorname{Exp}(\mathrm{B})$. The coefficients for the Cincinnati dummy variable indicate that the hazard of a forced move occurring is decreased 41.7 percent for participants in Cincinnati. Once again, the effect of the Behavioral Problems and Alcohol Abuse components are shown to have opposite effects.

Table 6.7 demonstrates the regression coefficients for the survival model when Other Moves is specified as the dependent variable. For Other Moves, the -2LL value was 386.68 for the model specified with only the constant and 358.02 for the model will all independent variables specified. Like the survival model for Forced Moves, this model yields similar results to the binary logistic models described above. Like the binary model, the independent variables of significance include Age, Participant Income, and 
the Neighborhood Quality component. For every factor increase in Neighborhood Quality, the hazard rate of Other Moves decreases 34.6 percent. The significance of this component in the Cox model confirms that the significant relationship found in the binary model holds true when accounting for duration of a participant's stay in housing.

Table 6.7. Cox Regression: DV = Other Moves

\begin{tabular}{|c|c|c|c|c|}
\hline & B & SE & Sig. & $\operatorname{Exp}(B)$ \\
\hline Cincinnati & -.295 & .396 & .457 & .745 \\
\hline Age & -.083 & .025 & .001 & .920 \\
\hline Female & -.016 & .549 & .977 & .984 \\
\hline Non-White & -.049 & .373 & .896 & .953 \\
\hline $\begin{array}{l}\text { Participant } \\
\text { Income }\end{array}$ & -.001 & .001 & .063 & .999 \\
\hline $\begin{array}{l}\text { Distance to } \\
\text { Bus }\end{array}$ & .000 & .000 & .552 & 1.000 \\
\hline $\begin{array}{l}\text { Neighborhood } \\
\text { Quality }\end{array}$ & -.425 & .177 & .016 & .654 \\
\hline $\begin{array}{l}\text { Behavioral } \\
\text { Problems }\end{array}$ & -.331 & .294 & .262 & .719 \\
\hline $\begin{array}{l}\text { Alcohol } \\
\text { Abuse }\end{array}$ & -.016 & .197 & .934 & .984 \\
\hline Law Abiding & .003 & .200 & .986 & 1.003 \\
\hline
\end{tabular}

The Cox regression results produce results very similar to that of our binary logistic models. While the Cox model does not produce R-square values to compare goodness of fit, the -2LL statistic provides some means of comparison for the models. Given that the four models discussed have the same number of degrees of freedom, lower -2LL values should indicate whether binary logistic or Cox models serve as a better fit. Models with a good fit will result in a high likelihood of getting the observed results which translates into a small value for -2LL (Carini 2008). For the binary logistic models, -2LL was 314.17 for Forced Moves and 215.29 for Other Moves. For the Cox models, -2LL was 763.08 for Forced Moves and 358.02 for Other Moves. The lower - 
2LL values of the binary logistic models suggest that they are better fit for analyzing the dataset used in this study. This is especially true for the Forced Moves model which produced an exceptionally high -2LL value. The rationale for using survival analysis was to account for the fact that time in housing would likely impact the outcome of whether or not a person moved from their housing placement. The better fit of the binary logistic models suggest that other factors, namely behavioral characteristics in the case of Forced Moves and neighborhood characteristics in the case of Other Moves, are more indicative to the likelihood of a move than time spent in housing. Furthermore, the similarity in the results for the two types of models suggests them to be be robust.

\section{Testing of Individual Neighborhood Factors}

The binary logistic and Cox regression models described above yielded interesting findings on the effect of characteristics of neighborhood quality for those moves classified as Other Moves. For each of these models, Neighborhood Quality was based on a component generated through PCA that captured the characteristics of population density, households in poverty, median household income, dwelling unit vacancies, distance to the $\mathrm{CBD}$, and crimes per capita. Each of these factors interact together to measure related aspects of neighborhood quality. As this component was consistently significant in the binary logistic and survival models, it is pertinent to consider what the independent impact of each of these independent variables would be when removing the other variables that comprise each of these components. However, because the four chosen components work together, all other factors comprising our components should be considered for their independent effects as well. Therefore, the models for Other Moves were re-estimated with all independent variables (both 
neighborhood and individual characteristics) as specified in their original form (pre-PCA analysis).

Binary logistic and Cox models were estimated using all independent variables in their original form. For both models, the variables of age and income maintained statistical significance $(\mathrm{p}<.1)$ and their original negative sign indicating that increases in both age and income would decrease the likelihood or hazard of a move occurring. Of the variables that comprised the Neighborhood Quality component, only Poverty was significant $(\mathrm{p}<.05)$. However, both binary and Cox models unexpectedly produced a negative sign for this variable suggesting that as the percentage of poverty increases in a census tract, the likelihood of a move will decrease. For the binary model, a coefficient of -.116 indicates that for every percent increase in poverty within the tract, the odds of a move occurring will increase by a factor of .89 or by 11 percent. For the survival models, the coefficient of -.126 indicates that for every percent increase in poverty, the hazard of a move occurring will decrease 11.8 percent. These results conflict with that of the model including the component score for Neighborhood Quality, which suggested that lower levels of poverty contributed to higher levels of neighborhood quality which in turn decreased the likelihood of a move occurring.

To determine whether this may have been a result of interaction with other variables, the models were estimated again, this time removing all neighborhood variables except for poverty. Again, results produced significant yet negative coefficient values of -.038 for the binary model and -.043 in the Cox model. To determine whether the other neighborhood variables produced a similar effect, they were also each tested independently in both binary logistic and Cox regression models. Only Median Income 
was statistically significant $(\mathrm{p}<.1)$ but the magnitude of the coefficient was too small to produce interpretable results. The reversal of the sign for Poverty, along with the low magnitude of Median Income and insignificance of the other neighborhood variables, suggest that the Neighborhood Quality component captures the interaction of the neighborhood factors in a way not demonstrated when each of these variables stand alone.

\section{Conclusion}

This chapter has presented results of both binary logistic and Cox regression models for the dependent variables of Forced Moves and Other Moves using a Neighborhood Quality component generated by PCA analysis. Results of these analyses suggest that Neighborhood Quality does affect residential stability but in a different way than expected. For Forced Moves, Neighborhood Quality was not statistically significant but instead Behavioral Problems and Alcohol Abuse served as significant influences on the likelihood of a move occurring. This suggests that personal attributes are a more influential determinant of housing stability than neighborhood characteristics. This finding is logical considering these moves were directly attributable to the actions of the participant including dismissal from the program, incarceration, or eviction. However, Neighborhood Quality did demonstrate a significant and negative impact for both the binary and Cox models that tested Other Moves as the dependent variable. These moves pertained to circumstances not directly attributable to the behavior of the client such as voluntary moves or building maintenance problems. As Neighborhood Quality improved, the likelihood or hazard of an Other Moves occurring diminished. These 
results suggest that participants living in higher quality neighborhoods will be more likely to remain to achieve housing stability.

The smaller -2LL statistics for the binary logistic regression models suggest that this modeling had more predictive power than the Cox regression models which accounted for days spent in housing. While these two models essentially measure two different types of outcomes, odds for binary models and hazard rate for Cox models, the magnitude of their coefficients also offer some means for comparison as well. For the logistic model, the effect of a unit of change in Neighborhood Quality was a 37.8 percent decrease in the odds of an Other Moves occurring. For the Cox model, the effect was a 34.6 decrease in the hazard of an Other Moves occurring. The slightly higher magnitude of the binary logistic coefficient, along with consideration for the more simplistic design of this type of model, suggest that the binary modeling technique provide a more meaningful results for demonstrating the influence of neighborhood variables on housing stability. 


\section{CHAPTER 7}

\section{CONCLUSION}

The goal of this study is to examine the relationship between neighborhood characteristics and housing stability for two Housing First projects. The study has focused on FHC-Phoenix's Louisville Housing First Project in Louisville, Kentucky, and GCBH's Paths to Recovery in Cincinnati, Ohio. The two programs are very similar except that the Cincinnati project includes both scattered-site and project-based housing while the Louisville project only includes scattered-site housing. The presence of the 25 unit Jimmy Heath House in Cincinnati allowed the study to also make comparisons between project-based and scattered-site housing. The study is framed by the five research questions posed in Chapter 1, which are intended to address the processes for making Housing First placements and describe the neighborhood characteristics of these placements as well as analyze project outcomes to determine whether or not these characteristics had any effect on housing stability. Chapter 2 reviewed literature on homelessness, Housing First, and the impacts of neighborhood and housing type. Chapter 3 detailed the methods used to answer the proposed research questions, and Chapters 4 through 6 discussed the findings of each component of the study. This chapter provides a summary of how the findings of this study have addressed questions 1 through 4 and answers question 5 through a cumulative discussion of these findings. 
1. What factors determine the location/housing type of a Housing First placement? What housing and neighborhood characteristics are most desired by project participants?

2. What are the characteristics (social, economic, etc.) of the neighborhoods in which Housing First participants live? Do these characteristics match the preferences of the program and its participants?

3. How do housing stability outcomes in a scattered-site Housing First project differ from those of a single-site project?

4. How do neighborhood characteristics impact the success of a Housing First project in meeting its housing stability goals?

5. What are the implications of this evaluation for designing and implementing future Housing First projects?

\section{Summary of Findings}

In Chapter 4, interviews with administrators, direct service staff, and project participants at the two projects were analyzed to better understand the housing placement process as well as what staff and participants felt were the most important characteristics of housing and neighborhood. Interviews with administrators at these two projects discussed how scattered-site housing vouchers were their preferred method of providing housing because they best correspond with the Housing First model and also because they felt scattered-site housing provided a more integrated and normalizing environment than project-based housing. GCBH's project manager stated that opposing preferences of community partners led his project to implement a dual housing approach that includes both scattered-site and project-based housing. Most administrators and direct services staff alike stated a preference for scattered-site housing because they saw it as more normalizing. However, there was also a strong consensus that project-based housing may 
better serve the needs of some participants especially those with more severe behavioral problems. While most staff members felt that neighborhood was an important component of the program, there was strong agreement that it was not the most important. Instead, they saw access to services and individual determination as more critical components to keeping participants stably housed.

Interviews with all three groups also discussed the range of housing options available to participants and the degree of choice that participants had in choosing their housing. While interviews demonstrated that participants had a great amount of autonomy in choosing their own housing, they also revealed that case managers were very involved in the decision making process. The extent of involvement varied depending upon the participant's needs and abilities, with some participants finding housing on their own and others relying solely on the case manager to find their housing placement. For participants in Cincinnati, the phased implementation of the project meant that original participants had little choice over whether they moved into project-based or scattered-site housing, and housing voucher restrictions have limited their ability to move between the two. However, the project manager stated that since the program has reached full implementation, participants now have a greater degree of choice in which type of housing they prefer when entering the program. For scattered-site placements at both projects, interviews demonstrated that while participants had a substantial number of housing choices, these choices were hindered by both the housing market and restrictions of the voucher program. According to these interviews, more desirable neighborhoods were harder to access because landlords were less willing to accept supportive housing vouchers and even if they did, rents in these neighborhoods usually exceeded the 
maximum amount allowed by the voucher. As one case manager at GCBH put it, "they [participants] have a lot of options but a lot of the options are very similar to each other."

Interviews with direct services staff and project participants polled participants about their housing and neighborhood preferences and whether or not they felt these preferences were met. For the most part, participants were generally satisfied with their housing. Some focused on the fact that any housing was better than living on the street. Neighborhood safety and proximity to transportation were identified as top neighborhood priorities. Some felt connected to neighbors and identified them as a source of friendship and support. Others expressed that they did not interact with their neighbors on a regular basis. For some participants, this lack of interaction was seen as intentional but for others it was not. Some participants felt that living in neighborhoods plagued by substance abuse and crime was not conducive to their own recovery. Participants also placed high importance on housing quality items such as building maintenance and having a unit with a separate bedroom (non-studio apartment). While participants in GCBH's project-based housing were more likely to reflect positively on the quality of their housing, they provided the least positive feedback about the state of their neighborhoods.

Chapter 5 turned to the task of providing descriptive data on the neighborhoods in which project participants lived. GIS was used to integrate administrative records at the two programs with data from the U.S. Census and other sources to create maps and tables depicting the characteristics of the census tracts occupied by Housing First participants compared to other census tracts in the city. This analysis of descriptive data showed that participants tended to live in census tracts with higher levels of poverty and dwelling vacancies, lower median incomes, and higher rates of per capita crimes when compared 
to other census tracts in their respective cities. This disparity was more severe in Cincinnati than in Louisville and especially pronounced in the census tract containing GCBH's project-based housing.

In Chapter 6, data on individual characteristics and neighborhood attributes were used to construct empirical models testing whether neighborhood characteristics had an effect on the housing stability of project participants. Housing stability was defined as whether or not a participant remained or exited a housing placement. Separate models were constructed to differentiate Forced Moves from Other Moves. Forced Moves were specified as those directly attributable to problems caused by the participant, including eviction, incarceration or dismissal from the program. Other Moves were specified as those caused by some other reason such as building maintenance problems, landlord issues, or participant choice. The study's original intent was to also include project-based housing as an independent variable in these models but the low rate of housing turnover at this project made this variable ill-suited for these models and it was thus excluded from the dataset.

Statistical analysis included both binary logistic regression and survival (Cox regression) models to analyze the effect of neighborhood attributes. Because multicollinearity was detected as a potential problem in the dataset, principal components analysis was used to construct four components which captured interaction between both neighborhood attributes and individual characteristics. These components served as independent variables in the model, with the first component designated an indicator of neighborhood quality and the other three components capturing various individual characteristics including behavioral problems, alcohol abuse, and involvement with the 
criminal justice system. For the outcome of Forced Moves, the neighborhood quality component did not produce statistically significant coefficients in either the binary or survival models. However, two of the individual characteristic components were significant indicating that Forced Moves are more likely to be a result of individual behavior than neighborhood characteristics. While the neighborhood component was not a significant predictor of Forced Moves, it did produce significant and negative coefficients in both the binary and survival models for Other Moves. Interpretation of these models suggests that, as neighborhood quality increased, participants were found less likely to leave their placement, indicating greater housing stability for this group. While the survival models were intended to capture the impact of time spent in housing, their results were not substantially different from those of the binary models. While consistency between the two models suggests of the results are robust, it also suggests that the more complex survival models did not contribute any more explanatory power than the binary logistic regression models.

\section{Implications for Housing First Policy}

What are the implications of this evaluation for designing and implementing future Housing First projects?

This final question is intended to synthesize the findings described above and discuss their implications for Housing First policy and research. This concluding section will consider how these findings may help guide Housing First policy as well as future research on the role of housing type and neighborhood in Housing First. While the study is limited to only two projects, its findings should be of interest to Housing First 
providers nationwide as well as local, state, and national policy makers interested in their efforts to address the needs of homeless individuals.

Statistical modeling demonstrated that Forced Moves were not influenced by neighborhood but instead by personal characteristics. This finding corresponded with staff perceptions that housing stability outcomes will be more dependent on the individual circumstances of the participant and their needed level of care. To address the problems that caused housing instability for this group, responses will likely need to be targeted toward the individual needs of the participant. This does not mean that housing and community do not play an important part in addressing the needs of this group. The low housing turnover at JHH suggests that project-based housing may promote better housing stability for certain participants.

In interviews at both agencies, staff discussed how project-based housing may better serve those with the highest level of need because services are provided onsite and staff have direct contact with participants on an almost daily basis. Contrary to this opinion, the analysis of individual characteristics demonstrated that GCBH's projectbased participants actually had a lower level of behavioral problems than those living in scattered-site housing. Therefore, it would appear that higher need participants are not being targeted for project-based housing. Staff interviews at GCBH suggest that this may be because there is also a perception that highly symptomatic individuals may not fare well in project-based housing because they may be disruptive to other participants. This presents a paradox of sorts for project-based housing in that while it may better serve those with the most needs, individuals with the highest level of behavioral problems may not be targeted because of their impact on other participants. 
Responding to this paradox requires creative solutions for $\mathrm{GCBH}$ and other agencies wishing to implement project-based housing. Some project-based Housing First projects have implemented some degree of separation of participants depending on their unique needs. For example, one floor of a building may house persons desiring sober living while active users are housed on another floor. While participants still maintain the personal choice granted by the Housing First model, they are also supported in achieving the environment needed to pursue their recovery goals. Because JHH is a small scale project of 25 units, it may not be possible to provide this degree of separation. However, should the community decide to expand its base of project-based housing, the argument could be made for a project that accommodates a slightly different population than that of JHH. For example, while JHH is targeted toward chronic inebriates, future projects may target those with other needs, such as those with severe and persistent mental illness.

While the Louisville Housing First program does not currently have project-based housing, it may want to consider this approach as it plans for new ways to serve its homeless population. As conveyed in Chapter 5, 60 FHC-Phoenix participants experienced forced moves from their housing placements between 2008 and 2013. While some of these participants were able to move to new locations, approximately two-thirds were discharged from the program and most reentered homelessness. This wave of participants presents the community with the challenge of trying to determine how this group may be better served. Staff interviews at FHC-Phoenix suggest that the agency may be willing to consider a project-based component to address higher need participants. However, a willing community partner would have to be identified to 
develop and manage such housing. For GCBH, such a partnership emerged with Over the Rhine Community Housing. Currently, there are no known entities in Louisville willing to accept such a task. As FHC-Phoenix and other community agencies move forward in addressing homelessness, it may be worthwhile to consider potential partnerships for developing project-based housing.

For the group identified as Other Movers, increased neighborhood quality did prove to significantly reduce the likelihood of a move occurring and thus promote greater housing stability for this group. Similarly, interview responses indicated that participants feel more settled and have less desire to move when they are comfortable in their neighborhood. If participants remain in their housing placements and neighborhoods, they are more likely to become integrated into the community and obtain the support and stability needed to reach their recovery goals. This finding demonstrates that neighborhood does matter for Housing First participants. For the projects themselves, a decreased number of moves can promote efficiency by saving the staff time needed to help participants find a new housing placement and relocate their belongings. In addition to saving staff time, it would also decrease expenses often incurred by the project such as security deposits and moving. Therefore, devoting more effort to finding housing placements in higher quality neighborhoods is likely to be very worthwhile to GCBH, FHC-Phoenix, or any other scattered-site Housing First project. Staff interviews indicate that a great deal of effort is already put into finding placements with access to transportation and services. Expanding this effort to include researching demographic characteristics, such as the ones explored in this study, as well as other pertinent 
characteristics, may further guide staff in helping participants find the highest quality placements possible.

Of course staff effort is not the primary barrier to placing participants in high quality neighborhoods. Staff already devote substantial effort to that task but they work within a highly restrictive housing market that often blocks access to the best neighborhoods. This is essentially a market function that keeps individuals deemed as less desirable from occupying the most desirable housing and neighborhoods. The two biggest challenges are finding landlords that will accept housing vouchers in higher quality neighborhoods and the high cost of these rental units. Landlords in more desirable neighborhoods often do not want to assume the risk of housing formerly homeless persons with substance abuse and mental illness. As one staff member indicated, they may also not to want invest the time and money required to meet the housing quality standards set forth by voucher programs. To compound this problem, the rent demanded by units in better neighborhoods often exceeds the fair market value for the respective city.

Beginning to resolve these barriers will require advocacy on many different levels. Housing First proponents will need to find ways to make providing housing to participants a more attractive option to landlords. At FHC-Phoenix, the agency has taken some initiative to promote the program to landlords such as advocating to landlords on the benefits of housing participants, such as guaranteed payment of rent through the housing subsidy and the support of a case manager to help resolve any housing issues that may emerge. The agency also holds events, such as landlord appreciation breakfasts, to acknowledge the contribution of landlords and make them feel that they are partners in 
ending homelessness in their community. However, to truly improve access to higher quality neighborhoods, cost barriers must be addressed and this will require advocacy on a governmental level. One solution would be for policy makers to amend the way fair market rent standards are administered so that they accommodate the fair market rent of a particular neighborhood rather than of the city as a whole. While such a controversial change would inflict a much higher cost for higher quality neighborhoods, it would likely reduce the maximum amount demanded in lower quality neighborhoods and create a more competitive market for publically subsidized housing. Another solution, which would address both landlord willingness and cost constraints, would be to provide incentives, such as tax breaks or more lax housing quality standards, to landlords willing to rent units to participants to higher quality neighborhoods. In this instance, the cost would be shifted toward the general public. However, with growing evidence of the cost effectiveness of Housing First, this cost may very well be worth the benefit of enhancing housing stability for Housing First participants.

\section{Implications for Future Research}

Finally, the findings of this study should be considered for both their limitations as well as guidance for future research on the role of community characteristics within a Housing First project. One of the key limitations of the study is that it focuses on only two Housing First projects. While the methodological framework and findings greatly contribute to our general understanding of how housing type and neighborhood characteristics affect a participant's experience, the study should be replicated on a larger scale to determine whether these patterns hold true for other Housing First projects. The limited scope of this sample was also problematic because it did not allow for project- 
based housing to be considered in the statistical models. Interviews suggest that integrating project-based and scattered-site approaches may serve a role in enhancing the ability of Housing First projects to offer the most effective mix of housing resources possible to their participants. Therefore, future work that includes a larger sample of project-based housing placements could provide more in-depth analysis of how scatteredsite and project-based housing differ in their abilities to promote housing stability.

Another limitation of this study is that it was not able to adequately capture the potential effects of proximity for participants. Because this was an original goal of the study, two measures, distance to public transportation and distance to the Central Business District (CBD), were considered. These measures were obtained by using GIS applications to calculate the distance of participant housing placements to the nearest bus stop and to the CBD of each city. A lack of data on distance to public transit for the general population of the two cities prohibits any comparisons in access for Housing First participants to be made. Distance to transit did not have a large factor loading in the PCA analysis and thus was not a variable contributing substantially to the Neighborhood Quality component. Therefore, the variable was considered for its independent effects in the statistical models but did not achieve statistical significance. While distance to the CBD did have a high factor loading in the PCA analysis, it did not function as expected. The variable was intended to serve as a proxy for access to services. Instead, its correspondence with the other neighborhood attributes made it representative of neighborhood quality rather than access. As specified through the PCA analysis, neighborhood quality was found to improve as distance to the CBD increased. Because staff and participants both discussed the importance of access to services and 
transportation, future studies should consider ways to operationalize more meaningful measures to represent these characteristics such as using GIS to calculate distances to certain service centers frequented by Housing First participants.

Another aspect of proximity not captured by the statistical models was that of proximity to family, friends, and other social ties. Interview responses from participants suggest that proximity to family members, friends, and peers were an important aspect of their neighborhood experiences. Some felt that proximity to other participants was a positive thing as it provided social support while others viewed it more negatively because it may hinder integration into the mainstream community. Access to social institutions, such as churches, was also deemed important. Future research could benefit from including variables that represent proximity to other project participants as well as other social ties to determine if these factors have an impact on housing stability.

Finally, the development of the methodological framework in this study may be useful in evaluating Housing First outcomes beyond housing stability as defined by whether a participant remained in or moved from his or her housing placement. The models used in this study could be easily modified to evaluate other project goals including changes in substance use, mental health, support systems, income, and criminal involvement. All SAMHSA grantees are required to administer the GPRA tool which this study used to define personal characteristics at two data collection points, intake and six-month follow-up. Some agencies elect to also use the tool to evaluate their project on a more long-term basis. For example, GCBH administers the GPRA follow-up at both six- and twelve-month data collection points, and FHC-Phoenix administers the survey at six-month intervals for the participants' first five years in the project. Changes between 
intake and follow-up data collection points could be used to operationalize a large array of dependent variables. Testing these dependent variables in a framework similar to the one used in this study would allow for investigations of the effects of neighborhood on a multitude of Housing First outcomes.

\section{Conclusion}

Findings from this study have demonstrated that housing-type and neighborhood are an important aspect of the experiences of Housing First participants in Louisville and Cincinnati. Both qualitative and quantitative components of this study suggest that participants will be more stably housed when placed in desirable neighborhoods. Further, while limited in its ability to investigate the impacts of project-based housing, qualitative findings suggest that while scattered-site housing is the preferred means of making Housing First placements, a meaningful subset of participants may better benefit from a greater mix of housing options that is inclusive of project-based housing. However, the tasks of improving access to both more desirable neighborhoods and a wider variety of housing types are likely to be particularly challenging due to factors such as housing market dynamics, subsidized housing policy guidelines, and limited availability of resources for developing new types of housing. The findings of this study provide new evidence to demonstrate these are worthwhile tasks. Future research on the impacts of housing type and neighborhood will hopefully provide further validation to support this cause. 


\section{REFERENCES}

Allison, P. D. (1984). Event History Analysis: Regression for Longitudinal Event Data (No. 46). Newbury Park, CA: Sage.

American Community Survey (2014). Accessed on January 20, 2014, from https://www.census.gov/acs/www/.

Appelbaum, R. P., Dolny, M., Dreier, P., \& Gilderbloom, J. I. (1991). Scapegoating rent control: Masking the causes of homelessness. Journal of the American Planning Association, 57(2), 153-164.

Anthony, W. A. (1993). Recovery from mental illness: The guiding vision of the mental health service system in the 1990s. Psychosocial Rehabilitation Journal, 16(4), 11-22.

Bahr, H. M. (1970). Disaffiliated Man: Essays and Bibliography on Skid Row, Vagrancy, and Outsiders. Toronto: University of Toronto Press.

Barber, G., Stone, R., Deck, S., Morris, V., Seelye, S., \& Clark, A. (2008). The costs of homelessness in Metropolitan Louisville. Paper prepared for the Louisville Coalition for the Homeless. Louisville, KY: Kent School of Social Work, University of Louisville.

Baum, A. S., \& Burnes, D. W. (1993). A Nation in Denial: The Truth about Homelessness. Boulder, CO: Westview Press.

Baxter, E., \& Hopper, K. (1981). Private Lives/Public Spaces: Homeless Adults on the Streets of New York City. New York: Community Service Society of New York, Institute for Social Welfare Research.

Bian, H. (2014). Survival analysis using SPSS [PowerPoint presentation]. Greenville, NC: Office for Faculty Excellence, East Carolina University.

Blanch, A. K., Carling, P. J., \& Ridgway, P. (1988). Normal housing with specialized supports: A psychiatric rehabilitation approach to living in the community. Rehabilitation Psychology, 33(1), 47-55.

Bronfenbrenner, U. (1979). The Ecology of Human Development. Cambridge, MA: Harvard University Press. 
Burt, M. R. (1992). Practical methods for counting homeless people: A manual for states and local jurisdictions. Washington, DC: Interagency Council on the Homeless and the US Department of Housing and Urban Development.

Burt, M. R. (1997). Future directions for programs serving the homeless. In D. Culhane \& P. Hornburg (Eds.), Understanding Homelessness: New Policy and Research Perspectives (pp. 360-381). Washington, DC: Fannie Mae Foundation.

Burt, M.R., \& Cohen, B.E. (1989). Differences among homeless single women with children and single men. Social Problems, 36(5): 508-524.

Burt, M. R., Aron, L. Y., Douglas, T., Valente, J., Lee, E., \& Iwen, B. (1999).

Homelessness: Programs and the people they serve. Summary Report. National Survey of Homeless Assistance Providers and Clients. Washington, DC: Urban Institute.

Carini, R. (2008) Binary logistic regression [class handout]. Louisville, KY: Department of Sociology, University of Louisville.

Caton, C. L., Wilkins, C., \& Anderson, J. (2007). People who experience long-term homelessness: characteristics and interventions. In D. Dennis, G. Locke, \& J. Khadduri (Eds.), Toward Understanding Homelessness: The 2007 National Symposium on Homelessness Research (pp. 143-196). Washington, DC: U.S. Department of Health and Human Services.

Coulton, C. J., Holland, T. P., \& Fitch, V. (1984). Person-environment congruence and psychiatric patient outcome in community care homes. Administration in Mental Health, 12(2), 71-88.

Courgeau, D., \& Lelièvre, E. (1992). Event History Analysis in Demography. Oxford: Clarendon Press.

Cournos, F. (1987). The impact of environmental factors on outcome in residential programs. Psychiatric Services, 38(8), 848-852.

Cragg, M., \& O'Flaherty, B. (1999). Do homeless shelter conditions determine shelter population? The case of the Dinkins deluge. Journal of Urban Economics, 46(3), 377415.

Culhane, D. P., Metraux, S., \& Hadley, T. (2002). Public service reductions associated with placement of homeless persons with severe mental illness in supportive housing. Housing Policy Debate, 13(1), 107-163.

Culhane, D. P., Metraux, S., Park, J. M., Schretzman, M. A., \& Valente, J. (2007). Testing a typology of family homelessness based on patterns of public shelter utilization in four US jurisdictions: Implications for policy and program planning. Housing Policy Debate, 18(1), 1-28. 
Culhane, D. P., \& Metraux, S. (2008). Rearranging the deck chairs or reallocating the lifeboats? Homelessness assistance and its alternatives. Journal of the American Planning Association, 74(1), 111-121.

Davies, M.A., Bromet, E.J., Schulz, C.S., Dunn, L.O. \& Morgenstern, M. (1989). Community adjustment of chronic schizophrenic patients in urban and rural settings. Hospital and Community Psychiatry, 40(8), 824-830.

Dear, M., \& Flusty, S. (1998). Postmodern urbanism. Annals of the Association of American Geographers, 88(1), 50-72.

Depp, F. C., Dawkins, J. E., Selzer, N., Briggs, C., Howe, R., \& Toth, G. (1986). Subsidized housing for the mentally ill. Social Work Research and Abstracts, 22(2), 3-7. Oxford: Oxford University Press.

DeVerteuil, G. (2006). The local state and homeless shelters: Beyond revanchism? Cities, 23(2), 109-120.

Early, D. W., \& Olsen, E. O. (2002). Subsidized housing, emergency shelters, and homelessness: An empirical investigation using data from the 1990 census. Advances in Economic Analysis \& Policy, 2(1), 1-34.

Ellen, I. G., \& Turner, M. A. (1997). Does neighborhood matter? Assessing recent evidence. Housing Policy Debate, 8(4), 833-866.

Ellickson, R. C. (1996). Controlling chronic misconduct in city spaces: Of panhandlers, skid rows, and public-space zoning. Yale Law Journal, 105(5), 1165-1248.

Galster, G., \& Zobel, A. (1998). Will dispersed housing programmes reduce social problems in the U.S.? Housing Studies, 13(5), 605-622.

Gounis, K. (1992). The manufacture of dependency: Shelterization revisited. New England Journal of Public Policy, 8(1), 685-693.

Greenwood, R. M., Schaefer-McDaniel, N. J., Winkel, G., \& Tsemberis, S. J. (2005). Decreasing psychiatric symptoms by increasing choice in services for adults with histories of homelessness. American Journal of Community Psychology, 36(3-4), 223238.

Gulcur, L., Stefancic, A., Shinn, M., Tsemberis, S., \& Fischer, S. N. (2003). Housing, hospitalization, and cost outcomes for homeless individuals with psychiatric disabilities participating in continuum of care and housing first programmes. Journal of Community \& Applied Social Psychology, 13(2), 171-186. 
Harkness, J., Newman, S. J., \& Salkever, D. (2004). The cost-effectiveness of independent housing for the chronically mentally ill: Do housing and neighborhood features matter? Health Services Research, 39(5), 1341-1360.

Health Care for the Homeless (2012). Who we serve. Retrieved March 1, 2013, from http://www.hchmd.org/demographics.shtml.

Hellman, I. D., Greene, L. R., Morrison, T. L., \& Abramowitz, S. I. (1985).

Organizational size and perceptions in a residential treatment program. American Journal of Community Psychology, 13(1), 99-109.

Hoch, C. (2000). Sheltering the homeless in the US: Social improvement and the Continuum of Care. Housing Studies, 15(6), 865-876.

Hopper, K., Jost, J., Hay, T., Welber, S., \& Haugland, G. (1997). Homelessness, severe mental illness, and the institutional circuit. Psychiatric Services, 48(5), 659-665.

Hull, J. T., \& Thompson, J. C. (1981). Factors which contribute to normalization in residential facilities for the mentally ill. Community Mental Health Journal, 17(2), 107113.

Ihlanfeldt, K. R., \&.Sjoquist, D. L. (1991). The effect of job access on black and white youth employment: A cross-sectional analysis. Urban Studies, 28(2): 255-265.

Kleinberg, B. (1995). Urban America in Transformation. Thousand Oaks, CA: Sage.

Kleit, R. G. (2001). The role of neighborhood social networks in scattered-site public housing residents' search for jobs. Housing Policy Debate, 12(3), 541-573.

Koegel, P., Burnam, M. A., \& Morton, S. C. (1996). Enumerating homeless people: Alternative strategies and their consequences. Evaluation Review, 20(4), 378-403.

Kroll, J., Carey, K., \& Dog, P. F. (1986). A survey of homeless adults in urban emergency shelters. Hospital and Community Psychiatry, 37(3), 283-286.

Kruzich, J. M., \& Berg, W. (1985). Predictors of self-sufficiency for the mentally ill in long-term care. Community Mental Health Journal, 21 (3), 198-207.

Kuhn, R., \& Culhane, D. P. (1998). Applying cluster analysis to test a typology of homelessness by pattern of shelter utilization: Results from the analysis of administrative data. American Journal of Community Psychology, 26(2), 207-232.

Larimer, M. E., Malone, D. K., Garner, M. D., Atkins, D. C., Burlingham, B., Lonczak, H. S., \& Marlatt, G. A., et al. (2009). Health care and public service use and costs before and after provision of housing for chronically homeless persons with severe alcohol problems. Journal of the American Medical Associaton, 301(13), 1349-1357. 
Lederman, J. (1993). Housing America: Mobilizing Bankers, Builders and Communities to Solve the Nation's Affordable Housing Crisis. Salem, MA: Probus.

Leff, H. S., Chow, C., Pepin, R., Conley, J., Allen, I. E., \& Seaman, C. (2009). Does one size fit all? What we can and can't learn from a meta-analysis of housing models for persons with mental illness. Psychiatric Services, 60(4), 473-482.

Main, T. (1998). How to think about homelessness: Balancing structural and individual causes. Journal of Social Distress and the Homeless, 7(1), 41-54.

Meschede, T. (2006). Moving here saved my life: The experience of formerly chronically homeless women and men in Quincy's Housing First projects: Interim report. Boston, MA: Center for Social Policy, McCormack Graduate School, University of Massachusetts at Boston.

Metraux, S., \& Culhane, D. P. (1999). Family dynamics, housing and recurring homelessness among women in New York City homeless shelters. Journal of Family Issues, 20(3), 371-398.

Metraux, S., Caterina, R., \& Cho, R. (2008). Incarceration and homelessness. In D. Dennis, G. Lock, \& J. Khadduri (eds.), Toward Understanding Homelessness. The 2007 National Symposium on Homelessness Research (pp. 336-367). Washington, DC: U.S. Department of Health and Human Services.

Moran, P., Walsh, E., Tyrer, P., Burns, T., Creed, F., \& Fahy, T. (2003). Impact of comorbid personality disorder on violence in psychosis: Report from the UK700 trial. The British Journal of Psychiatry, 182(2), 129-134.

National Alliance to End Homelessness (2011). State of homelessness in America in 2011. Accessed March 18, 2013, from http://www.endhomelessness.org/library/entry/state-of-homelessness-in-america-2011.

National Survey of Homeless Assistance Providers and Clients (1999). Retrieved April 4, 2013, from https://www.census.gov/prod/www/nshapc/NSHAPC4.html.

Nelson, G., Hall, G. B., \& Walsh-Bowers, R. (1998). The relationship between housing characteristics, emotional well-being and the personal empowerment of psychiatric consumer/survivors. Community Mental Health Journal, 34(1), 57-69.

Newman, S. J., Reschovsky, J. D., Kaneda, K., \& Hendrick, A. M. (1994). The effects of independent living on persons with chronic mental illness: An assessment of the Section 8 certificate program. The Milbank Quarterly, 72(1), 171-198.

Newman, S. J. (2001). Housing attributes and serious mental illness: Implications for research and practice. Psychiatric Services, 52(10), 1309-1317. 
North, C. S., Black, M., \& Pollio, D. E. (2012). Predictors of successful tracking over time in a homeless population. Social Work Research, 36(2), 153-159.

Padgett, D. K. (2007). There's no place like (a) home: Ontological security among persons with serious mental illness in the United States. Social Science and Medicine, 64(9), 1925-1936.

Patterson, A. (2008). Louisville Housing First project for homeless adults [grant TI020498 proposal to the Substance Abuse Mental Services Administration]. Louisville, KY.

Pearson, C. L., Locke, G., Montgomery, A. E., \& Buron, L. (2007) The Applicability of Housing First Models to Homeless Persons with Serious Mental Illness. Washington, DC: US Department of Housing and Urban Development.

Pearson, C., Montgomery, A. E., \& Locke, G. (2009). Housing stability among homeless individuals with serious mental illness participating in Housing First programs. Journal of Community Psychology, 37(3), 404-417.

Perlman, J., \& Parvensky, J. (2006). Denver Housing First Collaborative: Cost benefit analysis and program outcomes report. Denver, CO: Colorado Commission for the Homeless.

Ridgway, P., \& Zipple, A.M. (1990). The paradigm shift in residential services: From the linear continuum to supported housing approaches. Psychosocial Rehabilitation Journal, 13(4), 20-31.

Robertson, M.J. (1992). The prevalence of mental disorder among homeless people. In R.I. Jaheiel (ed.), Homelessness: A Prevention-Oriented Approach (pp. 57-86).

Baltimore: Johns Hopkins University Press.

Rog, D. J. (2004). The evidence on supported housing. Psychiatric Rehabilitation Journal, 27(4), 334-344.

Rosenbaum, J. E., \& Popkin, S. J. (1991). Employment and earnings of low-income blacks who move to middle-class suburbs. In C. Jencks \& P. Peterson (eds.), The Urban Underclass (pp. 342-356). Washington, DC: Brookings Institution.

Rosenheck, R. (2000). Cost-effectiveness of services for mentally ill homeless people: The application of research to policy and practice. American Journal of Psychiatry, 157(10), 1563-1570.

Rosenheck, R., Kasprow, W., Frisman, L., \& Liu-Mares, W. (2003). Cost-effectiveness of supported housing for homeless persons with mental illness. Archives of General Psychiatry, 60(9), 940-951. 
Rossi, P. H., \& Wright, J. D. (1987). The determinants of homelessness. Health Affairs, 6(1), 19-32.

Sainani, K. (2014). Introduction to survival analysis [PowerPoint presentation]. Stanford, CA: Department of Health Research and Policy, Stanford University.

Saelinger, D. (2006). Nowhere to go: The impacts of city ordinances criminalizing homelessness. Georgetown Journal of Law and Poverty, 13(3), 545-566.

SAMHSA (2013). National Registry of Evidence-Based Programs and Practices. Accessed March 29, 2013, from http://www.nrepp.samhsa.gov/.

Schutt, R. K., \& Garrett, G. R. (1992). The homeless alcoholic. In M. Robertson \& M. Greenblatt (eds.), Homelessness (pp. 177-186). New York: Springer US.

Segal, S. P., \& Aviram, U. (1978). The Mentally Ill in Community-Based Sheltered Care: A Study of Community Care and Social Integration. New York: Wiley.

Shinn, M., \& Tsemberis, S. (1998). Is housing the cure for homelessness. In S. Oskamp (ed.), Addressing Community Problems: Research and Intervention (pp. 52-77).

Thousand Oaks, CA: Sage.

Snow, D.A., \& Anderson, L. (1987). Identify work among the homeless: The verbal construction and avowal of personal identities. American Journal of Sociology, 92(6), 1336-1371.

Soja, E.J. (1989) Post Modern Geographies: The Reassertion of Space in Critical Social Theory. London: Verso.

Sommer, H. (2001). Homelessness in Urban America: A Review of the Literature. Berkeley, CA: ERIC Clearinghouse.

Sosin, M., Piliavin, I., \& Westerfelt, H. (1990). Toward a longitudinal analysis of homelessness. Journal of Social Issues, 46(4), 157-174.

Sowers, K., Ellis, R., Washington, T. A., \& Currant, M. (2002). Optimizing treatment effects for substance-abusing women with children: An evaluation of the Susan B. Anthony Center. Research on Social Work Practice, 12(1), 143-158.

Stark, L.R. (1994). The shelter as "total institution": An organizational barrier to remedying homelessness. American Behavioral Scientist, 37(4), 553-562.

Stefanic, A., \& Tsemberis, S. (2007). Housing First for long-term shelter dwellers with psychiatric disabilities in a suburban county: A four-year study of housing access and retention. Journal of Primary Prevention, 28(3-4), 265-279. 
Susser, I. (1996). The construction of poverty and homelessness in US cities. Annual Review of Anthropology, 24, 411-435.

Tabol, C., Drebing, C., \& Rosenheck, R. (2010). Studies of "supported" and "supportive" housing: A comprehensive review of model descriptions and measurement. Evaluation and Program Planning, 33(4), 446-456

Tanzman, B. (1993). An overview of surveys on mental health consumers' preferences for housing and support services. Hospital and Community Psychiatry, 44(5), 450-455.

Thompson, S. J., Pollio, D. E., Eyrich, K., Bradbury, E., \& North, C. S. (2004).

Successfully exiting homelessness: Experiences of formerly homeless mentally ill individuals. Evaluation and Program Planning, 27(4), 423-431.

Tranmer, M., \& Elliot, M. (2008). Binary logistic regression. Teaching Paper no. 20. Manchester, UK: Cathy Marsh Center for Census and Survey Research.

Trussell, J., Hankinson, R., \& Tilton, J. (1992). Demographic Applications of Event History Analysis. Oxford: Clarenden Press.

Tsai, J., Mares, A.S., \& Rosencheck, A.S. (2012). Does housing chronically homeless adults lead to social integration? Psychiatric Services, 63(4), 427-434.

Tsemberis, S. (1999). From streets to homes: An innovative approach to supported housing for homeless adults with psychiatric disabilities. Journal of Community Psychology, 27(2), 225-241.

Tsemberis, S. (2010). Housing First: Ending homelessness, promoting recovery and reducing costs. In I.E. Gould \& R. Flaherty (eds.), How to House the Homeless (pp. $37-$ 56). New York: Russell Sage.

Tsemberis, S., \& Eisenberg, R.F. (2000). Pathways to Housing: Supported housing for street-dwelling homeless individuals with psychiatric disabilities. Psychiatric Services 51(4), 487-493.

Tsemberis, S., Rogers, S., Rodis, E., Deshuttle, P., \& Skryha, V. (2003). Housing satisfaction for persons with psychiatric disabilities. Journal of Community Psychology $31(6), 581-590$.

Tsemberis, S., Gulcur, L. \& Nakae, M. (2004). Housing first, consumer choice, and harm reduction for homeless individuals with a dual diagnosis. American Journal of Public Health 94(4), 651-656.

U.S. Census (2010). Census of Population and Housing, 2010. Accessed January 20, 2014, from http://www.census.gov/2010census/data/. 
U.S. Department of Housing and Urban Development (2013). Homeless Data Exchange. Accessed March 15, 2013, from http://www.hudhdx.info/.

Waldron, J. (1991). Homelessness and the issue of freedom. UCLA Law Review, 39(1), 295-324.

Waldron, J. (2000). Homelessness and community. University of Toronto Law Journal, 50(4), 371-406.

Washington, T. A. (2002). The homeless need more than just a pillow, they need a pillar: An evaluation of a transitional housing program. Families in Society: The Journal of Contemporary Social Services, 83(2), 183-188.

Weitzman, B.C., Knickman, J.R., \& Shinn, M. (1990). Pathways to homelessness among New York City families. Journal of Social Issues, 46(4), 125-140.

Wilson, J. Q., \& Kelling, G. L. (1982). Broken windows. Atlantic Monthly, 249(3), 2938.

Wright, J. D., Rubin, B. A., \& Devine, J. A. (1998). Beside the Golden Door: Policy, Politics, and the Homeless. Hawthorne, NT: Transaction Publishers.

Yanos, P. T., Barrow, S. M., \& Tsemberis, S. (2004). Community integration in the early phase of housing among homeless persons diagnosed with severe mental illness:

Successes and challenges. Community Mental Health Journal, 40(2), 133-150.

Yanos, P. T., Felton, B. J., Tsemberis, S., \& Frye, V. A. (2007). Exploring the role of housing type, neighborhood characteristics, and lifestyle factors in the community integration of formerly homeless persons diagnosed with mental illness. Journal of Mental Health, 16(6), 703-717.

Zippay, A., \& Thompson, A. (2007). Psychiatric housing: Locational patterns and choices. American Journal of Orthopsychiatry, 77(3), 392-401. 


\section{APPENDIX 3.1. \\ Interview Questions for Project Administrators}

1. Please tell me about how your Housing First Project was designed and implemented?

2. What types of housing resources (i.e. vouchers, project sites) does your Housing First Project use?

3. What factors (political, economic, etc.) led your program to use these resources?

4. What do you feel are the components of your program that most help its participants maintain housing? What components does your program lack that would help improve participants' ability to maintain housing?

5. In your opinion what is the best type of housing to serve the target population of your Housing First project? Why?

6. Do you feel the type of housing resource used impacts housing stability?

7. How does the housing that you provide match these criteria?

8. What kind of barriers (political, economic, etc.) have you experienced in obtaining needed housing resources?

9. What kind of barriers (landlord cooperation, availability of affordable units, etc.) does staff experience in finding quality housing placements?

10. Have the guidelines and restrictions of your housing resources, such as voucher requirements, interfered with your project's ability to practice Housing First? If so, how?

11. One tenant of Housing First is that housing and supportive service operate independently of one another. Do you consider housing and supportive services to be separate from each other in your project? How does this impact housing stability for your participants?

12. Do you feel that neighborhood is an important factor in determining a participant's success in your project? Why or why not? 
13. What are the most important neighborhood characteristics to consider when participants are looking for a housing placement? 


\section{APPENDIX 3.2.}

\section{Interview Questions for Direct Services Staff}

1. Please tell me your job title and describe your role in your Housing First project in terms of the housing component of the project (i.e. housing placements, apartment searches, landlord locations, etc.)?

2. How do your participants find their housing placement? What kinds of things do they value most in regards to housing and neighborhood? How much choice do you feel that they have in choosing their housing placement?

3. How involved are you in the housing placement selection process? What do you personally feel are the most important housing and neighborhood characteristics for participants?

4. What type of housing do you feel best serves your participants, single-site or scattered-site? Why do you feel this way?

5. Do you feel like your participants life in apartments that are in good condition and maintained regularly? Why or why not?

6. Do you feel like your participants live in safe neighborhoods? Why or why not?

7. Do you feel like your participants live in places with easy access to places which they need or want to go? Why or why not?

8. Do you consider it be a positive or negative thing to have a large number of participants living in the same neighborhood or building? Why do you feel this way?

9. One tenant of Housing First is that housing and supportive service operate independently of one another. Do you consider housing and supportive services to be separate from each other in your project? How does this impact housing stability for your participants?

10. Do you feel that neighborhood is an important factor in determining a participant's success in your project? Why or why not? 


\section{APPENDIX 3.3}

\section{Interview Questions for Participants}

1. Tell me about your housing? How long have you lived there? What do you like most about it? What do you like least?

2. Are you happy with your housing placement (apartment, house, room)? Why or why not?

3. Tell me about your neighborhood? What do you like most about it? What do you like least?

4. Was the neighborhood that you live in your first choice? If so, what factors made it your first choice? If not, how was your first choice different from the neighborhood in which you live?

5. How involved were you in finding your housing? What were the most important things you looked for in your housing search? Were you able to find a place that met those wants and needs? Did your case manager suggest places to live for you? Did these places match your wants and needs?

6. Have you lived in more than one housing placement since entering the program? If so, how many? Did you move somewhere in the same neighborhood or to a new neighborhood? What were your reasons for moving (voluntary or involuntary move)? What things do you feel are most important for you to be successful in the program? Do you feel that you have these things?

7. Do you interact with other people in your neighborhood? If so, who? If not, why?

How many other project participants do you live near?

8. Do you interact regularly with other project participants? Why or why not? 
9. Now, I'm going to ask questions about specific things that you may value about your housing and neighborhood? For each item, please respond yes or no as to whether you feel like your housing provides that amenity. Then, I will ask how important you feel each of these items is. Please respond on a scale of 1-5 where $1=$ not important at all, $2=$ not very important, $3=$ neutral, $4=$ important, $5=$ very important.

\begin{tabular}{|c|c|c|}
\hline Item: & Amenity? & Importance? \\
\hline $\begin{array}{l}\text { a. Living in a small building with just a few } \\
\text { units (duplex, 4-plex)? }\end{array}$ & & \\
\hline $\begin{array}{l}\text { b. Living in a large building with many units } \\
\text { (apartment complex)? }\end{array}$ & & \\
\hline $\begin{array}{l}\text { c. Living in a unit with lots of space (square } \\
\text { footage)? }\end{array}$ & & \\
\hline $\begin{array}{l}\text { d. Living in a unit with your own bedroom } \\
\text { (non-studio apartment)? }\end{array}$ & & \\
\hline e. Living close to other project participants? & & \\
\hline $\begin{array}{l}\text { f. Living in a neighborhood that has } \\
\text { sidewalks and is easy to walk around? }\end{array}$ & & \\
\hline g. Living downtown? & & \\
\hline $\begin{array}{l}\text { h. Living in a neighborhood that you feel is } \\
\text { generally in good condition (buildings kept } \\
\text { in nice shape)? }\end{array}$ & & \\
\hline $\begin{array}{l}\text { i. Living in a neighborhood that you feel is } \\
\text { pleasant or beautiful to look at (attractive } \\
\text { buildings and landscape)? }\end{array}$ & & \\
\hline $\begin{array}{l}\text { j. Living in a neighborhood with lots of } \\
\text { places for you or your guests to park a } \\
\text { vehicle? }\end{array}$ & & \\
\hline $\begin{array}{l}\text { k. Living in a neighborhood with lots of } \\
\text { outdoor space like lawns, forests, and } \\
\text { parks? }\end{array}$ & & \\
\hline
\end{tabular}


10. Now, I am going to ask you about how safe you feel in your housing and neighborhood. Please respond on a scale of $1-5$ where $1=$ not safe at all, $2=$ not very safe, $3=$ neutral, $4=$ safe, $5=$ very safe. Then, I will ask how important each of these items are to you. Please respond on a scale of $1-5$ where $1=$ Not important at all, $2=$ Not very important, $3=$ neutral, $4=$ important, and $5=$ very important.

\begin{tabular}{|c|c|c|}
\hline Item: & How safe? & Importance? \\
\hline a. Your neighborhood in general? & & \\
\hline b. The people who live in your neighborhood? & & \\
\hline c. Your apartment in general? & & \\
\hline d. Being alone in your apartment at night? & & \\
\hline e. Walking alone in your neighborhood? & & \\
\hline $\begin{array}{l}\text { f. Walking alone in your neighborhood after } \\
\text { dark? }\end{array}$ & & \\
\hline $\begin{array}{l}\text { g. Leaving your apartment unattended for a } \\
\text { short period of time like just a few hours? }\end{array}$ & & \\
\hline $\begin{array}{l}\text { h. Leaving your apartment unattended } \\
\text { overnight or for longer periods? }\end{array}$ & & \\
\hline
\end{tabular}


11. Now, I'm going to ask about your access to places that you may need or want to go. Please indicate how accessible each of the following is to you. Please respond on a scale of 1-5 where $1=$ not accessible at all, $2=$ not very accessible, $3=$ neutral, $4=$ accessible, $5=$ very accessible. Then I will ask you how important it is for you to have access to each of these things. Please respond on a scale of 1-5 where $1=$ not important at all, $2=$ not very important, $3=$ neutral, $4=$ important, and $5=$ very important.

\begin{tabular}{|c|c|c|}
\hline Item: & Access? & Importance? \\
\hline $\begin{array}{l}\text { a. Places to shop for necessities like grocery } \\
\text { stores and pharmacies? }\end{array}$ & & \\
\hline $\begin{array}{l}\text { b. Places to go for resources like food and } \\
\text { clothing banks? }\end{array}$ & & \\
\hline $\begin{array}{l}\text { c. Place to go for needed services like a bank } \\
\text { or post office? }\end{array}$ & & \\
\hline $\begin{array}{l}\text { d. Places to go for medical care like a clinic or } \\
\text { doctor's office? }\end{array}$ & & \\
\hline $\begin{array}{l}\text { e. A Laundromat or other place to wash } \\
\text { clothes? }\end{array}$ & & \\
\hline $\begin{array}{l}\text { f. Places to go out to eat or for other } \\
\text { entertainment like a restaurant or movie } \\
\text { theater? }\end{array}$ & & \\
\hline $\begin{array}{l}\text { g. Public transportation to downtown or } \\
\text { another place that you need to go? }\end{array}$ & & \\
\hline $\begin{array}{l}\text { h. Places to go for recreation and exercise like } \\
\text { a park or gym? }\end{array}$ & & \\
\hline $\begin{array}{l}\text { i. Places to go for learning like a library or } \\
\text { educational center (voc rehab, college, } \\
\text { etc.)? }\end{array}$ & & \\
\hline j. Employment opportunities? & & \\
\hline $\begin{array}{l}\text { k. Program services like case management, } \\
\text { support groups, or treatment centers? }\end{array}$ & & \\
\hline
\end{tabular}


APPENDIX 3.4

GPRA Interview Tool

Form Approved OMB No. 0930-0208

Expiration Date 02/28/2013

\title{
CSAT GPRA Client Outcome Measures for Discretionary Programs (Revised 06/01/2012)
}

\begin{abstract}
Public reporting burden for this collection of information is estimated to average 30 minutes per response, including the time for reviewing instructions, searching existing data sources, gathering and maintaining the data needed, and completing and reviewing the collection of information, if all items are asked of a client'participant, to the extent that providers already obtain much of this information as part of their ongoing client/participant intake or followup, less time will be required. Send comments regarding this burden estimate or any other aspect of this collection of information to SAMHSA Reports Clearance Officer, Room 7-1044, 1 Choke Cherry Road, Rockville, MD 20857. An agency may not conduct or sponsor, and a person is not required to respond to a collection of information unless it displays a currently valid OMB control number. The control number for this project is 0930-0208.
\end{abstract}




\section{A. RECORDMANAGEMENT}

Client ID

Client Type:

O Treatment client

O Client in recovery

Contract/Grant ID

Interview Type [CIRCLE ONLY ONE TYPE.]

Intake [GO TO INTERVIEW DATE]

6-month follow-up $\rightarrow \rightarrow \rightarrow$ Did you conduct a follow-up interview? $\bigcirc$ Yes $\bigcirc$ No

IF NO, GO DIRE

CTLYTO SECTIONI]

3-month follow-up [ADOLESCENT PORTFOLIO ONLY] -

Did you conduct a follow-up interview? O Yes O No [IF NO, GO DIRECTLY TO SECTIONI]

Discharge $\rightarrow \rightarrow \rightarrow$ Did you conduct a discharge interview? $O$ Yes $\bigcirc$ No [IF NO, GO DIRECTLY TO SECTIONJ.]

Interview Date

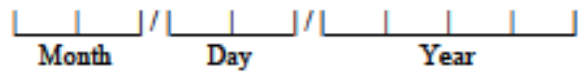

[FOLLOW-UP AND DISCHARGE INTERVIEWS: SKIP TO SECTION B.]

1. Was the client sereened by your program for co-occurring mental health and substance use disorders?

O YES

O NO [SKIP la.]

la. [IF YES] Did the client screen positive for co-occurring mental health and substance use disorders?

O YES

O NO

SBIRT CONTINUE. ALL OTHERS GO TO SECTION A "PLANNED SERVICES." 
THIS SECTION FOR SBIRT GRANTS ONLY [TTEMS 2, 2a, \& 3-REPORTED ONLYAT INTAKE/BASELINE].

1. How did the client screen for your SBIRT?

O Negative

O Positive

2a. What was his/her screening score?

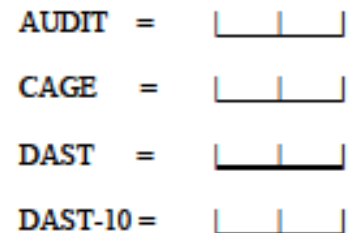

NIAAA Guide =

ASSIST/Alcohol Subscore

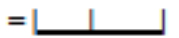

Other (Specify)
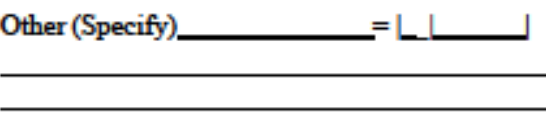

2. Was he/she willing to continue his/her participation in the SBIRT program?

O YES

O NO 
A. RECORD MANAGEMENT - PLANNED SERVICES [REPORTED BY PROGRAM STAFF ABOUT CLIENT ONLY AT INTAKE/BASELINE.]

Identify the services you plan to provide to the client during the client's course of treatment/recovery. [CIRCLE "T" FOR YES OR " $N$ " FOR NO FOR EACH ONE] Modality [SELECT AT LEAST ONE MODALITY.]

1. Case Management

2. Day Treatment

3. Inpatient/Hospital (Other Than Detox)

4. Outpatient

5. Outreach

6. Intensive Outpatient

7. Methadone

8. Residential/Rehabilitation

9. Detoxification (Select Only (Mnc)
A. Hospital Inpatient
B. Free Standing Residential
C. Ambulatory Detoxification

10. After Care

11. Recovery Support

12. Other (Specify)

\section{[SELECT AT LEAST ONE SERVTCE]}

Treatment Services

[SBIRT GRANTS: YOU MUST CIRCLE "Y"

FOR AT LEAST ONE OF THE TREATMENT

SERVTCES NUMBERED 1 THROUGH 4.]

1. Screening

Brief Intervention

Brief Treatment

Referral to Treatment

5. Assessment

Treatment/Recovery Planning

7. Individual Counseling

8. Group Counseling

9. Family/Marriage Counseling

10. Co-Occurring Treatment

Recovery Services

11. Pharmacological Interventions

12. HIV/AIDS Counseling

13. Other Clinical Services (Specify)

$\begin{array}{ll}\text { Yes } & \text { No } \\ \text { Y } & \text { N } \\ \text { Y } & \text { N } \\ \text { Y } & \text { N } \\ \text { Y } & \text { N } \\ \text { Y } & \text { N } \\ \text { Y } & \text { N } \\ \text { Y } & \text { N } \\ \text { Y } & \text { N } \\ & \\ \text { Y } & \text { N } \\ \text { Y } & \text { N } \\ \text { Y } & \text { N } \\ \text { Y } & \text { N } \\ \text { Y } & \text { N } \\ \text { Y } & \text { N }\end{array}$

Yes No

$\begin{array}{ll}\mathrm{Y} & \mathrm{N} \\ \mathrm{Y} & \mathrm{N} \\ \mathrm{Y} & \mathrm{N} \\ \mathrm{Y} & \mathrm{N} \\ \mathrm{Y} & \mathrm{N} \\ \mathrm{Y} & \mathrm{N} \\ \mathrm{Y} & \mathrm{N} \\ \mathrm{Y} & \mathrm{N} \\ \mathrm{Y} & \mathrm{N} \\ & \\ \mathrm{Y} & \mathrm{N} \\ \mathrm{Y} & \mathrm{N} \\ \mathrm{Y} & \mathrm{N} \\ \mathrm{Y} & \mathrm{N}\end{array}$

Case Management Services

1. Family Services (Including Marriage Education, Parenting, Child Development Services)

2. Child Care

3. Employment Service
A. Pre-Enmloyment

B. Employment Coaching

4. Individual Services Coordination

5. Transportation

6. HIV/AIDS Service

7. Supportive Transitional Drug-Free Housing

$\begin{array}{lll}\text { 8. Services } & \text { Y } & \text { N } \\ \text { Other Case Management Services } & \text { Y } & \text { N }\end{array}$ (Specify)

\section{Medical Services}

1. Medical Care

2. Alcohol/Drug Testing

HIV/AIDS Medical Support \& Testing $Y$ N

4. Other Medical Services

(Specify)

$\begin{array}{llcc}\text { After Care Services } & \text { Yes } & \text { No } \\ \text { 1. Continuing Care } & \text { Y } & \text { N } \\ \text { 2. Relapse Prevention } & \text { Y } & \text { N } \\ & & & \\ \text { 3. Recovery Coaching } & \text { Y } & \text { N } \\ \text { 4. Self-Help and Support Groups } & \text { Y } & \text { N } \\ \text { 5. Spiritual Support } & \text { Y } & \text { N } \\ \text { 6. Other After Care Services } & \text { Y } & \text { N }\end{array}$

(Specify)

\section{Education Services}

1. Substance Abuse Education

2. HIV/AIDS Education

3. Other Education Services (Specify)

Peer-to-Peer Recovery Support Services Yes No

1. Peer Coaching or Mentoring $\mathrm{Y} N$

2. Housing Support $\mathrm{Y}$ N

3. Alcohol- and Drug-Free Social Activities $\mathrm{Y} N$

4. Information and Referral $Y$ N

5. Other Peer-to-Peer Recovery Support Services

Y N

No 
A. RECORD MANAGEMENT - DEMOGRAPHICS [ASKED ONLY AT INTAKE/BASELINE]

1. What is your gender?

O MALE

FEMALE

O TRANSGENDER

O OTHER (SPECIFY)

$$
\text { O REFUSED }
$$

2. Are you Hispanic or Latino?

○ YES

O NO

O REFUSED

[IF YES] What ethnic group do you consider yourself? Please answer yes or no for each of the following. You may say yes to more than one.

Yes No Refused

Central American $\mathrm{Y}$ N REFUSED

Cuban $\quad \mathrm{Y} N$ REFUSED

Dominican $\quad \mathrm{Y} N$ REFUSED

Mexican $Y \mathrm{~N}$ REFUSED

Puerto Rican $Y$ N REFUSED

South American $\mathrm{Y}$ N REFUSED

Other $\quad \mathrm{Y} N$ REFUSED [IF YES, SPECIFY BELOW]

(Specify)

3. What is your race? Please answer yes or no for each of the following. You may say yes to more than one.

$\begin{array}{lcc} & \text { Yes No Refused } \\ \text { Black or African American } & \text { Y N REFUSED } \\ \text { Asian } & \text { Y N } & \text { REFUSED } \\ \text { Native Hawaiian or other Pacific Islander } & \text { Y N } & \text { REFUSED } \\ \text { Alaska Native } & \text { Y N } & \text { REFUSED } \\ \text { White } & \text { Y N } & \text { REFUSED } \\ \text { American Indian } & \text { Y N REFUSED }\end{array}$

4. What is your date of birth?*

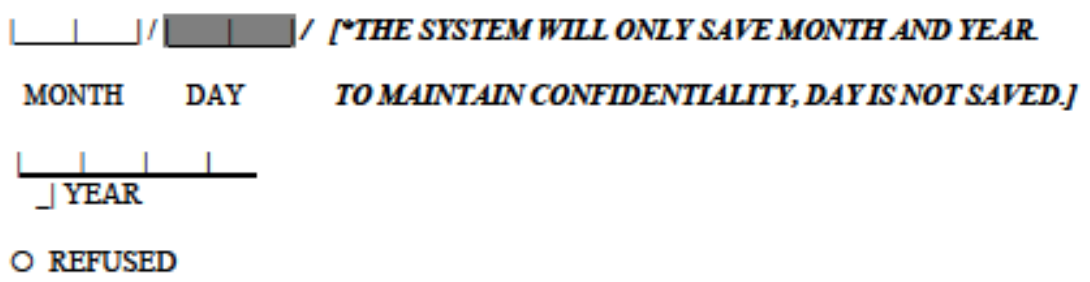




\section{MIIITARY FAMIIY AND DEPLOYMENT}

1. Have you ever served in the Armed Forces, in the Reserves, or in the National Guard? IF SERVED] What area, the Armed Forces, Reserves, or National Guard did you serve?

O NO

YES, IN THE ARMED FORCES

O YES, IN THE RESERVES

O YES, IN THE NATIONAL GUARD

O REFUSED

O DON'TKNOW

[IF NO, REFUSED, OR DON'T KNOW, SKIP TO QUESTIONA6.]

5a. Are you currently on active duty in the Armed Forces, in the Reserves, or in the National Guard? [IF ACTIVE] What area, the Armed Forces, Reserves, or National Guard?

O NO, SEPARATED OR RETIRED FROM THE ARMED FORCES, RESERVES OR NATIONAL GUARD

O YES, IN THE ARMED FORCES

O YES, IN THE RESERVES

O YES, IN THE NATIONAL GUARD

O REFUSED

O DON'T KNOW

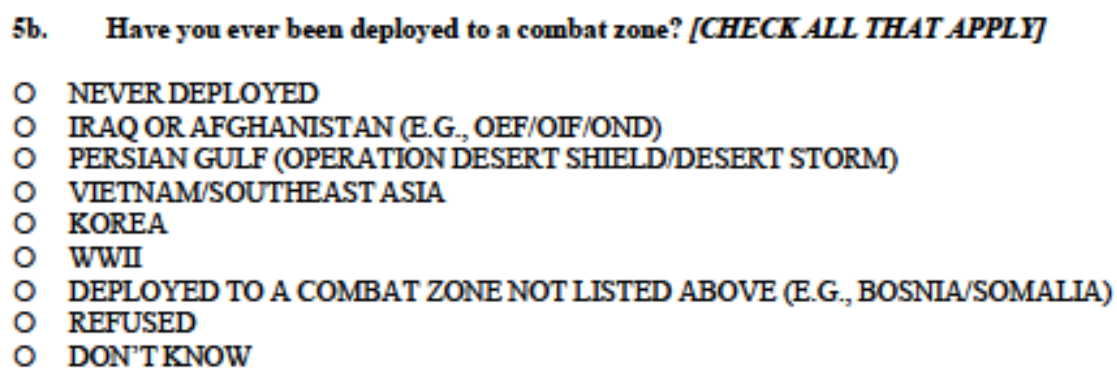

SBIRT GRANTEES: FOR CLIENTS WHO SCREENED NEGATIVE, SKIP ITEMS A6, A6A-A6D 
1. Is anyone in your family or someone close to you on active duty in the Armed Forces, in the Reserves, or in the National Guard or separated or retired from the Armed Forces, Reserves, or National Guard?

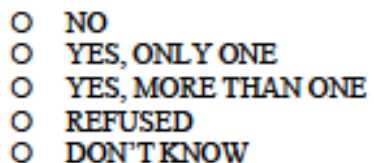

[IF NO, REFUSED, OR DON'T KNOW, SKIP TO SECTION B.]

\begin{tabular}{|c|c|c|c|c|c|c|}
\hline \multicolumn{7}{|c|}{$\begin{array}{l}\text { [IF YES, ANSWER FOR UP TO 6 PEOPLE] What is the relationship of that person (Service Member) to you? } \\
\text { [WRITE RELATIONSHIP IN COLUMNHEADING] }\end{array}$} \\
\hline $\begin{array}{l}1=\text { Mother } \\
2=\text { Father } \\
3=\text { Brother } \\
4=\text { Sister }\end{array}$ & \multicolumn{3}{|c|}{$\begin{array}{l}5=\text { Spouse } \\
6=\text { Partner } \\
7=\text { Child } \\
8=\text { Other (Specify) }\end{array}$} & & & \\
\hline \multicolumn{7}{|l|}{$\begin{array}{l}\text { Has the Service Member } \\
\text { experienced any of the } \\
\text { following? [CHECK } \\
\text { ANSWER IN }\end{array}$} \\
\hline $\begin{array}{l}\text { APPROPRLATE COLUMN } \\
\text { FOR ALL THAT APPLY] }\end{array}$ & $\begin{array}{l}\text { (Relationship) } \\
1 .\end{array}$ & \begin{tabular}{|c} 
(Relationship) \\
2.
\end{tabular} & $\begin{array}{l}\text { (Relationship) } \\
3 .\end{array}$ & $\begin{array}{c}\text { (Relationship) } \\
4 .\end{array}$ & $\begin{array}{c}\text { (Relationship) } \\
5 .\end{array}$ & $\begin{array}{c}\text { (Relationship) } \\
6 .\end{array}$ \\
\hline $\begin{array}{l}\text { 6a. Deployed in support of } \\
\text { combat operations } \\
\text { (e.g., Iraq or } \\
\text { Afghanistan)? }\end{array}$ & \begin{tabular}{|ll} 
& YES \\
0 & NO \\
$O$ & REFUSE \\
O & DON' \\
& T
\end{tabular} & \begin{tabular}{|ll} 
YES & YES \\
0 & NO \\
0 & REFUSE \\
0 & DON' \\
T
\end{tabular} & \begin{tabular}{|ll} 
& YES \\
0 & NO \\
0 & REFUSE \\
0 & DON' \\
& T
\end{tabular} & \begin{tabular}{|ll} 
& YES \\
0 & NO \\
0 & REFUSE \\
0 & DON \\
& $T$
\end{tabular} & \begin{tabular}{|ll} 
& YES \\
0 & NO \\
0 & REFUSE \\
O & DON \\
& T
\end{tabular} & $\begin{array}{ll} & \text { YES } \\
0 & \text { NO } \\
0 & \text { REFUSE } \\
0 & \text { DON' } \\
& \text { T }\end{array}$ \\
\hline $\begin{array}{l}\text { 6b. Was physically injured } \\
\text { during combat } \\
\text { operations? }\end{array}$ & \begin{tabular}{|ll}
$O$ & YES \\
O & NO \\
O & REFUSE \\
D & \\
$O$ & DON'
\end{tabular} & $\begin{array}{ll}\text { O } & \text { YES } \\
\text { O } & \text { NO } \\
0 & \text { REFUSE } \\
\text { D } & \\
\text { O } & \text { DON' }\end{array}$ & $\begin{array}{ll} & \text { YES } \\
0 & \text { NO } \\
0 & \text { REFUSE } \\
\text { D } & \\
0 & \text { DON' }\end{array}$ & $\begin{array}{ll}O & \text { YES } \\
0 & \text { NO } \\
0 & \text { REFUSE } \\
\text { D } & \\
\text { O } & \text { DON' }\end{array}$ & \begin{tabular}{|ll} 
& YES \\
O & NO \\
O & REFUSE \\
D & \\
$O$ & DON
\end{tabular} & $\begin{array}{ll}O & \text { YES } \\
O & \text { NO } \\
0 & \text { REFUSE } \\
\text { D } & \\
O & \text { DON }\end{array}$ \\
\hline \begin{tabular}{|l|} 
6c. Developed combat \\
stress symptoms/ \\
difficulties adjusting \\
following deployment, \\
including PTSD, \\
depression, or suicidal \\
thoughts?
\end{tabular} & \begin{tabular}{|ll} 
O & YES \\
O & NO \\
O & REFUSE \\
D & \\
$O$ & DON' \\
& T \\
KNOW
\end{tabular} & \begin{tabular}{|ll} 
O & YES \\
O & NO \\
O & REFUSE \\
D & \\
$O$ & DON' \\
& T \\
KNOW
\end{tabular} & \begin{tabular}{|ll} 
& YES \\
O & NO \\
O & REFUSE \\
D & \\
$O$ & DON' \\
& T \\
KNOW
\end{tabular} & $\begin{array}{ll}\text { Y } & \text { YES } \\
\text { O } & \text { NO } \\
\text { O } & \text { REFUSE } \\
\text { D } & \\
\text { O } & \text { DON' } \\
& \text { T } \\
\text { KNOW }\end{array}$ & \begin{tabular}{|ll} 
Y & YES \\
O & NO \\
O & REFUSE \\
D & \\
O & DON' \\
& T \\
KNOW
\end{tabular} & \begin{tabular}{|ll} 
O & YES \\
O & NO \\
O & REFUSE \\
D & \\
O & DON' \\
& T \\
KNOW
\end{tabular} \\
\hline 6d. Died or was killed? & $\begin{array}{ll}O & \text { YES } \\
\text { O } & \text { NO } \\
\text { O } & \text { REFUSE } \\
\text { D } & \\
\text { O } & \text { DON' }\end{array}$ & $\begin{array}{ll}\text { O } & \text { YES } \\
\text { O } & \text { NO } \\
0 & \text { REFUSE } \\
\text { D } & \\
\text { O } & \text { DON' }\end{array}$ & $\begin{array}{ll}O & \text { YES } \\
0 & \text { NO } \\
0 & \text { REFUSE } \\
\text { D } & \\
O & \text { DON' }\end{array}$ & $\begin{array}{ll} & \text { YES } \\
0 & \text { NO } \\
0 & \text { REFUSE } \\
\text { D } & \\
\text { O } & \text { DON' }\end{array}$ & $\begin{array}{ll}\text { O } & \text { YES } \\
\text { O } & \text { NO } \\
\text { O } & \text { REFUSE } \\
\text { D } & \\
\text { O } & \text { DON' }\end{array}$ & $\begin{array}{ll}O & \text { YES } \\
0 & \text { NO } \\
0 & \text { REFUSE } \\
\text { D } & \\
0 & \text { DON }\end{array}$ \\
\hline
\end{tabular}


A. DRUG AND ALCOHOL USE

1. During the past $\mathbf{3 0}$ days, how many days have you used

Number

of Days REFUSED DONT KNOW the following:
a. Any alcohol [IF ZERO, SKIP TO ITEM B1c.]
bl. Alcohol to intoxication (5+ drinks in one sitting)
b2. Alcohol to intoxication (4 or fewer drinks in one sitting and felt high)
c. Illegal drugs IF B1a ORB1c $=0, R F, D K, T H E N$ SKIP TO ITEM B2.]
d. Both alcohol and drugs (on the same day)

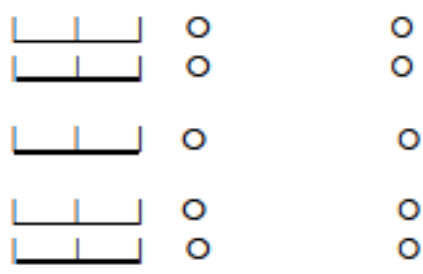

Route of Administration Types:

1. Oral 2. Nasal 3. Smoking 4. Non-IV injection 5.IV "NOTE THE USUAL ROUTE. FOR MORE THAN ONE ROUTE, CHOOSE THE MOST SEVERE. THE ROUTES ARE LISTED FROM LEAST SEVERE (1) TO MOST SEVERE (5).

2. During the past $\mathbf{3 0}$ days, how many days have you used any of the following: IIF THE VALUE IN ANY ITEM B2a THROUGH B2i > 0, THEN THE VALUE IN B1c MUST $B E>0$.]

a. Cocaine/Crack

b. Manjuana/Hashish (Pot, Joints, Blunts, Chronic, Weed, Mary Jane)

c. Opiates:
1. Heroin (Smack, H, Junk, Skag)
2. Morphine
3. Dilaudid
4. Demerol
5. Percocet
6. Darvon
7. Codeine
8. Tylenol 2, 3, 4
9. OxyContin/Oxycodone

d. Non-prescription methadone

e. Hallucinogens/psychedelics, PCP (Angel Dust, Ozone, Wack, Rocket Fuel), MDMA (Ecstasy, XTC $\mathrm{X}$, Adam), LSD (Acid, Boomers, Yellow Sunshine), Mushrooms, or Mescaline
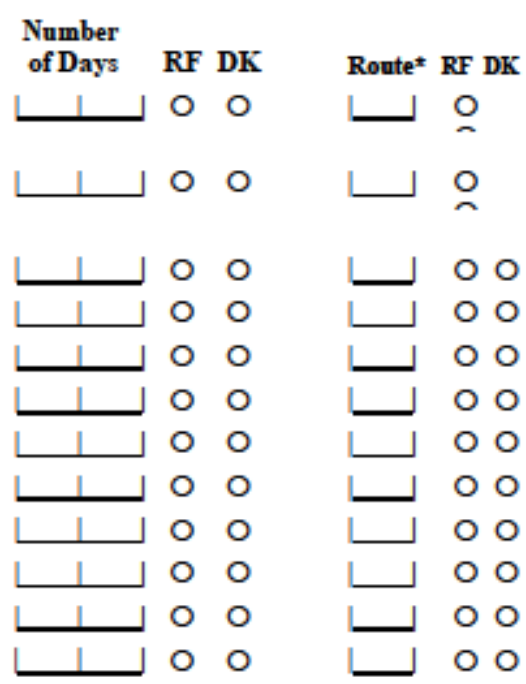

f. Methamphetamine or other amphetamines (Meth, Uppers, Speed, Ice, Chalk, Crystal, Glass, Fire, Crank)
0

O

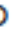




\section{B. DRUG AND ALCOHOL USE (Continued)}

Route of Administration Types:

1. Oral 2. Nasal 3. Smoking 4. Non-IV injection 5. IV NOTE THE USUAL ROUTE. FOR MORE THAN ONE ROUTE, CHOOSE THE MOST SEVERE. THE ROUTES ARE LISTED FROM LEAST SEVERE (1) TO MOST SEVERE (5).

2. During the past 30 days, how many days have you used any of the following: IIF THE VALUE IN ANY ITEM B2a THROUGH B2i $>0$, THEN THE VALUE IN B1c MUST $B E>0$.]

Benzodiazepines: Diazepam(Valium);

Number

of Days RF DK Route* RF DK

Alprazolam (Xanax); Triazolam (Halcion); and Estasolam (Prosom and Rohypnol-also known as roofies, roche, and cope)

2. Barbiturates: Mephobarbital (Mebacut) and pentobarbital sodium(Nembutal)

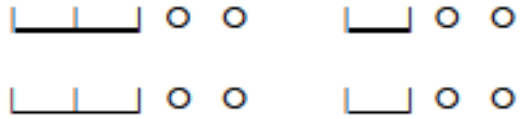

3. Non-prescription GHB (known as Grievous Bodily Harm, Liquid Ecstasy, and Georgia Home Boy)

4. Ketamine (known as Special K or Vitamin K)

5. Other tranquilizers, downers, sedatives, or hypnotics

h. Inhalants (poppers, snappers, rush, whippets)

i. Other illegal drugs (Specify)

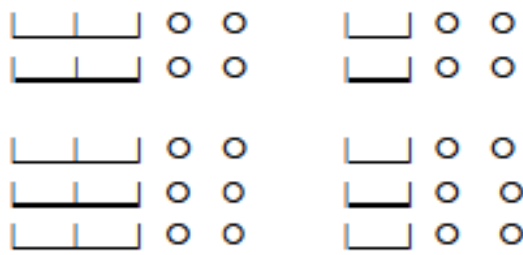

3. In the past 30 days, have you injected drugs? IIF ANY ROUTE OF ADMINISTRATION IN B2a THROUGH B2i $=4$ or 5 , THEN B3 MUST $=$ YES.]

O YES

O NO

O REFUSED

O DON'T KNOW

[IF NO, REFUSED, OR DON'T KNOW, SKIP TO SECTIONC.]

4. In the past $\mathbf{3 0}$ days, how often did you use a syringe/needle, cooker, cotton, or water that someone else used?

O Always

O More than half the time

O Half the time

O Less than half the time

O Never

- REFUSED

O DON'T KNOW 


\section{B. FAMILY AND LIVING CONDITIONS}

1. In the past 30 days, where have you been living most of the time? [DO NOT READ RESPONSE OPTIONS TO CLIENT.]

O SHEL TER (SAFE HAVENS, TRANSITIONAL LIVING CENTER [TLC], LOW-DEMAND FACILITIES, RECEPTION CENTERS, OTHER TEMPORARY DAY OR EVENING FACILITY)

O STREET/OUTDOORS (SIDEWALK, DOORWAY, PARK, PUBLIC OR ABANDONED BUILDING)

O INSTITUTION (HOSPITAL, NURSING HOME, JAIL/PRISON)

O HOUSED: [IF HOUSED, CHECKAPPROPRLATE SUBCATEGORY:] O OWN/RENT APARTMENT, ROOM, OR HOUSE

O SOMEONE ELSE'S APARTMENT, ROOM, OR HOUSE

O DORMTTORY/COLLEGERESIDENCE

O HALFWAY HOUSE

O RESIDENTIAL TREATMENT

O REFUSED

OTHER HOUSED (SPECIFY)

O DON'TKNOW

2. During the past $\mathbf{3 0}$ days, how stressful have things been for you because of your use of alcohol or other drugs? [IF B1a ORB1c > 0, THEN C2 CANNOT = "NOT APPLICABLE."]

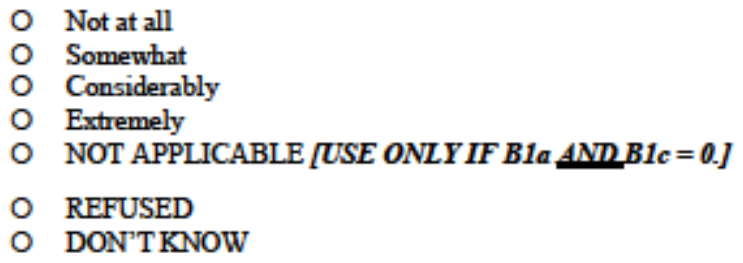

3. During the past $\mathbf{3 0}$ days, has your use of alcohol or other drugs caused you to reduce or give up important activities? [F B1a QRB B1c >0, THENC3 CANNOT $=$ "NOT APPLICABLE."]

O Not at all

O Somewhat

- Considerably

O Extremely

O NOT APPLICABLE [USE ONLY IF B1a ANDB1c $=0$.]

O REFUSED

O DON'T KNOW 


\section{FAMIIY AND LIVING CONDITIONS (Continued)}

1. During the past $\mathbf{3 0}$ days, has your use of alcohol or other drugs caused you to have emotional problems? [IF B1a ORB1c $>0$, THENC4 CANNOT = "NOT APPLICABLE."]

Not at all

O Somewhat

O Considerably

O Extremely

O NOT APPLICABLE [USE ONLY IF B1a AND B1c $=0$.]

O REFUSED

O DON'TKNOW

2. [IF NOT MALE] Are you currently pregnant?

O YES

O NO

O REFUSED

O DON'TKNOW

3. Do you have children?

O YES

O NO

O REFUSED

O DON'TKNOW

[IF NO, REFUSED, OR DON'T KNOW, SKIP TO SECTIOND.]

a. How many children do you have? IF C6 = YES, THEN THE VALUE IN C6a MUST BE > o.]
L ل
O REFUSED
DON'T KNOW

b. Are any of your children living with someone else due to a child protection court order?

O YES

O NO

O REFUSED

O DON'TKNOW

[IF NO, REFUSED, OR DON'T KNOW, SKIP TO ITEM C6d.]

c. IF YES] How many of your children are living with someone else due to a child protection court order? [THE VALUE IN C6c CANNOT EXCEED THE VALUE IN C6a]

$\perp$ - 


\section{FAMIIY AND LIVING CONDITIONS (Continued)}

a. For how many of your children have you lost parental rights? [THE CLIENT'S PARENTAL RIGHTS WERE TERMINATED.] [THE VALUE IN ITEM C6d CANNOT EXCEED THE VALUE IN C6a.]

لـ $\bigcirc$ REFUSED $\bigcirc$ DON'T KNOW

D. EDUCATION, EMPLOYMENT, AND INCOME

1. Are you currently enrolled in school or a job training program? [IF ENROLLED] Is that full time or part time? [IF CLIENT IS INCARCERATED, CODE D1 AS "NOT ENROLLED."]

O NOT ENROLLED

O ENROLLED, FULL TIME

O ENROLLED, PART TIME

O OTHER (SPECIFY)

O REFUSED

O DON'TKNOW

2. What is the highest level of education you have finished, whether or not you received a degree?

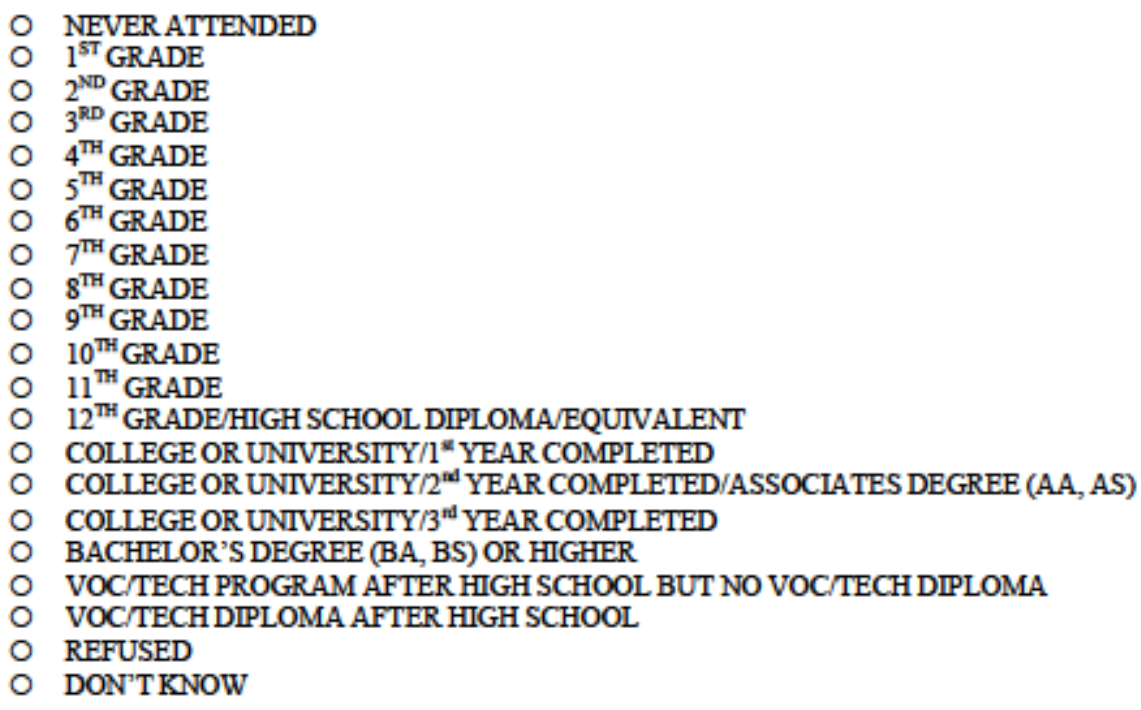


D. EDUCATION, EMPLOYMENT, AND INCOME (Continued)

1. Are you currently employed? [CLARIFY BY FOCUSING ON STATUS DURING MOST OF THE PREVIOUS WEEK, DETERMINING WHETHER CLIENT WORKED AT ALL OR HAD A REGULAR JOB BUT WAS OFF WORK] [IF CLIENT IS “ENROLLED, FULL TIME" IN D1 AND INDICATES "EMPLOYED, FULL TIME" IN D3, ASK FOR CLARIFICATION. IF CLIENT IS INCARCERATED AND HAS NO WORK OUTSIDE OF JAIL, CODE D3 AS “UNEMPLOYED, NOT LOOKING FOR WORK"]

O EMPLOYED, FULL TIME (35+ HOURS PER WEEK, OR WOULD HAVE BEEN)

EMPLOYED, PART TIME

O UNEMPLOYED, LOOKING FOR WORK

O UNEMPLOYED, DISABLED

O UNEMPLOYED, VOLUNTEER WORK

UNEMPLOYED, RETIRED

O UNEMPLOYED, NOT LOOKING FOR WORK

O OTHER (SPECIFY)

O REFUSED

DON'T KNOW

2. Approximately, how much money did YOU receive (pre-tax individual income) in the past $\mathbf{3 0}$ days from... IF D3 DOES NOT = "EMPLOYED" AND THE VALUE IN D4a IS GREATER THAN ZERO, PROBE. IF D3 = "UNEMPLOYED, LOOKTNG FOR WORK" AND THE VALUE IN D4b = 0, PROBE. IF D3 = "UNEMPLOYED, RETIRED" AND THE VALUE IN D4c =0, PROBE. IF D3 = "UNEMPLOYED, DISABLED" AND THE VALUE IN D4d = 0, PROBE.]
a. Wages
b. Public assistance
c. Retirement
d. Disability
e. Non-legal income
f. Family and/or friends
g. Other (Specify)

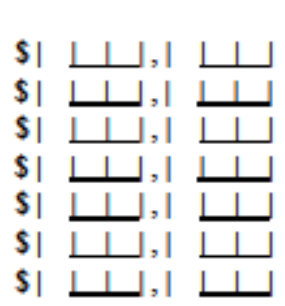

$\begin{array}{cc}\text { RF } & \text { DK } \\ 0 & 0 \\ 0 & 0 \\ 0 & 0 \\ 0 & 0 \\ 0 & 0 \\ 0 & 0 \\ 0 & 0\end{array}$

\section{E. CRIME AND CRIMINAL JUSTICE STATUS}

1. In the past $\mathbf{3 0}$ days, how many times have you been arrested?

$\downarrow \perp$ TIMES O REFUSED O DON'T KNOW

[IF NO ARRESTS, SKIP TO ITEM E3.]

2. In the past $\mathbf{3 0}$ days, how many times have you been arrested for drug-related offenses? [THE VALUE INE2 CANNOT BE GREATER THANTHE VALUE INE1.] 
E. CRIME AND CRIMINAL JUSTICE STATUS (Continued)

1. In the past 30 days, how many nights have you spent in jail/prison? IF THE VALUE IN E3 IS GREATER THAN 15, THEN C1 MUST = INSTITUTION (JAILPRISON). IF C1 = INSTITUTION (JAILPRISON), THEN THE VALUE INE3 MUST BE GREATER THANOR EQUAL TO 15.]

L $\perp$ NIGHTS O REFUSED O DON'T KNOW

2. In the past 30 days, how many times have you committed a crime? [CHECK NUMBER OF DAYS USED ILLEGAL DRUGS INITEM B1c ON PAGE 7. ANSWER HERE IN E4 SHOULD BE EQUAL TO OR GREATER THAN NUMBER IN B1C BECAUSE USING ILLEGAL DRUGS IS A CRIME.]

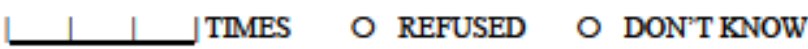

3. Are you currently awaiting charges, trial, or sentencing?

$\begin{array}{ll}\circ & \text { YES } \\ \circ & \text { NO } \\ \circ & \text { REFUSED } \\ \circ & \text { DON'T KNOW }\end{array}$

4. Are you currently on parole or probation?
O YES
O NO
O REFUSED
O DON'TKNOW

\section{F. MENTAL AND PHYSICAL HEALTH PROBLEMS AND TREATMENT/RECOVERY}

1. How would you rate your overall health right now?

$\begin{array}{ll}\text { O } & \text { Excellent } \\ \text { O } & \text { Very good } \\ \text { O } & \text { Good } \\ \text { O } & \text { Fair } \\ \text { O } & \text { Poor } \\ \text { O } & \text { REFUSED } \\ \text { O } & \text { DON'T KNOW }\end{array}$


MENTAL AND PHYSICAL HEALTH PROBLEMS AND TREATMENT/RECOVERY

(Continued)

1. During the past $\mathbf{3 0}$ days, did you receive:

a. Inpatient Treatment for:

\begin{tabular}{|c|c|c|c|c|}
\hline YES & $\begin{array}{c}\text { [IF YES] } \\
\text { Altogether } \\
\text { for how many nights }\end{array}$ & No & RF & DK \\
\hline 0 & _nights & 0 & 0 & 0 \\
\hline 0 & _nights & 0 & 0 & 0 \\
\hline 0 & nights & 0 & 0 & 0 \\
\hline
\end{tabular}

b. Outpatient Treatment for:

[IF YES]

Altogether

i. Physical complaint
ii. Mental or emotional difficulties

iii. Alcohol or substance abuse

0
i. Physical complaint
ii. Mental or emotional difficulties
iii. Alcohol or substance abuse

c. Emergency Room Treatment for:
i. Physical complaint
ii. Mental or emotional difficulties
iii. Alcohol or substance abuse

\begin{tabular}{|c|c|c|c|c|}
\hline YES & $\begin{array}{l}\text { Altogether } \\
\text { for how many times }\end{array}$ & No & RF & DK \\
\hline 0 & times & O & 0 & 0 \\
\hline 0 & times & 0 & 0 & 0 \\
\hline O & - times & O & 0 & 0 \\
\hline YES & $\begin{array}{c}\text { [IF YES] } \\
\text { Altogether } \\
\text { for how many times }\end{array}$ & No & RF & DK \\
\hline O & times & O & 0 & 0 \\
\hline O & - times & O & 0 & 0 \\
\hline 0 & _times & 0 & 0 & 0 \\
\hline
\end{tabular}


MENTAL AND PHYSICAL HEALTH PROBLEMS AND TREATMENT/RECOVERY

(Continued)

1. During the past $\mathbf{3 0}$ days, did you engage in serual activity?

O Yes

O No $\rightarrow$ [SKIP TO F4.]

O NOT PERMITTED TO ASK $\rightarrow$ [SKIP TO F4.]

O REFUSED $\rightarrow$ [SKIP TO F4.]

○ DON'T KNOW $\rightarrow$ [SKIP TO F4.]

[IF YES] Altogether, how many:

a. Sexual contacts (vaginal, oral, or anal) did you have?

b. Unprotected sexual contacts did you have? [THE VALUE IN F3b SHOULD NOT BE GREATER THAN THE VALUE IN F3a.] [IF ZERO, SKTP TO F4.]

c. Unprotected sexual contacts were with an individual who is or was: [NONE OF THE VALUES IN F3c1 THROUGH F3c3 CAN BE GREATER THAN THE VALUE IN F3b.]

1. HIV positive or has AIDS

2. An injection drug user

3. High on some substance

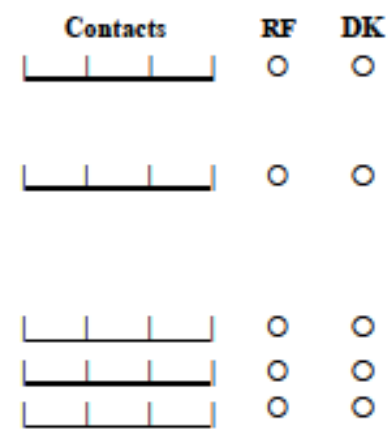

4. Have you ever been tested for HIV?

O Yes .......................... [GO TOF4a.]

O No ................................ [SIP TOF5.]

O REFUSED ….............. [SKIP TO F5]

O DON'T KNOW ........... [SKIP TO F5.]

4a. Do you know the results of your HIV testing?

O Yes

O No 
MENTAL AND PHYSICAL HEALTH PROBLEMS AND TREATMENT/RECOVERY

(Continued)

4. In the past $\mathbf{3 0}$ days, not due to your use of alcohol or drugs, how many days have you:
a. Experienced serious depression
b. Experienced serious anxiety or tension
c. Experiencedhallucinations

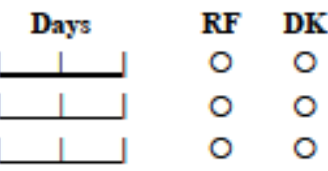
d. Experienced trouble understanding, concentrating, or remembering
e. Experienced trouble controlling violent behavior
f. Attempted suicide
g. Been prescribed medication for psychological/emotional problem

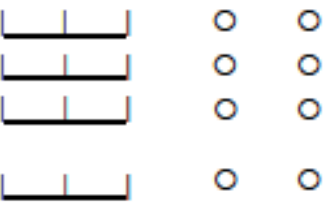

[IF CLIENT REPORTS ZERO DAYS, RF, OR DK TO ALLITEMS IN QUESTION S, SKIP TO ITEM F7.]

5. How much have you been bothered by these psychological or emotional problems in the past 30 days?

O Not at all

O Slightly

O Moderately

O Considerably

O Extremely

O REFUSED

O DON'T KNOW

\section{VIOLENCE AND TRAUMA}

7. Have you ever experienced violence or trauma in any setting (including community or school violence; domestic violence; physical, psychological, or sexual maltreatment/assault within or outside of the family; natural disaster; terrorism; neglect; or traumatic grief?)
O YES
O NO [SKIP TO ITEM F8.]
O REFUSED
O DON'T KNOW

[IF NO, REFUSED, OR DON'T KNOW, SKIP TO ITEM F8.] 


\section{F. MENTAL AND PHYSICAL HEALTH PROBLEMS AND TREATMENT/RECOVERY}

(Continued)

Did any of these experiences feel so frightening, horrible, or upsetting that, in the past and/or the present, you:

7a. Have had nightmares about it or thought about it when you did not want to?

O YES

O NO

O REFUSED

O DON'T KNOW

7b. Tried hard not to think about it or went out of your way to avoid situations that remind you of it?

O YES

O NO

O REFUSED

O DON'T KNOW

7c. Were constantly on guard, watchful, or easily startled?

O YES

O NO

O REFUSED

DON'T KNOW

7d. Felt numb and detached from others, activities, or your surroundings?
O YES
O NO
O REFUSED
O DON'T KNOW

7. In the past 30 days, how often have you been hit, kicked, slapped, or otherwise physically hurt?
O Never
O A few times
O More than a few times
O REFUSED
O DON'T KNOW 


\section{F. SOCIALCONNECTEDNESS}

1. In the past $\mathbf{3 0}$ days, did you attend any voluntary self-help groups for recovery that were not affiliated with a religious or faith-based organization? In other words, did you participate in a nonprofessional, peer-operated organization that is devoted to helping individuals who have addictionrelated problems such as: Alcoholics Anonymous, Narcotics Anonymous, Oxford House, Secular Organization for Sobriety, or Women for Sobriety, etc.?

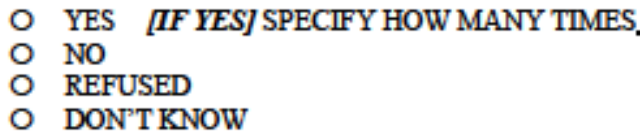

2. In the past $\mathbf{3 0}$ days, did you attend any religious/faith-affiliated recovery self-help groups?
O YES [IF YES] SPECIFY HOW MANY TIMES O REFUSED
O DON'TKNOW
O NO
O REFUSED
O DON'T KNOW

3. In the past $\mathbf{3 0}$ days, did you attend meetings of organizations that support recovery other than the organizations described above?

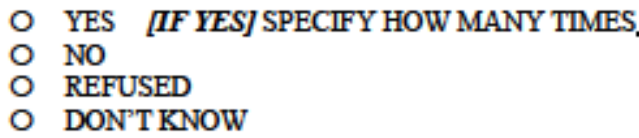

4. In the past $\mathbf{3 0}$ days, did you have interaction with family and/or friends that are supportive of your recovery?
O YES
O NO
O REFUSED
O DON'TKNOW

5. To whom do you turn when you are having trouble? [SELECT ONLY ONE.]
O NOONE
O CLERGYMEMBER
O FAMIIIYMEMBER
O FRIEINDS
O REFUSED
O DON'T KNOW
O OTHER (SPECIFY) 
I. FOLLOW-UP STATUS

[REPORTED BY PROGRAM STAFF ABOUT CLIENT ONLY AT FOLLOW-UP.]

1. What is the follow-up status of the client? [THIS IS A REQUIRED FIELD: NA, REFUSED, DONT KNOW, AND MISSING WILL NOT BE ACCEPTED.]

O $01=$ Deceased at time of due date

O $11=$ Completed interview within specified window

O $12=$ Completed interview outside specified window

O 21 = Located, but refused, unspecified

O $22=$ Located, but unable to gain institutional access

O $23=$ Located, but otherwise unable to gain access

O $24=$ Located, but withdrawn from project

O 31 = Unable to locate, moved

O 32 =Unable to locate, other (Specify)

2. Is the client still receiving services from your program?

- Yes

No

[IF THIS IS A FOLLOW-UP INTERVIEW, STOP NOW; THE INTERVIEW IS COMPLETE.] 


\section{J. SERVICESRECEIVED}

[REPORTED BY PROGRAM STAFF ABOUT CLIENT ONLYAT DISCHARGE]

Identify the number of DAYS of services provided to the client during the client's course of treatment/recovery. [ENTER ZERO IF NO SERVICES PROVIDED. YOU SHOULD HAVE AT LEAST ONE DAY FOR MODALITY.]

Modality

1. Case Management

2. Day Treatment

3. Inpatient/Hospital (Other Than Detox)

4. Outpatient

5. Outreach

6. Intensive Outpatient

7. Methadone

8. Residential/Rehabilitation

9. Detoxification (Select Only (Inci

A. Hospital Inpatient

B. Free Standing Residential

C. Ambulatory Detoxification

10. After Care

11. Recovery Support

12. Other (Specify)

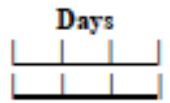

Identify the number of SESSIONS provided to the client during the client's course of treatment/ recovery. [ENTER ZERO IF NO SERVICES PROVIDED.]

\section{Services}

[SBIRT GRANTS: YOU MUST HAVE AT LEAST ONE SESSION FOR ONE OF THE TREATMENT SERVTCES NUMBERED 1 THROUGH 4.]

1. Screening

2 Brief Intervention

3. Brief Treatment

4. Referral to Treatment

5. Assessment

6. Treatment/Recovery Planning

7. Individual Counseling

8. Group Counseling

9. Family/Mamiage Counseling

10. Co-Occurring Treatment/ Recovery Services

11. Pharmacological Interventions

12. HIV/AIDS Counseling

13. Other Clinical Services (Specify)

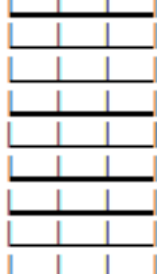

Case Management Services

Sessions

1. Family Services (Including Marriage Education, Parenting Child Development Services)

2. Child Care

3. Employment Service A. Pre-Employment B. Employment Coaching

4. Individual Services Coordination

5. Transportation

6. HIV/AIDS Service

7. Supportive Transitional DrugFree Housing Services

8. Other Case Management Services (Specify)

Medical Services

1. Medical Care

2. Alcohol/Drug Testing

3. HIV/ AIDS Medical Support \& Testing

4. Other Medical Services (Specify)
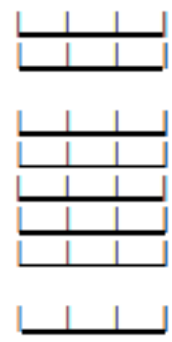

After Care Services

1. Continuing Care

2. Relapse Prevention

3. Recovery Coaching

4. Self-Help and Support Groups | لـ Treatment

5. Spinitual Support

6. Other After Care Services (Specify)

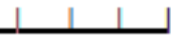

Education Services

1. Substance Abuse Education

2. HIV/AIDS Education

3. Other Education Services (Specify)

Sessions

Peer-to-Peer Recovery Support Services

1. Peer Coaching or Mentoring

2. Housing Support

3. Alcohol- and Drug-Free Social Activities

4. Information and Referral

Sessions
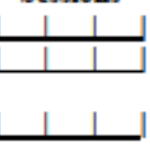

Other Peer-to-Peer Recovery

Support Services (Specify) 
APPENDIX 6.1a. Variance Inflation Factor Scores for Independent Variable (Individual Characteristics)

\begin{tabular}{|c|c|c|c|c|c|c|c|c|c|c|c|c|c|}
\hline Variable: & Age & Female & $\begin{array}{l}\text { Non- } \\
\text { White }\end{array}$ & $\begin{array}{l}\text { Participant } \\
\text { Income }\end{array}$ & $\begin{array}{c}\text { Days of } \\
\text { Alcohol } \\
\text { Use }\end{array}$ & $\begin{array}{l}\text { Days of } \\
\text { Drug } \\
\text { Use }\end{array}$ & $\begin{array}{c}\text { Days of } \\
\text { Serious } \\
\text { Depression }\end{array}$ & $\begin{array}{l}\text { Days of } \\
\text { Serious } \\
\text { Anxiety }\end{array}$ & $\begin{array}{c}\text { Days of } \\
\text { Hallucinations }\end{array}$ & $\begin{array}{c}\text { Days of } \\
\text { Impaired } \\
\text { Brain } \\
\text { Function }\end{array}$ & $\begin{array}{c}\text { Days of } \\
\text { Violent } \\
\text { Behavior }\end{array}$ & $\begin{array}{l}\text { Number } \\
\text { of Arrests }\end{array}$ & $\begin{array}{c}\text { Days } \\
\text { Incarcerated }\end{array}$ \\
\hline Cincinnati & 4.1 & 4.0 & 4.0 & 3.8 & 3.5 & 3.4 & 4.1 & 4.1 & 4.1 & 3.9 & 4.1 & 3.9 & 4.0 \\
\hline Age & $\mathrm{x}$ & 1.1 & 1.1 & 1.1 & 1.1 & 1.1 & 1.1 & 1.1 & 1.1 & 1.1 & 1.1 & 1.1 & 1.1 \\
\hline Female & 1.1 & $\mathrm{x}$ & 1.1 & 1.1 & 1.1 & 1.1 & 1.1 & 1.1 & 1.1 & 1.1 & 1.1 & 1.1 & 1.1 \\
\hline Non-White & 1.2 & 1.2 & $\mathrm{x}$ & 1.2 & 1.2 & 1.2 & 1.2 & 1.2 & 1.2 & 1.2 & 1.2 & 1.2 & 1.2 \\
\hline $\begin{array}{l}\text { Participant } \\
\text { Income }\end{array}$ & 1.4 & 1.4 & 1.4 & $\mathrm{x}$ & 1.3 & 1.3 & 1.4 & 1.4 & 1.4 & 1.4 & 1.3 & 1.4 & 1.4 \\
\hline Days of Alcohol Use & 2.5 & 2.5 & 2.5 & 2.5 & $\mathrm{x}$ & 2.3 & 2.5 & 2.5 & 2.4 & 2.5 & 2.5 & 2.5 & 2.5 \\
\hline Days of Drug Use & 2.2 & 2.2 & 2.2 & 2.1 & 2.0 & $\mathrm{x}$ & 2.2 & 2.2 & 2.2 & 2.2 & 2.2 & 2.2 & 2.2 \\
\hline $\begin{array}{l}\text { Days of Serious } \\
\text { Depression }\end{array}$ & 1.9 & 1.9 & 1.9 & 1.9 & 1.9 & 1.9 & $\mathrm{x}$ & 1.4 & 1.9 & 1.9 & 1.9 & 1.9 & 1.9 \\
\hline $\begin{array}{l}\text { Days of Serious } \\
\text { Anxiety }\end{array}$ & 2.0 & 2.0 & 1.9 & 2.0 & 2.0 & 2.0 & 1.5 & $\mathrm{x}$ & 2.0 & 1.9 & 2.0 & 2.0 & 2.0 \\
\hline $\begin{array}{l}\text { Days of } \\
\text { Hallucinations }\end{array}$ & 1.6 & 1.6 & 1.6 & 1.6 & 1.6 & 1.6 & 1.6 & 1.6 & $\mathrm{x}$ & 1.5 & 1.6 & 1.6 & 1.6 \\
\hline $\begin{array}{l}\text { Days of Impaired } \\
\text { Brain Function }\end{array}$ & 1.7 & 1.7 & 1.7 & 1.7 & 1.7 & 1.7 & 1.7 & 1.6 & 1.6 & $\mathrm{x}$ & 1.6 & 1.7 & 1.7 \\
\hline $\begin{array}{l}\text { Days of Violent } \\
\text { Behavior }\end{array}$ & 1.6 & 1.6 & 1.6 & 1.5 & 1.6 & 1.6 & 1.5 & 1.6 & 1.5 & 1.5 & $\mathrm{x}$ & 1.5 & 1.5 \\
\hline Number of Arrests & 2.8 & 2.8 & 2.8 & 2.8 & 2.8 & 2.8 & 2.8 & 2.8 & 2.8 & 2.8 & 2.7 & $\mathrm{x}$ & 1.5 \\
\hline Days Incarcerated & 2.6 & 2.6 & 2.6 & 2.6 & 2.5 & 2.5 & 2.6 & 2.6 & 2.6 & 2.6 & 2.5 & 1.4 & $\mathrm{x}$ \\
\hline Population Density & 2.7 & 2.7 & 2.7 & 2.7 & 2.7 & 2.7 & 2.7 & 2.7 & 2.7 & 2.7 & 2.7 & 2.7 & 2.7 \\
\hline $\begin{array}{l}\text { Percent of Vacant } \\
\text { Dwellings }\end{array}$ & 4.5 & 4.5 & 4.5 & 4.5 & 4.5 & 4.5 & 4.5 & 4.5 & 4.5 & 4.5 & 4.5 & 4.5 & 4.5 \\
\hline $\begin{array}{l}\text { Percent of } \\
\text { Households in } \\
\text { Poverty }\end{array}$ & 8.6 & 8.6 & 8.7 & 8.6 & 8.6 & 8.6 & 8.6 & 8.6 & 8.6 & 8.6 & 8.7 & 8.7 & 8.6 \\
\hline $\begin{array}{l}\text { Median Household } \\
\text { Income }\end{array}$ & 7.2 & 7.3 & 7.3 & 7.2 & 7.3 & 7.2 & 7.3 & 7.3 & 7.3 & 7.2 & 7.3 & 7.3 & 7.3 \\
\hline $\begin{array}{l}\text { Distance to Bus } \\
\text { Stop }\end{array}$ & 1.2 & 1.2 & 1.2 & 1.2 & 1.2 & 1.2 & 1.2 & 1.2 & 1.2 & 1.2 & 1.2 & 1.2 & 1.2 \\
\hline $\begin{array}{l}\text { Distance to Central } \\
\text { Business District }\end{array}$ & 2.9 & 2.9 & 2.9 & 2.8 & 2.9 & 2.9 & 2.9 & 2.9 & 2.9 & 2.9 & 2.9 & 2.9 & 2.9 \\
\hline Crimes Per Capita & 1.7 & 1.7 & 1.7 & 1.7 & 1.7 & 1.7 & 1.7 & 1.7 & 1.7 & 1.7 & 1.7 & 1.7 & 1.7 \\
\hline
\end{tabular}


APPENDIX 6.1b. Variance Inflation Factors for Independent Variables (Neighborhood Characteristics)

\begin{tabular}{|c|c|c|c|c|c|c|c|c|}
\hline Variable: & Cincinnati & $\begin{array}{l}\text { Population } \\
\text { Density }\end{array}$ & $\begin{array}{c}\text { Percent } \\
\text { of Vacant } \\
\text { Dwellings }\end{array}$ & $\begin{array}{l}\text { Percent of } \\
\text { Households } \\
\text { in Poverty }\end{array}$ & $\begin{array}{l}\text { Median } \\
\text { Household } \\
\text { Income }\end{array}$ & $\begin{array}{c}\text { Distance } \\
\text { to Bus } \\
\text { Stop }\end{array}$ & $\begin{array}{c}\text { Distance } \\
\text { to } \\
\text { Central } \\
\text { Business } \\
\text { District }\end{array}$ & $\begin{array}{c}\text { Crimes } \\
\text { Per } \\
\text { Capita }\end{array}$ \\
\hline Cincinnati & $\mathrm{x}$ & 4.1 & 3.5 & 4.1 & 4.1 & 4.1 & 4.0 & 4.1 \\
\hline Age & 1.1 & 1.1 & 1.1 & 1.1 & 1.1 & 1.1 & 1.1 & 1.1 \\
\hline Female & 1.1 & 1.1 & 1.1 & 1.1 & 1.1 & 1.1 & 1.1 & 1.1 \\
\hline Non-White & 1.2 & 1.2 & 1.2 & 1.2 & 1.2 & 1.2 & 1.2 & 1.2 \\
\hline Participant Income & 1.3 & 1.4 & 1.4 & 1.4 & 1.4 & 1.4 & 1.3 & 1.4 \\
\hline $\begin{array}{l}\text { Days of Alcohol } \\
\text { Use }\end{array}$ & 2.2 & 2.5 & 2.5 & 2.5 & 2.5 & 2.5 & 2.5 & 2.5 \\
\hline Days of Drug Use & 1.9 & 2.2 & 2.2 & 2.2 & 2.2 & 2.2 & 2.2 & 2.2 \\
\hline $\begin{array}{l}\text { Days of Serious } \\
\text { Depression }\end{array}$ & 1.9 & 1.9 & 1.9 & 1.9 & 1.9 & 1.9 & 1.9 & 1.9 \\
\hline $\begin{array}{l}\text { Days of Serious } \\
\text { Anxiety }\end{array}$ & 2.0 & 2.0 & 2.0 & 2.0 & 2.0 & 2.0 & 2.0 & 2.0 \\
\hline $\begin{array}{l}\text { Days of } \\
\text { Hallucinations }\end{array}$ & 1.6 & 1.6 & 1.6 & 1.6 & 1.6 & 1.6 & 1.6 & 1.6 \\
\hline $\begin{array}{l}\text { Days of Impaired } \\
\text { Brain Function }\end{array}$ & 1.7 & 1.7 & 1.7 & 1.7 & 1.7 & 1.7 & 1.7 & 1.7 \\
\hline $\begin{array}{l}\text { Days of Violent } \\
\text { Behavior }\end{array}$ & 1.6 & 1.5 & 1.6 & 1.6 & 1.6 & 1.6 & 1.6 & 1.6 \\
\hline Number of Arrests & 2.7 & 2.8 & 2.8 & 2.8 & 2.8 & 2.8 & 2.8 & 2.8 \\
\hline Days Incarcerated & 2.6 & 2.6 & 2.6 & 2.6 & 2.6 & 2.6 & 2.6 & 2.6 \\
\hline Population Density & 2.7 & $\mathrm{x}$ & 1.7 & 2.7 & 2.7 & 2.7 & 2.4 & 2.4 \\
\hline $\begin{array}{l}\text { Percent of Vacant } \\
\text { Dwellings }\end{array}$ & 3.9 & 2.9 & $\mathrm{~s}$ & 4.2 & 4.5 & 4.5 & 4.5 & 4.1 \\
\hline $\begin{array}{l}\text { Percent of } \\
\text { Households in } \\
\text { Poverty }\end{array}$ & 8.6 & 8.7 & 8.1 & $\mathrm{x}$ & 2.8 & 8.5 & 8.3 & 8.5 \\
\hline $\begin{array}{l}\text { Median Household } \\
\text { Income }\end{array}$ & 7.3 & 7.3 & 7.3 & 2.3 & $\mathrm{x}$ & 7.1 & 7.2 & 7.2 \\
\hline $\begin{array}{l}\text { Distance to Bus } \\
\text { Stop }\end{array}$ & 1.2 & 1.2 & 1.2 & 1.2 & 1.2 & $\mathrm{x}$ & 1.2 & 1.2 \\
\hline $\begin{array}{l}\text { Distance to Central } \\
\text { Business District }\end{array}$ & 2.9 & 2.6 & 2.9 & 2.8 & 2.9 & 2.8 & $\mathrm{x}$ & 2.5 \\
\hline Crimes Per Capita & 1.7 & 1.5 & 1.5 & 1.7 & 1.7 & 1.7 & 1.4 & $\mathrm{x}$ \\
\hline
\end{tabular}


APPENDIX 6.2a. Pearson Correlation Coefficients for Independent Variables (Individual Characteristics)

\begin{tabular}{|c|c|c|c|c|c|c|c|c|c|c|c|c|c|}
\hline Variable: & Age & Female & Non-White & Income & Alcohol & Drug & Depression & Anxiety & Hallucinations & Impaired & Violent & Arrests & Incarceration \\
\hline Cincinnati & $.116^{*}$ & .044 & $.151^{* *}$ & $-.280^{* *}$ & $.628^{* *}$ & $.617^{* *}$ & -.046 & -.052 & -.094 & $-.276^{* *}$ & -.034 & -.078 & -.065 \\
\hline Age & 1 & -.095 & .037 & -.017 & .100 & .004 & .034 & .046 & $-.134^{*}$ & .002 & -.101 & -.038 & -.048 \\
\hline Female & -.095 & 1 & -.093 & .093 & -.028 & .087 & .006 & .028 & $.118^{*}$ & .052 & $.127^{*}$ & -.029 & -.056 \\
\hline Non-White & .037 & -.093 & 1 & .008 & .045 & .027 & $-.195^{* *}$ & $-.246^{* *}$ & .058 & -.090 & .039 & .034 & .045 \\
\hline Participant Income & -.017 & .093 & .008 & 1 & $-.206^{* *}$ & -.002 & .040 & .070 & $.228^{* *}$ & .100 & $.239^{* *}$ & .066 & .088 \\
\hline Days of Alcohol Use & .100 & -.028 & .045 & $-.206^{* *}$ & 1 & $.571^{* *}$ & $.170^{* *}$ & $.144^{*}$ & -.024 & $-.130^{*}$ & $.139^{*}$ & $.240^{* *}$ & $.219^{* *}$ \\
\hline Days of Drug Use & .004 & .087 & .027 & -.002 & $.571^{* *}$ & 1 & .105 & $.149^{* * *}$ & $.122^{*}$ & -.084 & $.213^{* *}$ & .069 & .002 \\
\hline $\begin{array}{l}\text { Days of Serious } \\
\text { Depression }\end{array}$ & .034 & .006 & $-.195^{* *}$ & .040 & $.170^{* *}$ & .105 & 1 & $.631^{* *}$ & $.268^{* *}$ & $.392^{* *}$ & $.290^{* *}$ & $.253^{* *}$ & $.209^{* *}$ \\
\hline $\begin{array}{l}\text { Days of Serous } \\
\text { Anxiety }\end{array}$ & .046 & .028 & $-.246^{* *}$ & .070 & $.144^{*}$ & $.149^{* *}$ & $.631^{* *}$ & 1 & $.265^{* *}$ & $.455^{* *}$ & $.222^{* *}$ & .097 & .063 \\
\hline $\begin{array}{l}\text { Days of } \\
\text { Hallucinations }\end{array}$ & $-.134^{*}$ & $.118^{*}$ & .058 & $.228^{* *}$ & -.024 & $.122^{*}$ & $.268^{* *}$ & $.265^{* *}$ & 1 & $.387^{* *}$ & $.398^{* *}$ & $.316^{* *}$ & $.270^{* *}$ \\
\hline $\begin{array}{l}\text { Days of Impaired } \\
\text { Brain Function }\end{array}$ & .002 & .052 & -.090 & .100 & $-.130^{*}$ & -.084 & $.392^{* *}$ & $.455^{* *}$ & $.387^{* *}$ & 1 & $.314^{* *}$ & .086 & .102 \\
\hline $\begin{array}{l}\text { Days of Violent } \\
\text { Behavior }\end{array}$ & -.101 & $.127^{*}$ & .039 & $.239^{* *}$ & $.139^{*}$ & $.213^{* *}$ & $.290^{* *}$ & $.222^{* *}$ & $.398^{* *}$ & $.314^{* *}$ & 1 & $.345^{* *}$ & $.204^{* *}$ \\
\hline Number of Arrests & -.038 & -.029 & .034 & .066 & $.240^{* *}$ & .069 & $.253^{* *}$ & .097 & $.316^{* *}$ & .086 & $.345^{* *}$ & 1 & $.758^{* *}$ \\
\hline Days Incarcerated & -.048 & -.056 & .045 & .088 & $.219^{* *}$ & .002 & $.209^{* *}$ & .063 & $.270^{* *}$ & .102 & $.204^{* *}$ & $.758^{* *}$ & 1 \\
\hline Population Density & $.116^{*}$ & .062 & $.183^{* *}$ & -.070 & $.175^{* *}$ & $.135^{*}$ & -.016 & -.078 & -.061 & -.089 & -.076 & -.069 & -.075 \\
\hline $\begin{array}{l}\text { Percent of Vacant } \\
\text { Dwellings }\end{array}$ & $.162^{* *}$ & .035 & $.149^{* *}$ & $-.150^{* *}$ & $.370^{* *}$ & $.339^{* *}$ & -.057 & -.087 & -.077 & $-.199^{* *}$ & -.027 & -.079 & -.105 \\
\hline $\begin{array}{l}\text { Percent of } \\
\text { Households in } \\
\text { Poverty }\end{array}$ & $.128^{*}$ & .016 & $.179^{* *}$ & $-.157^{* *}$ & $.179^{* *}$ & $.223^{* *}$ & -.003 & -.087 & -.071 & $-.116^{*}$ & .021 & -.034 & -.045 \\
\hline $\begin{array}{l}\text { Median Household } \\
\text { Income }\end{array}$ & -.074 & -.048 & $-.191^{* *}$ & .090 & -.072 & -.100 & .044 & .108 & .073 & .080 & -.023 & .050 & .061 \\
\hline $\begin{array}{l}\text { Distance to Bus } \\
\text { Stop }\end{array}$ & -.025 & -.022 & $-.129^{*}$ & .056 & .071 & .063 & .029 & .087 & .007 & .075 & .033 & .050 & $.128^{*}$ \\
\hline $\begin{array}{l}\text { Distance to Central } \\
\text { Business District }\end{array}$ & -.103 & -.041 & $-.140^{*}$ & $.185^{* *}$ & -.013 & -.081 & .051 & .071 & $.138^{*}$ & .050 & .032 & .097 & $.114^{*}$ \\
\hline Crimes Per Capita & .063 & .050 & .069 & -.096 & $.157^{* *}$ & $.176^{* *}$ & -.098 & $-.134^{*}$ & -.111 & $-.158^{* *}$ & -.026 & -.057 & -.070 \\
\hline
\end{tabular}


APPENDIX 6.2b. Pearson Correlation Coefficients for Independent Variables (Neighborhood Characteristics)

\begin{tabular}{|c|c|c|c|c|c|c|c|c|}
\hline Variables: & Cincinnati & $\begin{array}{c}\text { Population } \\
\text { Density }\end{array}$ & $\begin{array}{c}\text { Percent of } \\
\text { Vacant } \\
\text { Dwellings }\end{array}$ & $\begin{array}{l}\text { Percent of } \\
\text { Households } \\
\text { in Poverty }\end{array}$ & $\begin{array}{l}\text { Median } \\
\text { Household } \\
\text { Income }\end{array}$ & $\begin{array}{l}\text { Distance to } \\
\text { Bus Stop }\end{array}$ & $\begin{array}{c}\text { Distance to } \\
\text { Central } \\
\text { Business } \\
\text { District } \\
\end{array}$ & $\begin{array}{c}\text { Crimes Per } \\
\text { Capita }\end{array}$ \\
\hline Cincinnati & 1 & $.392^{* *}$ & $.668^{* *}$ & $.423^{* *}$ & $-.271^{* *}$ & .004 & $-.211^{* *}$ & $.325^{* *}$ \\
\hline Age & $.116^{*}$ & $.116^{*}$ & $.162^{* *}$ & $.128^{*}$ & -.074 & -.025 & -.103 & .063 \\
\hline Female & .044 & .062 & .035 & .016 & -.048 & -.022 & -.041 & .050 \\
\hline Non-White & $.151^{* *}$ & $.183^{* *}$ & $.149^{* *}$ & $.179^{* *}$ & $-.191^{* *}$ & $-.129^{*}$ & $-.140^{*}$ & .069 \\
\hline Participant Income & $-.280^{* *}$ & -.070 & $-.150^{* *}$ & $-.157^{* *}$ & .090 & .056 & $.185^{* *}$ & -.096 \\
\hline Days of Alcohol Use & $.628^{* *}$ & $.175^{* *}$ & $.370^{* *}$ & $.179^{* *}$ & -.072 & .071 & -.013 & $.157^{* *}$ \\
\hline Days of Drug Use & $.617^{* *}$ & $.135^{*}$ & $.339^{* *}$ & $.223^{* *}$ & -.100 & .063 & -.081 & $.176^{* *}$ \\
\hline $\begin{array}{l}\text { Days of Serious } \\
\text { Depression }\end{array}$ & -.046 & -.016 & -.057 & -.003 & .044 & .029 & .051 & -.098 \\
\hline Days of Serious Anxiety & -.052 & -.078 & -.087 & -.087 & .108 & .087 & .071 & $-.134^{*}$ \\
\hline Days of Hallucinations & -.094 & -.061 & -.077 & -.071 & .073 & .007 & $.138^{*}$ & -.111 \\
\hline $\begin{array}{l}\text { Days of Impaired Brain } \\
\text { Function }\end{array}$ & $-.276^{* *}$ & -.089 & $-.199^{* *}$ & $-.116^{*}$ & .080 & .075 & .050 & $-.158^{* *}$ \\
\hline $\begin{array}{l}\text { Days of Violent } \\
\text { Behavior }\end{array}$ & -.034 & -.076 & -.027 & .021 & -.023 & .033 & .032 & -.026 \\
\hline Number of Arrests & -.078 & -.069 & -.079 & -.034 & .050 & .050 & .097 & -.057 \\
\hline Days Incarcerated & -.065 & -.075 & -.105 & -.045 & .061 & $.128^{*}$ & $.114^{*}$ & -.070 \\
\hline Population Density & $.392^{* *}$ & 1 & $.718^{* *}$ & $.515^{* *}$ & $-.451^{* *}$ & $-.163^{* *}$ & $-.489^{* *}$ & $.182^{* *}$ \\
\hline $\begin{array}{l}\text { Percent of Vacant } \\
\text { Dwellings }\end{array}$ & $.668^{* *}$ & $.718^{* *}$ & 1 & $.644^{* *}$ & $-.522^{* *}$ & $-.121^{*}$ & $-.464^{* *}$ & $.438^{* *}$ \\
\hline $\begin{array}{l}\text { Percent of Households } \\
\text { in Poverty }\end{array}$ & $.423^{* *}$ & $.515^{* *}$ & $.644^{* *}$ & 1 & $-.906^{* *}$ & $-.202^{* *}$ & $-.690^{* *}$ & $.412^{* *}$ \\
\hline $\begin{array}{l}\text { Median Household } \\
\text { Income }\end{array}$ & $-.271^{* *}$ & $-.451^{* *}$ & $-.522^{* *}$ & $-.906^{* *}$ & 1 & $.275^{* *}$ & $.688^{* *}$ & $-.416^{* *}$ \\
\hline Distance to Bus Stop & .004 & $-.163^{* *}$ & $-.121^{*}$ & $-.202^{* *}$ & $.275^{* *}$ & 1 & $.337^{* *}$ & $-.162^{* *}$ \\
\hline $\begin{array}{l}\text { Distance to Central } \\
\text { Business District }\end{array}$ & $-.211^{* *}$ & $-.489^{* *}$ & $-.464^{* *}$ & $-.690^{* *}$ & $.688^{* *}$ & $.337^{* *}$ & 1 & $-.492^{* *}$ \\
\hline Crimes Per Capita & $.325^{* *}$ & $.182^{* *}$ & $.438^{* *}$ & $.412^{* *}$ & $-.416^{* *}$ & $-.162^{* *}$ & $-.492^{* *}$ & 1 \\
\hline
\end{tabular}




\section{CURRICULUM VITA}

NAME:

ADDRESS:

EDUCATION:

HONORS:
Carey D. Addison, Jr.

Family Health Centers-Phoenix

712 E. Muhammad Ali Blvd.

Louisville, KY 40202

B.S., Social Sciences

Radford University

2001-2004

M.A., Urban Affairs and Public Policy

University of Delaware

2005-2007

Ph.D., Urban and Public Affairs

University of Louisville

2007-2014

United Alumni of Urban Affairs Award, University of Delaware, 2007

Marvin S. Gillman National Endowment Scholarship in Housing Policy, University of Delaware, 2006

Dean's List, Radford University, 2001-2004

\section{TEACHING}

EXPERIENCE: $\quad$ Instructor, Political Science 302: Urban Political Economy Department of Political Science University of Louisville:

Spring 2010

Teaching Assistant, Public Administration 602: Statistics for Urban and Public Affairs

School of Urban and Public Affairs

University of Louisville

Summer 2009 
RESEARCH

EXPERIENCE: $\quad$ Project Evaluator

Family Health Centers Phoenix

Health Care for the Homeless

Louisville, KY

2010-Present

Research Assistant

Urban Studies Institute

University of Louisville

Louisville, KY

2007-2010

Research Assistant

Center for Community Research and Service

University of Delaware

Newark, DE

2005-2007

PUBLICATIONS: $\quad$ Addison, C., Zhang, S., \& Coomes, B. (2013). Smart Growth and Housing Affordability A Review of Regulatory Mechanisms and Planning Practices. Journal of Planning Literature, 28(3), 215257.

CONFERENCE

PRESENTATIONS: "American Manifestations of the Garden City." Conference of the Delaware-Maryland Chapter of the American Planning Association, 2006.

"An Econometric Evaluation of the Community Development Block Grant in Rural Areas." Conference of the Association of Collegiate Schools of Planning (with S. Zhang), 2009.

"Housing as a Pathway: A Longitudinal Evaluation of Housing First Outcomes in Louisville, KY." Conference of the National Association of Welfare Research and Statistics (with S. Deck), 2013.

"Street Outreach to Permanent Housing: Partnering to Serve Vulnerable Homeless Persons." International Street Medicine Symposium (with A. Patterson), 2013.

STUDY ABROAD: Netherlands Housing and Community Development Study TRIP University of Delaware 2007 